NBER WORKING PAPER SERIES

THE CHANGING ROLE OF FAMILY INCOME AND ABILITY IN DETERMINING
EDUCATIONAL ACHIEVEMENT

Philippe Belley

Lance Lochner

Working Paper 13527

http://www.nber.org/papers/w13527

\author{
NATIONAL BUREAU OF ECONOMIC RESEARCH \\ 1050 Massachusetts Avenue \\ Cambridge, MA 02138 \\ October 2007
}

We are grateful for financial support from the Canadian Labour Market and Skills Researcher Network. We thank Flavio Cunha, Jim Heckman, Mike Keane, Abigail Payne, Sol Polachek and participants at the Inaugural Center of Human Capital and Journal of Human Capital Conference, 2007 University of Michigan/Michigan State/University of Western Ontario Labor Economics Conference, 2007 IRP Summer Research Workshop, ITAM, Johns Hopkins University, UCLA, University of Chicago's Harris School of Public Policy, University of Rochester, USC, and University of Western Ontario. The views expressed herein are those of the author(s) and do not necessarily reflect the views of the National Bureau of Economic Research.

(C) 2007 by Philippe Belley and Lance Lochner. All rights reserved. Short sections of text, not to exceed two paragraphs, may be quoted without explicit permission provided that full credit, including $@$ notice, is given to the source. 
The Changing Role of Family Income and Ability in Determining Educational Achievement Philippe Belley and Lance Lochner

NBER Working Paper No. 13527

October 2007

JEL No. H52,I2,J24

\begin{abstract}
$\underline{\text { ABSTRACT }}$
This paper uses data from the 1979 and 1997 National Longitudinal Survey of Youth cohorts (NLSY79 and NLSY97) to estimate changes in the effects of ability and family income on educational attainment for youth in their late teens during the early 1980s and early 2000s. Cognitive ability plays an important role in determining educational outcomes for both NLSY cohorts, while family income plays little role in determining high school completion in either cohort. Most interestingly, we document a dramatic increase in the effects of family income on college attendance (particularly among the least able) from the NLSY79 to the NLSY97. Family income has also become a much more important determinant of college 'quality' and hours/weeks worked during the academic year (the latter among the most able) in the NLSY97. Family income has little effect on college delay in either sample.

To interpret our empirical findings on college attendance, we develop an educational choice model that incorporates both borrowing constraints and a 'consumption' value of schooling - two of the most commonly invoked explanations for a positive family income - schooling relationship. Without borrowing constraints, the model cannot explain the rising effects of family income on college attendance in response to the sharply rising costs and returns to college experienced from the early 1980s to early 2000s: the incentives created by a 'consumption' value of schooling imply that income should have become less important over time (or even negatively related to attendance). Instead, the data are more broadly consistent with the hypothesis that more youth are borrowing constrained today than were in the early 1980s.
\end{abstract}

\author{
Philippe Belley \\ Department of Economics \\ University of Western Ontario \\ London, ON N6A 5C2 \\ Canada \\ pbelley@uwo.ca \\ Lance Lochner \\ Department of Economics, Faculty of Social Science \\ University of Western Ontario \\ 1151 Richmond Street, North \\ London, ON N6A 5C2 \\ Canada \\ and NBER \\ llochner@uwo.ca
}




\title{
The Changing Role of Family Income and Ability in Determining Educational Achievement*
}

\author{
Philippe Belley \\ University of Western Ontario
}

\author{
Lance Lochner \\ University of Western Ontario \\ NBER
}

October 7, 2007

\begin{abstract}
This paper uses data from the 1979 and 1997 National Longitudinal Survey of Youth cohorts (NLSY79 and NLSY97) to estimate changes in the effects of ability and family income on educational attainment for youth in their late teens during the early 1980s and early 2000s. Cognitive ability plays an important role in determining educational outcomes for both NLSY cohorts, while family income plays little role in determining high school completion in either cohort. Most interestingly, we document a dramatic increase in the effects of family income on college attendance (particularly among the least able) from the NLSY79 to the NLSY97. Family income has also become a much more important determinant of college 'quality' and hours/weeks worked during the academic year (the latter among the most able) in the NLSY97. Family income has little effect on college delay in either sample.

To interpret our empirical findings on college attendance, we develop an educational choice model that incorporates both borrowing constraints and a 'consumption' value of schooling - two of the most commonly invoked explanations for a positive family income - schooling relationship. Without borrowing constraints, the model cannot explain the rising effects of family income on college attendance in response to the sharply rising costs and returns to college experienced from the early 1980s to early 2000s: the incentives created by a 'consumption' value of schooling imply that income should have become less important over time (or even negatively related to attendance). Instead, the data are more broadly consistent with the hypothesis that more youth are borrowing constrained today than were in the early 1980s.
\end{abstract}

\section{Introduction}

A number of studies have documented important gaps in post-secondary enrollment by family income and cognitive ability or achievement (Manski and Wise 1983, Cameron and Heckman 1998, 2001, Ellwood and Kane 2000, Carneiro and Heckman 2002). This paper uses data from the 1979 and 1997 National Longitudinal Survey of Youth cohorts (NLSY79 and NLSY97) to analyze changes in the

\footnotetext{
${ }^{*}$ We are grateful for financial support from the Canadian Labour Market and Skills Researcher Network. We thank Flavio Cunha, Jim Heckman, Mike Keane, Abigail Payne, Sol Polachek and participants at the Inaugural Center of Human Capital and Journal of Human Capital Conference, 2007 University of Michigan/Michigan State/University of Western Ontario Labor Economics Conference, 2007 IRP Summer Research Workshop, ITAM, Johns Hopkins University, UCLA, University of Chicago's Harris School of Public Policy, University of Rochester, USC, and University of Western Ontario. Please send comments to llochner@uwo.ca.
} 
effects of ability and family income on educational attainment for cohorts making their final schooling decisions in the early 1980s to the early 2000s. We document a dramatic increase in the effect of family income on college attendance rates (particularly among the least able), even after controlling for family background and ability. However, we find little change in the effect of income on high school completion. Cognitive ability plays an important role in determining educational outcomes for both NLSY cohorts. The effects of ability on high school completion weaken somewhat for the later cohort, while its effects on college attendance are more stable over time.

To help interpret these findings, we develop a simple model of college attendance that incorporates both borrowing constraints and a 'consumption' or 'psychic' value of schooling — two of the most commonly invoked explanations for a positive family income - schooling relationship. ${ }^{1}$ Most previous studies of the relationship between schooling, ability, and family income have focused on the potential role played by borrowing constraints. As discussed in Becker (1975), low income families may face limited borrowing opportunities, which raises their marginal cost of attending college. ${ }^{2}$ Thus, borrowing constraints may discourage college attendance among youth from low-income families even when the financial returns are high. Researchers appealing to a 'consumption' value argue that students (or their parents) derive direct utility from schooling independent of its financial rewards (e.g. Carneiro and Heckman 2002, Keane 2002). As such, wealthier families will choose to 'purchase' more schooling for their children than poorer families. Of course, some youth may derive disutility from school as well, a possibility that is often ignored by academics but one which plays an important role in our analysis. In fact, our model suggests that among youth with positive net financial returns from college, those on the margin who are indifferent about attending college must dislike school. As such, they are willing to pay to avoid it. When the financial returns to college are high (as recent studies suggest — see, e.g., Heckman, Lochner, and Todd (2007)), this tends to generate a negative family income attendance relationship rather than a positive one. As a result, it is difficult to explain the increased effect of family income on college attendance based only on a standard 'consumption' value story.

To further explore the effects of family income on other margins of choice (particularly those that may be affected by borrowing constraints), we empirically examine the effects of family income

\footnotetext{
${ }^{1}$ Family income may affect educational attainment for many reasons. For example, peer groups, social networks, and information about the costs and benefits of college may differ by socio-economic status. Financial aid formulas themselves may generate different college-going decisions by family income, since they create different implicit tuition costs based on family resources. We briefly discuss the latter in Section 5 but are silent on the role of peer groups, social networks, and information.

${ }^{2}$ See Lochner and Monge (2007) for an in-depth analysis of borrowing constraints inherent in government student loan programs and the endogenous constraints that arise in private lending markets due to limited commitment.
} 
on the type of post-secondary institution attended (i.e. two-year, four-year, and four-year private institutions), college delay, and work during the academic year for our two NLSY cohorts. We find that family income has much larger effects on the 'quality' of institution attended (as measured by two-year vs. four-year schools) for the more recent NLSY cohort but little effect on college delay in either sample. Consistent with the hypothesis that those who delay college are more likely to be borrowing constrained, family income has a larger effect on college quality among youth who delayed college in the NLSY97 than among those who did not; however, the sample of delayers is small and the corresponding estimates imprecise. Delay itself has a strong negative effect on the quality of college attended for both NLSY cohorts. Finally, we examine the effects of family income on hours and weeks worked during the academic year among those enrolled in college at age 20. ${ }^{3}$ Among the most able, we find significantly negative effects of family income on work activity in the NLSY97 but not in the NLSY79. The effects of family income on work are generally smaller and more imprecisely measured for other ability quartiles.

A number of economists have argued that the increased returns to schooling over the past few decades can be linked to a sharp increase in demand for skilled labor and a slow rise in the supply of skill to the labor market. ${ }^{4}$ Kane (2007) suggests that the recent rise in tuition costs, decline in Pell Grant offerings, and gradual erosion of real student loan borrowing limits in the U.S. may be responsible for the modest response in aggregate college attendance rates despite the sharp rise in its economic returns. Our theoretical and empirical results are broadly consistent with this hypothesis. By studying how and why ability - family income - schooling patterns have changed over time (rather than using a single cohort to analyze these relationships), we are in a better position to understand the fundamental roles played by borrowing constraints, financial returns to schooling, and the consumption value of schooling.

This paper proceeds as follows. The following section briefly reviews the related literature on borrowing constraints and educational attainment. Section 3 describes the NLSY79 and NLSY97 data in detail. Our main empirical results are reported in Section 4. In this section, we examine ability - family income - schooling patterns for high school completion and college attendance. We also examine the effects of family wealth on these schooling outcomes in the NLSY97. Section 5 develops a simple model of college attendance to help interpret our findings. We explore the roles

\footnotetext{
${ }^{3}$ Using NLSY79 data, Keane and Wolpin (2001) estimate that this is an important margin affected by borrowing constraints in their model.

${ }^{4}$ See, e.g. Katz and Murphy (1992) and Heckman, Lochner, and Taber (1998).
} 
played by a 'consumption' value of schooling and borrowing constraints in determining ability - family income - college attendance patterns. We also examine how these patterns are predicted to change in response to a rising skill premium, rising tuition, and more limited borrowing opportunities. In Section 6, we empirically examine the effects of income and ability on college quality, college delay, and work during the academic year (for those enrolled in college). We offer concluding thoughts in Section 7 .

\section{Related Literature on Borrowing Constraints and Schooling}

Most previous studies of the relationship between schooling, ability, and family income have focused on the potential role played by borrowing constraints in determining college attendance. These studies have generally recognized the strong correlation between cognitive ability and family income, so some researchers have attempted to simultaneously control for ability and family income as well as other family background characteristics that might affect schooling decisions. ${ }^{5}$ Doing so substantially reduces the role of family income in most studies, but does not generally eliminate it. Elwood and Kane (2000) and Carneiro and Heckman (2002) have largely attributed lower college enrollment rates among low income families (after controlling for ability and other family background factors) to inefficiencies caused by borrowing constraints; although, their findings differ in the role played by family income. Elwood and Kane (2000) argue that differences by income are sizeable (in the High School and Beyond Survey and National Education Longitudinal Study of 1992) after controlling for math achievement test scores taken during the senior year of high school. However, Cameron and Heckman (1998, 2001) and Carneiro and Heckman (2002) find relatively small gaps by family income (in the NLSY79) after controlling for Armed Forces Qualifying Test (AFQT) scores. ${ }^{6}$ Thus, they argue that long-run family factors which are highly correlated with family income (e.g. quality of the home environment, early investments in children) are far more important in explaining differential college enrollment rates by family income than are short-term borrowing constraints during college-going years.

Other researchers have taken different approaches to 'test' for the importance of borrowing constraints. Cameron and Taber (2004) use different instrumental variables estimators to test for individual heterogeneity in rates of return to school that would be consistent with differential borrowing

\footnotetext{
${ }^{5}$ Estimated differences in educational attainment by measured cognitive achievement are generally quite large (even after controlling for family income) and attributed to differential financial returns by ability.

${ }^{6}$ AFQT test scores are a widely used measure of cognitive achievement by social scientists using the NLSY and are strongly correlated with positive outcomes like education and post-school earnings. (See, e.g., Blackburn and Neumark 1993, Murnane, Willett, and Levy 1995, and Cawley, et al. 2000.)
} 
interest rates. They find no evidence of discount rate heterogeneity and conclude that borrowing constraints are not important. Structural estimation of their model yields similar conclusions. Keane and Wolpin (2001) estimate a dynamic structural model of schooling behavior, allowing for individual heterogeneity, parental transfers, borrowing (with limits), and work while in school. While they estimate tight borrowing limits, their estimates suggest that these limits have little impact on final schooling outcomes. Instead, relaxing borrowing constraints tends to increase consumption and reduce labor supply while in school.

All of the aforementioned studies arguing that borrowing constraints have little impact on collegegoing (Cameron and Heckman 1998, 2001, Keane and Wolpin 2001, Carneiro and Heckman 2002, Cameron and Taber, 2004) are based on the NLSY79 data. ${ }^{7}$ However, Kane (2007) argues that the role of family income may have become more important in recent years. Thus, it is natural to ask whether the same ability - family income - schooling patterns exist for more recent cohorts. If not, have credit constraints become more limiting, or is there some other explanation? Our analysis uses similar methods to Carneiro and Heckman (2002) to analyze both the NLSY79 and NLSY97 data, so that we can place our findings in the context of this literature. We largely replicate Carneiro and Heckman's findings with the NLSY79 data (that family income has little effect on college attendance measured at older ages - after controlling for ability and family background), but find a substantially more important role for income in affecting college attendance in the NLSY97. We find moderate effects of family income on high school completion rates in both surveys, but the effects are fairly stable over time.

\section{Data}

Our analysis utilizes data from the NLSY 1979 and 1997 cohorts. The former reflects a random survey of American youth ages 14-21 at the beginning of 1979 and the latter samples youth ages 12-16 at the beginning of 1997 . Thus, the 1997 cohort was born approximately twenty years after the 1979 cohort. We focus on high school completion and college attendance decisions, which took place in the early 1980s for the 1979 cohort and in the early 2000's for the 1997 cohort. (The young age of NLSY97

\footnotetext{
${ }^{7}$ Stinebrickner and Stinebrickner (2007) find little effect of borrowing constraints on total college dropout rates for a recent cohort of students at Berea College. Despite low family income levels among most Berea students, only $20 \%$ are determined to be borrowing constrained in the sense that they report a desire to borrow additional money (at 'reasonable' interest rates). However, among these 'constrained' students, subsequent drop out rates are roughly twice as high as among similar students who report that they would not like to borrow. Stinebrickner and Stinebrickner (2007) are unable to explore the effects of borrowing constraints on attendance, since their sample only includes youth already enrolled at Berea.
} 
respondents limits our capacity to look at college completion.) We exclude youths that are part of the minority and poor white over-samples, using only the full random samples in our analysis.

These data contain rich measures of family background, including parental education, mother's age, family composition, race and ethnicity, and geographical indicators for urban or metropolitan residence. Most importantly, both data sources contain comparable measures of ability embodied in AFQT scores, a composite derived from tests of arithmetic reasoning, word knowledge, paragraph comprehension, and numerical operations. These four tests are only a subset of the full set of tests taken by respondents embodied in the Armed Forces Vocational Aptitude Battery (ASVAB). ${ }^{8}$ Our main analysis is conducted after categorizing individuals according to their AFQT score quartiles. Since AFQT percentile scores increase with age in the NLSY79, we determine an individual's quartile based on year of birth. ${ }^{9}$ AFQT percentile scores in the NLSY97 have already been adjusted to account for age differences.

The NLSY79 contains measures of family income reported in early survey years, while the NLSY97 contains measures of both family income and net wealth in $1997 .{ }^{10}$ For the 1979 cohort, we use average family income when youth are ages 16-17, excluding those not living with their parents at these ages. ${ }^{11}$ This limits our sample to the younger cohorts of the NLSY79 born in 1961-1964. The NLSY97 analysis is based on family income and family net wealth in 1997, dropping individuals not living with their parents that year. ${ }^{12}$ For our main analysis of educational attainment at age 21, these income reports are taken when youth are ages 13-17 (with over 75\% ages 14-16) in our NLSY97 sample. For comparability with our NLSY79 analysis, we categorize youth in the NLSY97 into income or wealth quartiles based on the random sample of persons who were at least 21 years old by 2004 , the last year of our data. In both NLSY samples, we denominate income in year 2000 dollars using the CPI for all urban consumers.

Since the oldest individuals in the NLSY97 turned 24 in the most recent 2004 wave of data, ${ }^{13}$ we

\footnotetext{
${ }^{8}$ The full set of tests includes arithmetic reasoning, assembling objects (only in NLSY97), auto information, coding speed, electronics information, general science, mathematics knowledge, mechanical comprehension, numerical operations, paragraph comprehension, shop information (combined with auto information in NLSY79), and word knowledge.

${ }^{9}$ All NLSY79 respondents took the ASVAB tests in the summer and fall of 1980. See the NLSY79 User's Guide for details.

${ }^{10}$ Net wealth measures the net value of owned home, real estate, business and vehicles. Added to that is money kept in checking and savings bank accounts as well as Educational IRA accounts or other prepaid tuition savings accounts. Loans and credit card debt are subtracted. Assets like bills, bonds, life insurance policies, pension savings, shares in publicly-held corporations and mutual funds are included.

${ }^{11}$ When income is only available at age 16 or 17 and not both, we use the available measure.

${ }^{12}$ We note that the NLSY79 family income variable is limited to those household members related to the respondent by blood or marriage, while the NLSY97 variable includes income for all members of the household.

${ }^{13} \mathrm{~A}$ very small number of respondents were age 25 at the time of the 2004 wave of the NLSY97.
} 
are forced to focus on schooling measured at a slightly younger age than one might like. Our main analysis, therefore, focuses on the effects of family income and ability on high school completion and college attendance as of age $21 .{ }^{14}$ However, we also examine a few other measures of college-going, including completion of at least two or at least four years of college (as of age 23) and current college enrollment measured at age 20 .

The NLSY data also contain information on work throughout the calendar year. We examine how ability and family income affect work decisions (fraction of weeks worked and average hours worked per week) during the academic year among students enrolled in college at age 20. We define the academic year as the last 16 weeks of a calendar year and the first 16 weeks of the following year.

Our multivariate analysis controls for a host of family background variables. For both cohorts, we control for maternal education by categorizing mothers as high school dropouts, those who completed high school or more, and those who completed at least one year of college. ${ }^{15}$ We also account for family structure in the NLSY79 by controlling for the number of siblings the youth reported in 1979 . For the NLSY97, we control for the number of household members under the age of 18 as of the 1997 survey date. Additional family structure information is provided by an indicator variable for whether both parents are present in the home at age 14 in the NLSY79 and in 1997 (i.e. ages 13-17) in the NLSY97. Family residence in an urban (metropolitan) area at age 14 (age 12) is accounted for with the 1979 (1997) cohort. We control for the mother's age at birth as well as gender and race (blacks, hispanics and whites for the NLSY79; blacks, hispanics, other non-whites, and whites for the NLSY97 data). Finally, we allow for differences by year of birth in both samples.

Descriptive statistics for these variables are provided in Table 1 for both cohorts. ${ }^{16}$ Comparisons across cohorts reveal that schooling attainment is higher for the 1997 cohort. We observe the same phenomenon for maternal education, which is substantially higher for the later cohort. ${ }^{17}$ Another striking difference across cohorts is the much greater likelihood that both biological parents are present in the household during the child's adolescence in the NLSY79; however, mother's age at respondent's

\footnotetext{
${ }^{14}$ Respondents are assumed to have completed high school if they completed 12 or more years of school. As discussed further below, some of these youth received a GED rather than high school diploma. Individuals are considered to have attended college if they attended at least 13 years of school. Schooling attainment at age 22 is used if it is missing or unavailable at age 21 (fewer than $10 \%$ of all respondents in both surveys).

${ }^{15}$ While our main specifications do not control for father's education (since many observations are missing), we check the robustness of our findings to the inclusion of indicators for whether father completed high school, completed at least one year of college, and completed college.

${ }^{16}$ These samples are restricted to individuals for whom we observe both AFQT scores and family income.

${ }^{17} \mathrm{MaCurdy}$ and Vytlacil (2003) report that the NLSY97 appears to have slightly over-sampled more educated youth with more educated mothers when compared against other nationally representative surveys like the 1997 Current Population Survey or 1996 Survey of Income and Program Participation.
} 
birth has changed very little. Minorities are slightly more prevalent in the NLSY97 data, consistent with national demographic trends. Average income levels are similar across cohorts; however, there is greater dispersion in the NLSY97. For the 1997 cohort, average family wealth is quite close to average gross home value - most assets are in home equity. Table 2 reproduces the joint distribution of AFQT and income quartiles across cohorts. The distributions are remarkably similar, except for the larger fraction of individuals in the lowest ability/lowest AFQT quartiles in the NLSY79. Both distributions show a strong positive correlation; however, there are non-trivial percentages in high income/low AFQT and low income/high AFQT cells.

To further check the comparability of family income measures in the NLSY surveys, we estimate regressions of log family income (measured in $\$ 10,000$ denominated in year 2000 dollars) on mother and family background characteristics used in our main analysis of educational attainment. These estimates are shown in appendix Table A1 along with analogous estimates using the 1980 and 2000 U.S. Censuses. Census variables and samples have been chosen to closely replicate those used in our NLSY analysis. ${ }^{18}$ As can be seen from the table, the estimates are qualitatively similar across the NLSY and Census samples; however, a few differences are worth discussing. The modest decline in black - white family income differences in the NLSY contrasts with the modest increase across the 1980 and 2000 Censuses. Still, the estimates are fairly close given the variability of the NLSY estimates. ${ }^{19}$ The smaller effects of urban or metropolitan area in the NLSY relative to their Census counterparts are likely due to the fact that area of residence in the NLSY is measured a few years before the family income measure, while the two measures are contemporaneous in the Census data. Finally, the effect of mother's high school completion appears to increase more in the NLSY, while the effect of mother's college attendance is stable in the NLSY but increases in the Census data. The differential effects of schooling in the NLSY97 and 2000 Census can be at least partly explained by a slight difference in the definition of college attendance that is likely to have inflated the incomes of high school graduates in the Census relative to the NLSY97. ${ }^{20}$ Overall, most of the estimates are fairly consistent across the

\footnotetext{
${ }^{18}$ We use the 1980 Census $1 \%$ urban/rural sample and the 2000 Census $1 \%$ unweighted sample from Integrated Public Use Microdata Series (IPUMS). Samples are restricted to youths aged 16 or 17 for the 1980 Census and youths aged $14-17$ in the 2000 Census. We use family income in 1979 , truncated at $\$ 75,000$ to match the NLSY79, for the 1980 Census. The 2000 Census reports household income in 1999 - to match the NLSY97 topcoding, all incomes in the top 2 percent of the household income distribution are given the average income for that group. An indicator for urban area of residence is used in the 1980 Census while metropolitan area of residence is used in the 2000 Census. Race and ethnicity were coded to match their respective NLSY samples.

${ }^{19}$ The 'other non-white' indicator is significantly negative in the 2000 Census but zero in the NLSY97. It is possible that minor differences in race and ethnicity codings between the NLSY and Census explain this finding, since the sample of 'other non-whites' is quite small in the NLSY.

${ }^{20}$ Mother's 'college attendance' implies completion of at least one year of college in the NLSY97, while it only implies
} 
samples and quite reasonable. The R-squared statistics imply that roughly one-fifth of the variation in family income is explained by these standard background characteristics in all but the 1980 Census (where only $16 \%$ of the variation is explained). These results, along with Table 2, provide confidence in the family income measures and suggest that they are quite comparable across both NLSY samples. ${ }^{21}$

\section{The Changing Role of Ability and Family Resources on Educa- tional Achievement}

Raw differences in high school completion and college attendance rates by family income are sizeable for both NLSY cohorts. The difference in high school completion rates between the highest and lowest family income quartiles falls from 0.29 in the NLSY79 to 0.19 in the NLSY97. By contrast, the high income - low income college attendance rate differential rises from 0.38 to 0.43 across cohorts. We next examine the extent to which differences in cognitive ability and family background contribute to these gaps.

Figures 1 and 2 show high school completion and college attendance rates by family income quartile and AFQT quartile in the NLSY79 and NLSY97 data. Not surprisingly, ability plays an important role in determining educational attainment in both cohorts. Figures 1a and $1 \mathrm{~b}$ reveal that nearly everyone in the highest ability quartile completes high school from both cohorts; however, completion rates are substantially lower for those in the lowest ability quartile, especially those raised in low-income families. Ability appears to have become a less important determinant of high school graduation for the recent cohort, while family income appears to have become more important for youth of low ability. Put another way, nearly all of the rise in high school completion rates comes at the bottom half of the ability distribution, especially the least able from high income families.

Figures $2 \mathrm{a}$ and $2 \mathrm{~b}$ show that college attendance rates are positively correlated with both ability and family income. For both cohorts, ability plays the more decisive role; however, differences by family income are substantial for the higher ability quartiles in the 1979 cohort and for all ability levels in the 1997 cohort. Based on these simple comparisons, the role of ability appears to have changed little over the last two decades while family income has become more important in determining college-going (especially among the least able). The overall increase in college attendance rates over this period

attendance and not necessarily completion of a full year in the Census. Accordingly, approximately $7 \%$ more mothers are coded as 'college attendees' in the 2000 Census than in the NLSY97.

${ }^{21}$ Though not shown, switching family income for household income in either Census sample has very little effect on the estimates, suggesting that this difference across NLSY samples is not very important. 
has come from all parts of the ability distribution. However, among the bottom half of the ability distribution, the rise in attendance rates has come entirely from higher income quartiles. Thus, the expansion of post-secondary education in the U.S. has left the least able from low income backgrounds behind. This is, perhaps, surprising given the important role community colleges and vocational institutions have come to play in higher education (Kane and Rouse 1999).

To further explore these relationships, we employ a similar methodology to that used in Carneiro and Heckman (2002), who use the NLSY79 to analyze the effects of family income and ability on college attendance and completion rates after controlling for other family background characteristics. We extend their basic methodology to analyze high school completion rates in addition to college attendance rates for all men and women (not just white men as in their paper). As we are mainly interested in how ability - family income - educational achievement relationships have changed over time, we employ nearly identical estimation specifications for both the NLSY79 and the NLSY97 cohorts. ${ }^{22}$ Specifically, we regress educational outcomes on family income quartiles during the respondent's late teenage years, AFQT quartiles, and family background measures for both NLSY cohorts. We use family income and AFQT quartiles to allow for general non-linear relationships. For comparability, our main specifications control for family background measures very similar to those employed in Carneiro and Heckman (2002), including parental education, whether the family is intact during adolescence, residence in an urban/metropolitan area during adolescence, and number of siblings (children under age 18 in the household for the NLSY97 analysis). ${ }^{23}$ Because we examine the full random samples rather than just white males, we also control for race, hispanic ethnicity, and gender. The main difference between our analyses is the age of our samples. Carneiro and Heckman (2002) analyze schooling outcomes at late ages (early 30s), while our main results measure educational attainment as of age 21 due to the youth of the NLSY97 sample. As we discuss further below, using attendance measured at age 21 rather than at older ages implies a slightly larger role of family income in the NLSY79.

Table 3 reports estimates of our main specifications for both the NLSY79 and NLSY97 data. The first two columns report results for high school completion and the second two reflect estimates for

\footnotetext{
${ }^{22}$ Elwood and Kane (2000) also employ a similar strategy in examining the HSB Survey of high school classes of 1980 and 1982 and the NELS study of the graduating high school class of 1992; although they do not have consistent test scores (i.e. ability measures) across the two surveys.

${ }^{23}$ We note that Carneiro and Heckman (2002) use AFQT terciles rather than quartiles, and they use family income measured at age 17 or in 1979, while we use average income measured over ages 16 and 17 for the NLSY79 data and family income in 1997 for the NLSY97 (corresponding to ages 13-17 for our sample). We do not control for father's education or residence in the south in our main specifications, while Carneiro and Heckman (2002) do; however, adding these additional covariates does not affect our main conclusions about the roles of ability and family income.
} 
college attendance. The high school completion specifications are qualitatively similar across the two cohorts. Youth raised in an intact family or with a mother who completed high school are significantly more likely to finish high school themselves. Mother's college attendance has no discernable impact on youth's high school completion decisions. Blacks and hispanics are more likely to complete high school, all else equal, than are whites; however, the black - white difference appears to have declined significantly for the NLSY97 cohort. ${ }^{24}$ The effects of most family background characteristics decline somewhat from the NLSY79 to NLSY97 as nearly all youth complete high school today.

We are most interested in the role of ability, as measured by AFQT scores, and family income after controlling for family background. The estimates suggest that ability is an important determinant of high school completion for both cohorts as implied by Figures 1a and 1b; however, the estimates also reveal that ability has become less important over time. For both cohorts, ability is most important at the bottom of the distribution. Family income plays a modest role in determining high school completion with little change across cohorts. The difference in completion rates between the lowest and highest income quartiles is 7-8 percentage points in both the NLSY79 and NLSY97. ${ }^{25}$

Turning to the college attendance specifications in Table 3 , we observe more noticeable changes across cohorts. Black - white and hispanic - white differences are roughly 20 percentage points in the NLSY79; the black - white difference falls to around 15 percentage points and the hispanic white difference drops to less than 5 percentage points for the more recent cohort. Among NLSY79 youth, mother's high school completion and college attendance have substantial effects on college-going behavior, both raising the probability of attending college by about 15 percentage points. The effects are much smaller but still significant for NLSY97 youth.

As with high school completion, ability plays a key role in college attendance decisions after controlling for family background and income. Moving from the lowest to second AFQT quartile

\footnotetext{
${ }^{24}$ Rivkin (1995) and Cameron and Heckman (2001) also find that minorities acquire more schooling than whites after conditioning on ability/achievement and family background. There is no consensus as to the explanation for this finding in the literature. While Rivkin (1995) finds that the minority advantage (conditional on ability and family background) in college attendance is largely explained by racial differences in local labor market conditions, Cameron and Heckman (2001) estimate little role of local labor markets. Using Census data, Heckman, Lochner, and Todd (2007) estimate slightly higher internal rates of return to high school and college for blacks relative to whites in recent decades; however, their estimates do not control for differences in ability. Barrow and Rouse (2005) find very similar effects of schooling on wages for minorities and whites when they attempt to control for ability using AFQT scores or family fixed effects estimators. Affirmative action policies may help explain minority advantages in college attendance, but it seems unlikely that such policies play an important role in explaining high school completion differentials.

${ }^{25}$ We cannot reject that the income coefficients are the same across cohorts as seen in the second-to-last row of Table 3. Family income has become slightly more important for high school completion when individuals with a GED are not considered to have finished high school. In this case, the highest-lowest income quartile difference rises slightly for the NLSY79 (to 0.9) and increases more for the NLSY97 (to 0.12).
} 
raises attendance rates by 13 percentage points for the NLSY79 youth and by 24 percentage points for NLSY97 youth, suggesting that ability has become more important at the low end of the distribution. Moving from the second to third or third to top ability quartiles each raises attendance rates by about 20 percentage points for the older cohort and by about 15 percentage points for the more recent cohort. Thus, ability has become more important at the low end and slightly less important at the high end of the distribution. The difference in attendance between the most and least able has changed very little over time.

While ability is equally important for both cohorts, family income plays a substantially more important role in determining college attendance for the NLSY97 youth. Our estimates suggest modest effects of family income on attendance for the NLSY79 sample (a 9 percentage point difference between the highest and lowest income quartiles), slightly larger than reported in Carneiro and Heckman (2002). As can be seen from appendix Tables A2 and A3, our larger NLSY79 estimates are the result of measuring attendance as of age 21 rather than at older ages as in Carneiro and Heckman (2002). When we measure attendance as of age 24, attendance differences between the highest and lowest income quartiles shrink to 6.7 percentage points, consistent with their results. Altogether, our results suggest that NLSY79 youth from lower family income quartiles were more likely to delay college a few years (by about 3 percentage points) than their higher income counterparts, but final attendance rates are largely invariant to family income. The NLSY97 results imply substantial effects of family income on college attendance measured at all ages from 20-23, with little evidence of any systematic decline in attendance gaps with age. Measuring attendance as of age 21 (our baseline specification), suggests that college attendance rates are 16 percentage points higher for NLSY97 youth from the highest income quartile relative to the lowest - nearly twice the NLSY79 difference. This difference is statistically significant at the $10 \%$ level; however, we cannot reject the joint chi-square test that all three income coefficients are the same across cohorts (second-to-last row of Table 3). Regardless of the age at which we measure college attendance, differences by family income have risen substantially across cohorts.

One concern with using family income quartiles to account for a non-linear relationship is the widening of the income distribution over time (e.g. the difference in average family income between the highest and lowest income quartiles rose by nearly $\$ 12,000$, about $15 \%$ ). To see whether this explains the rise in college attendance gaps by family income quartiles, we estimate a specification analogous to that of Table 3 using a fifth order polynomial in family income rather than income 
quartile indicators. This also allows for a very general income - schooling relationship and enables us to compare the effects of family income across cohorts at any level of income. Figure 3 plots the estimated polynomials for high school completion and college attendance along with their $95 \%$ confidence intervals as a function of family income (ranging from $\$ 5,000$ to $\$ 100,000$ ). These figures clearly show that the effects reported in Table 3 are not driven by changes in the distribution of family income. ${ }^{26}$ Most importantly, both Table 3 and Figure 3 suggest that family income has a much larger effect on college attendance at low to middle income levels in the NLSY97 than it does in the NLSY79.

We look more closely at the joint role of ability and family income in Table 4, which reports the estimated effects of family income (using quartile indicators) on high school completion and college attendance within each AFQT quartile. ${ }^{27}$ These specifications control for the same background characteristics as in Table 3. Consistent with the patterns shown in Figures 1a and 1b, we find that family income has moderate effects on high school completion for the lowest ability types and small effects for the higher ability quartiles. Estimated effects of income are quite similar across cohorts. We cannot reject that the income coefficients are the same across cohorts for any ability quartile.

Results for college attendance are quite different, in line with the patterns shown in Figures 2a and 2b. Among NLSY79 youth, family income only appears to matter for those in the top two ability quartiles. Among the more able, moving from the lowest to second family income quartile raises college attendance rates by nearly 10 percentage points. Moving from the second to the top income quartile raises attendance rates by an additional 7-9 percentage points. Our results for NLSY97 youth show sizeable and statistically significant effects of family income for all but the highest ability quartile. Among the most able, the effects of family income actually declined relative the NLSY79 cohort. Family income effects remained stable across cohorts for quartile 3. For the lowest two ability quartiles, the effects of income are substantially larger for the NLSY97 cohort. Among all but the top ability quartile, moving from the lowest to highest family income quartile raises college attendance rates by 15-30 percentage points. In the NLSY97, we strongly reject the hypothesis of no family income effects for all but the most able. We also reject that the income coefficients are equal across cohorts for the two lowest AFQT quartiles.

Since we find such a large change in the role of family income on college attendance rates across

\footnotetext{
${ }^{26}$ Based on these polynomial specifications, chi-square tests do not reject equality of the effects of income over time for high school completion ( $\mathrm{p}$-value of 0.602 ), but they do reject equality for college attendance at the $10 \%$ level ( $\mathrm{p}$-value of 0.083 ).

${ }^{27}$ While not shown, using polynomials in income (rather than income quartile indicators) yields similar conclusions.
} 
the two NLSY cohorts, we explore the robustness of these results in Appendix Tables A4 and A5 using specifications similar to those in Table $3 .^{28}$ Column (i) in both tables examines the effects of controlling for finer categories of mother's education (adding an indicator for college completion) and the same categories for father's education (plus an indicator for missing father's education) in addition to the baseline controls. For both cohorts, this reduces the estimated effect of family income by a few percentage points but does not affect our main conclusion about the increasing importance of family income. Column (ii) conditions the sample on high school graduates only, which also has little effect on the family income estimates.

Columns (iii) and (iv) of Tables A4 and A5 control for additional measures of cognitive and non-cognitive skills/abilities in addition to AFQT quartiles. In particular, column (iii) controls for all ASVAB test scores - ten tests in the NLSY79 and twelve in the NLSY97 ranging in subject from arithmetic reasoning to auto and shop information to reading comprehension to general science. ${ }^{29}$ Not surprisingly, the estimated effects of AFQT largely disappear when these additional ability measures are included. Interestingly, however, the effects of family income on college attendance decline very little from our baseline estimates in Table 3. Column (iv) controls for participation in a variety of different property, drug, and violent crimes during adolescence to further account for potential differences in non-cognitive skills. ${ }^{30}$ These estimates are almost indistinguishable from our baseline estimates. Though not shown, simultaneously controlling for all ASVAB scores and measures of adolescent criminal participation produces very similar estimates to those of column (iii). Including a wide range of ability measures, both cognitive and non-cognitive in nature, has little impact on our conclusions about the role of family income in determining college attendance rates. (Similarly, for high school completion, including ASVAB scores and criminal participation measures has very little impact on the estimated effects of family income.) Our main measures of family background and AFQT do a good job of accounting for individual differences in a very broad set of abilities and skills.

Column (v) of Tables A4 and A5 uses a per capita measure of family income, dividing total family

\footnotetext{
${ }^{28}$ Although not shown, the estimated effects of family income and AFQT are nearly identical when we control for birth order (i.e. the number of older siblings).

${ }^{29}$ Specifications linearly include all test scores, which are normalized to have a mean of zero and standard deviation of one by year of birth (NLSY79) or by age at test date (NLSY97).

${ }^{30}$ In the NLSY79, we control for participation in the following crimes reported in the 1980 survey (youth ages 15-18) and retrospective over the previous year: theft of something worth less than $\$ 50$, theft of something worth $\$ 50$ or more, shoplifting, use of force to get something, hitting or attacking someone, and selling marijuana or hard drugs. In the NLSY97, we control for participation in the following crimes reported in the 1998 survey (youth ages 14-18) retrospective since the 1997 survey: theft of something worth $\$ 50$ or less, theft of something worth more than $\$ 50$, other property crimes, hurting or attacking someone, and selling drugs. The results are nearly identical when including other additional measures of crime (e.g. gang membership, arrests, drinking, smoking, taking drugs, etc.)
} 
income by the number of persons in the household. ${ }^{31}$ Using per capita income rather than total family income suggests an even more dramatic rise in the role of income, with slightly smaller effects of income in the NLSY79 and slightly larger effects in the NLSY97. While not shown, effects estimated separately by AFQT quartile are broadly consistent with those of Table 4.

Overall economic conditions were worse in the early 1980s than they were in the early 2000s, which could imply different opportunity costs of college attendance for our two NLSY samples. As measured by the U.S. Bureau of Labor Statistics, the unemployment rate for 16-19 year olds reached $24 \%$ by late 1982, the year our oldest NLSY79 birth cohort reached age 18; however, it was substantially lower (around 16\%) in 1979-80 when our youngest NLSY79 cohorts turned 18. The unemployment rate for 16-19 year olds was 13-16\% over most of the 1999-2001 period when our NLSY97 youth turned age 18 - comparable to that for the youngest NLSY79 cohorts. To help gauge the importance of national economic conditions, we estimated separate specifications analogous to Table 3 for those NLSY79 youth born in 1961-62 and in 1963-64. The estimated effects of family income and ability were quite similar across the two subsamples and to those shown in Table $3 .{ }^{32}$ Thus, differences in the relative timing of the U.S. business cycle for the two NLSY samples does not appear to play an important role in our main findings.

Appendix Tables A6 and A7 report estimates for college attendance separately by race and by gender. The estimated effects of income increase noticeably between the NLSY79 and NLSY97 for both males and females, as well as whites and hispanics. Estimates for blacks are fairly similar across the samples. The effects of income appear to be larger for males than for females in both NLSY samples. In the NLSY97, the estimated effects of income are smallest for females and for blacks 14 and 13 percentage point differences, respectively, between the highest and lowest income quartiles. The attendance difference is largest for whites in the NLSY97 at 21 percentage points. For all groups, ability as measured by AFQT plays an important role in college attendance decisions. For the recent cohort, ability appears to be much more important at the bottom of the distribution relative to the middle and top for blacks. Ability has more similar effects throughout the distribution for hispanics and whites.

With the NLSY97, it is also possible to explore the effects of net family wealth on educational attainment. Since income fluctuates from year to year, family wealth may be more indicative of long-

\footnotetext{
${ }^{31}$ Since the NLSY79 only uses family members in the household to compute total family income, we divide by the number of family members in the household for that cohort.

${ }^{32}$ Estimates available from authors upon request.
} 
run family resources and the ability of families to finance large out-of-pocket expenses associated with higher education. Of course, it may also reflect the decisions of parents to save for their children's education - an endogenous response to family tastes or aspirations for college. Table 5 explores the extent to which net family wealth affects educational outcomes for the later NLSY cohort. Columns 1 and 2 report estimates for high school completion, while columns 3 and 4 report estimates for college attendance. All specifications control for the same family background characteristics as in previous tables. The estimates suggest that net family wealth plays a similar role to that of family income, with slightly larger effects. Youth from families in the highest wealth quartile are about 10 percentage points more likely to complete high school and 24 percentage points more likely to attend college than are youth from the lowest wealth quartile. Columns 2 and 4 simultaneously control for family income and wealth quartiles. Interestingly, the estimated effects of wealth decline only slightly relative to those in columns 1 and 3, while the effects of family income typically drop by about one-third to one-half their values in Table 3. F-tests strongly reject the hypothesis that wealth has zero effect on high school completion and college attendance. F-tests also reject that income has no effect on college attendance. The combined effects of wealth and income on college attendance are substantial. Youth raised in low wealth and low income families (lowest quartiles in both) are nearly 30 percentage points less likely to attend college than youth with similar family backgrounds in the highest family income and wealth quartiles.

Most of the financial gains from college come from completion and not only attendance (e.g. see Heckman, Lochner, and Todd 2007). While our NLSY97 cohort is still fairly young, it is possible to examine whether income and ability have similar effects on completion of at least two or at least four years of college. Table 6 reports estimates from specifications similar to Table 3, using completion of at least two or at least four years of college as the dependent variables instead of college attendance. We explore the effects of ability and income on the first measure at both ages 21 and 23 and the latter at age 23 only. For reference, $29 \%$ (32.4\%) of the NLSY79 sample had completed at least two years of college by age 21 (age 23), while 41\% (45\%) of the NLSY97 had completed at least two years by that age. Only $19 \%$ of the NLSY79 respondents and 27\% of the NLSY97 respondents had completed four or more years of college by age 23 ; however, many still remain in school at that age. As is clear from the table, the main conclusions from our analysis of attendance carry over here. Ability has strong effects on completion of at least two or four year of college (smaller effects on the latter). Family income plays little role in determining completion of two or four years of college for NLSY79 youth 
(differences between the highest and lowest income quartiles range from 3-6 percentage points), but it is important for the NLSY97 youth. Estimated effects on completion of two years in the NLSY97 are comparable to the estimated effects on attendance (a 15 percentage point difference between the highest and lowest income quartiles). While the same difference for completion of four years is onethird smaller at 10 percentage points, the overall four-year completion rate is only about half the two-year completion rate. In percentage terms, the effects of income are quite similar for both twoand four-year completion rates (both around 35\%).

\section{What Explains the Increased Importance of Family Income?}

Much has been made of the fact that family income does not appear to affect college attendance after controlling for ability and family background in the NLSY79. Most studies rejecting the idea that credit constraints play an important role at college-going ages are based on these data. ${ }^{33}$ Therefore, our findings that family income has become substantially more important in the NLSY97 data (using very similar estimation specifications, measures of ability, and family income) is likely to re-new the debate about borrowing constraints and educational achievement. However, it is important to exercise caution before attributing gaps in attendance by family income to borrowing constraints or to conclude that borrowing constraints have become more severe since the early 1980s. As discussed earlier, there are other reasons educational attainment may be related to family income conditional on ability. One force often appealed to is a 'consumption' or 'psychic' value of schooling: this explanation assumes that individuals or families place an intrinsic value on schooling that they are willing to pay for. It is argued that families with more resources are simply willing to pay for more schooling, thereby generating a positive income - schooling relationship. To see whether this model can rationalize the observed patterns in the NLSY79 and NLSY97, we consider a simple model of college-going that incorporates both financial and non-financial (i.e. 'consumption') benefits from schooling. Of particular interest is the extent to which the model can explain our estimated ability - family income - college attendance relationships and how those relationships changed from the early 1980s to the early 2000s in response to the well-documented increase in the financial returns to education and ability in the labor market as well as the dramatic rise in net tuition costs. We explore the model's predictions first when borrowing is unconstrained and then when it is constrained by an upper loan limit. While the model abstracts

\footnotetext{
${ }^{33}$ Cameron and Heckman (1998, 2001), Keane and Wolpin (2001), Carneiro and Heckman (2002), and Cameron and Taber (2004) all use the NLSY79 and conclude that credit constraints have little effect on college-going decisions.
} 
from a number of factors that could affect the family income - college attendance relationship (e.g. heterogeneous information about the costs or benefits of schooling, different peer groups, or social networks), it helps clarify the potential roles played by two of the factors most commonly cited by economists: borrowing constraints and a 'consumption' value of schooling.

\subsection{A Simple Model of College Attendance}

Consider a two-period model in which individuals must choose to either attend college $(s=1)$ or not $(s=0)$ in the first period. Let $W \geq 0$ reflect the initial resources of individuals (and implicitly their families) and $y_{s}(\theta)$ reflect earnings (when not enrolled in school) for someone with schooling level $s$ and ability $\theta$. We assume that $y_{1}(\theta)>y_{0}(\theta)>0$ and $y_{1}^{\prime}(\theta)>y_{0}^{\prime}(\theta)>0$ so that earnings are strictly increasing in schooling and ability, with ability having a greater effect on college earnings. While enrolled in college, students must pay tuition $T(W)$, which is assumed to be increasing in initial resources (specifically, $T(W) \geq 0$ and $0 \leq T^{\prime}(W) \leq 1$ ). This reflects the fact that financial aid policies are more generous to youth from lower income backgrounds (i.e. financial aid is decreasing in family income). This is certainly true of federal financial aid schedules (e.g. Pell Grants) but is also typically true of institutional aid (see, e.g., Dick, Edlin, and Emch 2003). ${ }^{34}$ Those who do not enroll in college are assumed to work and earn $y_{0}(\theta)$ in both periods. Thus, college entails both direct and indirect costs. Individuals value consumption, $c_{t}$, in each period $t=1,2$ according to the increasing and strictly concave function $u\left(c_{t}\right)$ and discount the future at rate $\beta$. They also place an intrinsic value on attending college. This 'consumption value' of school is $\xi$, which is distributed in the population according to the density function $F(\xi)$. Individuals may borrow $d$ (savings reflects $d<0$ ) to smooth consumption over time at a gross interest rate of $R$. We begin our analysis by assuming that there are no constraints on borrowing, then discuss how the addition of borrowing constraints affects the model's implications for the ability - family income/wealth - college attendance relationship.

\section{No Borrowing Constraints}

When there are no constraints on borrowing, the value function for schooling level $s$ is

$$
V_{s}(W, \theta, \xi)=\max _{d}\left\{u\left(c_{1}\right)+\beta u\left(c_{2}\right)+s \xi\right\}
$$

\footnotetext{
${ }^{34}$ For simplicity, we do not model merit-based aid; although, some have argued that this has become more important in recent years (McPherson and Schapiro 1998). Allowing $T(\cdot)$ to depend on ability as well as family resources does not alter our main results regarding the effects of income on attendance. Merit-based aid will clearly lead to a more positive ability - attendance relationship than is discussed here.
} 
subject to

$$
\begin{aligned}
& c_{1}=W+d+(1-s) y_{0}(\theta)-s T(W) \\
& c_{2}=y_{s}(\theta)-R d .
\end{aligned}
$$

Individuals choose the schooling level that offers them the higher lifetime utility. Since the utility value of college, $\xi$, does not affect consumption and borrowing decisions conditional on schooling, it is helpful to define $v_{s}(W, \theta)=V_{s}(W, \theta, \xi)-s \xi$, which reflects the maximized lifetime utility from consumption alone for schooling choice $s$. Using this notation, individuals attend college if and only if $\xi \geq v_{0}(W, \theta)-v_{1}(W, \theta)$. College attendance rates for someone with resources $W$ and ability $\theta$ are $1-F\left(v_{0}(W, \theta)-v_{1}(W, \theta)\right)$.

To simplify the analysis, assume that $\beta R=1$, so that agents want to perfectly smooth consumption across periods. Given our specification (i.e. no income growth), this implies that non-college youth will always choose to save while young. Their consumption in each period will be

$$
\bar{c}^{0}=\left[\frac{R}{1+R}\right] W+y_{0}(\theta) .
$$

The value of the non-college alternative is, therefore,

$$
v_{0}(W, \theta)=(1+\beta) u\left(\left[\frac{R}{1+R}\right] W+y_{0}(\theta)\right) .
$$

Clearly, this is increasing in wealth and non-college earnings levels, the latter increasing in $\theta$. Tuition policy has no effect on non-college utility.

Now, consider the value associated with college attendance. The optimal amount of consumption each period is

$$
\bar{c}^{1}=\frac{R(W-T(W))+y_{1}(\theta)}{1+R}
$$

yielding a value of college, $v_{1}(W, \theta)$, equal to

$$
v_{1}^{u}(W, \theta)=(1+\beta) u\left(\frac{R(W-T(W))+y_{1}(\theta)}{1+R}\right) .
$$

This is increasing in college earnings, ability, and initial resources. The optimal borrowing amount is

$$
d_{1}^{u}=\frac{y_{1}(\theta)-W+T(W)}{1+R},
$$

which is increasing in college earnings and ability and decreasing in initial resources. ${ }^{35}$

\footnotetext{
${ }^{35}$ We use the ' $u$ ' superscript to denote unconstrained optimal values and choices, since they will also play a role in the model with borrowing constraints.
} 
It is useful to define the net lifetime financial gain from college, $G(W, \theta)$ :

$$
G(W, \theta) \equiv y_{1}(\theta)-R T(W)-(1+R) y_{0}(\theta)
$$

We assume that this earnings gain is increasing in ability, so $\frac{\partial G}{\partial \theta}=y_{1}^{\prime}(\theta)-(1+R) y_{0}^{\prime}(\theta)>0$; otherwise, attendance rates will tend to be decreasing in ability (a pattern inconsistent with both NLSY cohorts). This assumption further implies that there is a unique $\theta=\bar{\theta}(W)$ for all $W$ that satisfies $G(W, \theta)=0$. For individuals with initial resources $W$ and $\theta>\bar{\theta}(W)$, the net financial gain from college is strictly positive. Those with $\theta<\bar{\theta}(W)$ would lose financially from attending. It can easily be shown that $\bar{\theta}^{\prime}(W) \geq 0$ (the derivative equals zero when $T^{\prime}(W)=0$ and is otherwise positive), so youth with high initial resources must be more able if they are to financially gain from college (since they pay higher tuition). Holding initial resources constant, more able youth gain more from college; holding ability constant, those with lower initial resources gain more.

The effect of resources and ability on attendance rates depends on how marginal agents are affected - those indifferent about attending college. These are the agents who will alter their schooling decisions if anything changes. Indifference implies that $\xi=v_{0}(W, \theta)-v_{1}(W, \theta) \equiv \bar{\xi}(W, \theta)$. Anything that lowers $\bar{\xi}$ will raise attendance rates. Changes in attendance rates for any $(W, \theta)$ type will depend on how $\bar{\xi}$ is affected as well as the density of college tastes at $\bar{\xi}$. With this in mind, we now analyze what this simple model predicts for the ability - initial resources - schooling relationship and how that relationship changes in response to economic or policy changes.

Differentiating the value functions for non-college and college-goers with respect to family resources yields:

$$
\begin{aligned}
& \frac{\partial v_{0}}{\partial W}=u^{\prime}\left(\bar{c}^{0}\right) \\
& \frac{\partial v_{1}^{u}}{\partial W}=\left(1-T^{\prime}(W)\right) u^{\prime}\left(\bar{c}^{1}\right) .
\end{aligned}
$$

The effect of initial resources on non-college vs. college utility depends on the effects of family resources on tuition (or financial aid) as well as marginal utility values $u^{\prime}\left(\bar{c}^{0}\right)$ and $u^{\prime}\left(\bar{c}^{1}\right)$, which depend on the consumption levels associated with the two schooling choices. In the absence of binding constraints, consumption levels $\bar{c}^{0}$ and $\bar{c}^{1}$ depend only on lifetime earnings. College consumption will be greater than non-college consumption when $G(W, \theta)>0$ or, equivalently, $\theta>\bar{\theta}(W)$; otherwise, non-college consumption will be higher. Among those with positive net financial gains, the marginal person must dislike college (i.e. $\xi<0$ ). This person would be willing to pay money to avoid college and 
would only attend if it provides financial benefits and greater lifetime consumption opportunities. An increase in family resources would make him more willing to forego the financial gains to avoid the 'distaste' of college. This implies a negative relationship between family resources and attendance even if $T^{\prime}(W)=0$. When tuition is increasing in family resources (i.e. $T^{\prime}(W)>0$ ), there is an additional price disincentive associated with higher family resources. In the absence of borrowing constraints, both wealth and price effects imply an unambiguously negative family resource - college attendance relationship for everyone with a positive financial gain from college. ${ }^{36}$

Among less able youth with a negative financial gain to college, the marginal person must enjoy college (i.e. $\xi>0$ ) such that they are willing to 'pay' for it. An increase in family resources makes this person more willing to pay for the intrinsic benefits of college, which tends to encourage attendance; however, the tuition 'tax' on family resources still serves to discourage attendance as resources increase. The net effects of resources on attendance are ambiguous for lower ability youth, but they will be more positive (or less negative) for the least able. The effects will tend to be positive for the least able when financial aid is relatively unresponsive to resources. Thus, the 'consumption' value of schooling explanation for a positive income - college attendance relationship is plausible for the least able who would lose financially from attending but not for more able youth who would gain.

When tuition and financial aid are tightly linked to resources (i.e. $T^{\prime}(W)$ is large), resources are more likely to be negatively related to attendance. ${ }^{37}$ The shape of the $T(W)$ function, through federal and institutional financial aid policies, plays a key role in determining the effects of wealth on attendance rates. In practice, financial aid policies tend to generate an S-shaped $T(W)$ function. Financial aid is generous and not very responsive to changes in family income/wealth at the very low end of the distribution; as wealth and income increase, the implicit 'tax' through reduced aid increases over a range until aid becomes zero, at which point youth pay full tuition prices regardless of their family resource levels. This pattern suggests that the effects of family resources on tuition levels are small for low and high resource families but may be high for middle class families. This force may

\footnotetext{
${ }^{36}$ This important result holds in more general intergenerational models with altruistic parents endogenously making financial transfers to their college-age children. Appendix B analyzes an extended model in which parents value their children's utility, their own consumption, and have a 'psychic' or 'consumption' value associated with their child's attendance status. When parents can directly make schooling choices for their children (perhaps through transfers tied directly to schooling behavior), the problem is nearly identical to that described here. When parents can only make transfers that are not contingent on their child's schooling choices, the decision problem becomes more complicated. However, the same result holds in either case: when financial returns to college are positive, the effect of increased family resources on attendance rates is negative.

${ }^{37}$ To the extent that tuition is decreasing in ability as schools compete for smarter students, ability will tend to more positively affect attendance. This has little impact on any of the other patterns or predicted changes we discuss.
} 
create negative effects of family resources on attendance rates among middle income/wealth families.

Now, consider the effect of ability, $\theta$, on the value of non-college and college:

$$
\begin{aligned}
\frac{\partial v_{0}}{\partial \theta} & =(1+\beta) u^{\prime}\left(\bar{c}^{0}\right) y_{0}^{\prime}(\theta) \\
\frac{\partial v_{1}^{u}}{\partial \theta} & =(1+\beta) u^{\prime}\left(\bar{c}^{1}\right)\left[\frac{y_{1}^{\prime}(\theta)}{1+R}\right] .
\end{aligned}
$$

For lower ability youth $(\theta \leq \bar{\theta}(W))$, ability unambiguously increases attendance rates, since $\frac{\partial G}{\partial \theta}>0$ and $u^{\prime}\left(\bar{c}^{1}\right)>u^{\prime}\left(\bar{c}^{0}\right)$. For more able youth $(\theta>\bar{\theta}(W))$ who receive a positive financial gain from college, the marginal utility of consumption is higher for the non-college choice, which may generate a negative ability - attendance pattern if $\frac{\partial G}{\partial \theta}$ is small enough. Empirically, ability always appears to be positively related to attendance, suggesting that the substitution effects of ability on the financial returns to college dominate any wealth effects acting through the marginal utility of consumption.

To understand what might have changed ability - family income - college attendance patterns over time, it is useful to analyze how the returns to skill and tuition/financial aid policies impact attendance decisions. In particular, we are interested in determining what policy or economic changes might lead to a stronger positive effect of family income on attendance, without dramatically changing the effects of ability. ${ }^{38}$

Changes in the structure of earnings have been dramatic in the past few decades, with both the returns to ability and education rising significantly since the early 1980s. Suppose $y_{1}(\theta)=\pi_{1} h_{1}(\theta)$, where $\pi_{1}$ reflects the market price of skill and $h_{1}(\theta)$ reflects the skill associated with college attendance. Then, we can model an increase in returns to market skills (including an increase in returns to both ability and college attendance) with an increase in $\pi_{1} \cdot{ }^{39}$ Not surprisingly, an increase in returns to skill will increase college attendance rates. Impacts on the ability - attendance relationship are ambiguous; however, increasing returns to skill will tend to reduce the role of ability among the wealthy and increase it among the poor. ${ }^{40}$ Because the marginal utility of consumption is decreasing in family resources, the effects of an increasing skill premium will be greater on more disadvantaged

\footnotetext{
${ }^{38}$ Define attendance rates, $A R(W, \theta)=1-F(\bar{\xi}(W, \theta))$. For any policy or economic parameter, $x$, that does not affect the value of non-college (this is true for all of the parameters we analyze, including the skill premium, tuition levels, and borrowing limits), $\frac{\partial^{2} A R}{\partial W \partial x}=f(\bar{\xi}(W, \theta))\left[\frac{\partial^{2} v_{1}}{\partial W \partial x}\right]+f^{\prime}(\bar{\xi}(W, \theta))\left[\frac{\partial v_{1}}{\partial W}-\frac{\partial v_{0}}{\partial W}\right] \frac{\partial v_{1}}{\partial x}$ where $f(\cdot)$ is the pdf associated with the density function $F(\cdot)$. In the discussion below, we implicitly assume that the sign of $\frac{\partial^{2} A R}{\partial W \partial x}$ is the same as the sign of $\frac{\partial^{2} v_{1}}{\partial W \partial x}$, which is always true if $f^{\prime}(\cdot)$ is sufficiently close to zero (i.e. the density function for the consumption value of schooling is sufficiently flat at the point of analysis). We make a similar assumption when discussing the effects of economic and policy changes on the ability - attendance relationship.

${ }^{39}$ Decreases in the earnings associated with non-college would produce similar effects to those discussed here.

${ }^{40}$ See Appendix $\mathrm{C}$ for the mathematical derivation of all comparative static results discussed in this section.
} 
youth thereby weakening any positive relationship (or strengthening a negative relationship) between resources and attendance. This theoretical prediction is strongly at odds with the empirical evidence, which suggests that the effects of family income have become significantly more positive over time.

Between 1980 and 2000, the sum of tuition, fees, room, and board roughly doubled at four-year public institutions (College Board 2005). This should increase student borrowing and discourage attendance for all types of students. To consider how changes in the level of tuition affect income ability - attendance patterns, suppose $T(W)=T$ is independent of resources. ${ }^{41}$ The negative effects of tuition on attendance will be greater for the least able and those with lower family resources, since they have the greatest marginal utility of wealth. Because tuition effects on attendance are monotonically declining in family resources for all ability types, an increase in tuition should make the resource attendance relationship more positive. This prediction is consistent with our empirical findings.

If college raises lifetime earnings for most youth (as most estimates suggest), it is difficult to reconcile the data with the theoretical predictions of this schooling choice model. ${ }^{42}$ In particular, the theory predicts a negative relationship between family resources and college attendance for all youth who earn a positive financial return. The NLSY79 reveals a positive family income - attendance relationship for the most able, who should have the highest financial return, and little effect of income for other ability types. The NLSY97 reveals a strong positive relationship for all but the most able. The fact that income - attendance relationships are strongest for the least able in the NLSY97 (see Table 4) is roughly consistent with this prediction, since they are likely to benefit the least financially from college. Most importantly, however, even if the financial gains from college are or were negative for many youth in the past, the rising returns to college should have weakened rather than strengthened any positive family income - attendance relationship. Although, net tuition also rose over this period, which should have strengthened any positive income effects, the rising college wage premium clearly dominates in terms of the net financial gains to college (Heckman, Lochner, and Todd 2007). Still,

\footnotetext{
${ }^{41}$ Since implicit taxes on income through financial aid formulae tend to discourage attendance among youth from high income/wealth families, reductions in these tax rates will tend to create a more positive family income - college attendance relationship. Historically, the financial aid formula employed by the federal government and most colleges and universities has changed little since the early 1980s. One notable change was that home equity was dropped from the federal expected family contribution formula by the Higher Education Amendments of 1992. However, this does not appear to have any important effects, as Dick, Edlin, and Emch (2003) estimate similar implicit 'financial aid taxes' in 1986-87 and 1995-96 using data from National Postsecondary Aid Surveys.

${ }^{42}$ Heckman, Lochner, and Todd (2007) estimate high internal rates of return to college in recent decades, suggesting that the financial returns are positive for reasonable interest rates. They further summarize findings from a number of recent studies (e.g. Cunha, Heckman, and Navarro 2005, and Cunha and Heckman 2006) that account for heterogeneity in returns and psychic costs. These findings typically suggest high financial returns to college along with high 'psychic costs' for marginal students.
} 
increasing tuition levels may have played some role in the rising importance of family income. This effect becomes more important when we introduce borrowing constraints.

\section{Adding Borrowing Constraints}

Now allow for the possibility that some youth may be borrowing constrained. This seems increasingly important given that more than half of all student borrowers took out the maximum allowable amount from the federal Stafford Loan Program in 1999, up from only 18\% in 1989 (Berkner 2000 and Titus 2002).

Suppose that individuals can borrow no more than a specified borrowing limit, $\bar{d}$. Because youth want to save if they do not attend college (due to consumption smoothing and the lack of earnings growth), non-college decisions are unaffected by the introduction of a borrowing limit. ${ }^{43}$ Thus, the value of non-college is defined above by equation (1).

College attendees will be borrowing constrained if and only if $d_{1}^{u}>\bar{d}$, or when

$$
\theta>y_{1}^{-1}(W-T(W)+(1+R) \bar{d}) \equiv \theta^{c}(W, \bar{d}) .
$$

The cutoff ability level, $\theta^{c}$, is increasing in both $\bar{d}$ and $W$. This implies that youth with low resources and high ability will be constrained if they attend college. Constrained students will borrow the maximum, consuming

$$
\begin{aligned}
c_{1}^{c} & =W-T(W)+\bar{d}<\bar{c}^{1}, \\
c_{2}^{c} & =y_{1}(\theta)-R \bar{d}>\bar{c}^{1},
\end{aligned}
$$

during and after school, respectively. Thus, their lifetime value is

$$
v_{1}^{c}(W, \theta)=u(W-T(W)+\bar{d})+\beta u\left(y_{1}(\theta)-R \bar{d}\right)<v_{1}^{u}(W, \theta) .
$$

As with unconstrained utility, this is increasing in initial resources and college earnings, while it is decreasing in tuition payments.

Youth with ability below $\theta^{c}$ will be unconstrained if they choose to attend college, so their value function is defined by equation (2) above. Altogether,

$$
v_{1}(W, \theta)= \begin{cases}v_{1}^{u}(W, \theta) & \text { if } \theta \leq \theta^{c}(W, \bar{d}) \\ v_{1}^{c}(W, \theta) & \text { otherwise. }\end{cases}
$$

\footnotetext{
${ }^{43}$ If individuals prefer declining consumption profiles or experience wage growth, it is possible that some non-college youth may find borrowing limits binding. In this case, constraints on college attendees would be even more severe.
} 
The value of college will be independent of the borrowing limit for low ability individuals who are unconstrained, but it will be increasing in the limit for more able youth who cannot borrow as much as they would like.

In the absence of borrowing constraints, the model predicts that college attendance should be decreasing in family resources except possibly for those with negative financial returns from college (i.e. the least able and wealthiest). The presence of borrowing constraints implies a more positive effect of family resources among the more able poor who find the constraints binding. Since

$$
\frac{\partial v_{1}^{c}}{\partial W}=\left(1-T^{\prime}(W)\right) u^{\prime}\left(c_{1}^{c}\right)
$$

and $c_{1}^{c}<\bar{c}^{1}$, initial resources have a more positive effect on the value of college if an individual is constrained than if he is not. Thus, for higher ability youth who are more likely to be constrained, initial resources are more likely to have a positive effect on attendance rates.

As noted above, the S-shape of the $T(W)$ function implies more negative price effects for youth from middle income families. Borrowing constraints should contribute to more positive effects of wealth at the low end of the income/wealth distribution, but should have little bearing on those from wealthier families. The combined effects of tuition price responses and borrowing constraints suggest a positive effect of family resources on the lowest income/wealth families and small or even negative effects of resources for the rest of the population as long as financial gains from college are positive. Empirically, both the NLSY79 and NLSY97 reveal effects of income changes throughout the income distribution (see Table 3). It is possible that high tuition prices for recent cohorts imply a negative financial return to college for the those with high family incomes paying full tuition levels (often at expensive private universities). As noted above, this can generate a positive income - attendance relationship. The fact that tuition rose substantially more among private four-year colleges (where wealthier students tend to go) than public two- and four-year colleges (College Board 2005) makes this an interesting possibility. In this case, the positive effects of income on attendance observed in the NLSY97 might reflect a combination of borrowing constraints acting on lower income youth and a positive consumption value of schooling for marginal youth from wealthier families.

The marginal value of ability for constrained college attendees is

$$
\frac{\partial v_{1}^{c}(W, \theta)}{\partial \theta}=\beta u^{\prime}\left(c_{2}^{c}\right) y_{1}^{\prime}(\theta)=(1+\beta) u^{\prime}\left(c_{2}^{c}\right)\left[\frac{y_{1}^{\prime}(\theta)}{1+R}\right],
$$

which is less than $\frac{\partial v_{1}^{u}(W, \theta)}{\partial \theta}$ for any values of $(W, \theta)$ for which the constraints bind. Thus, ability has smaller effects on attendance rates if individuals are borrowing constrained than if they are not. A 
reduction in borrowing opportunities should tend to weaken a positive ability - attendance relationship. ${ }^{44}$

An increasing college skill premium, $\pi_{1}$, raises attendance rates among constrained and unconstrained youth, but it reduces $\theta^{c}$ thereby increasing the population of youth that are constrained. Among those who become constrained, the effects of resources should become more positive. Among the least able who remain unconstrained, a rising skill premium should weaken any positive relationship between resources and attendance. The effects of an increase in $\pi_{1}$ should be independent of initial resource levels for more able youth that are constrained in the first place, since their postschool consumption is independent of $W$. The family resource - attendance relationship for previously constrained borrowers is, therefore, unaffected by a rise in the college wage return. Overall, the model predicts that the rising college wage premium should have increased attendance rates. While it weakens any positive income - attendance relationship for those who remain unconstrained, it is likely to generate a more positive relationship for those who become constrained as a result of the change in wages. This is consistent with the NLSY data if the least able have only become constrained in recent years.

Increases in tuition levels will reduce $\theta^{c}$, adding to the population that is borrowing constrained. As noted above, the effects of tuition on attendance among unconstrained youth will be larger for the least able and those with lower family resources, since they have the greatest marginal utility of wealth. The effects will be even larger for any particular individual that is constrained, since he faces a higher marginal utility of wealth while in college. Altogether, an increase in tuition will make the resource - attendance relationship more positive, with the largest effects on those that are or become constrained. As discussed above, the predicted responses to rising tuition levels are broadly consistent with the changes in the role of income across the NLSY79 and NLSY97, except that higher tuition alone should reduce attendance rather than raise it.

While borrowing limits have actually risen slightly in nominal terms since the early 1980s, their real values have declined (especially for first and second year undergraduates) since that time. ${ }^{45}$ The

\footnotetext{
${ }^{44}$ As noted earlier, the effects of ability may be negative for some unconstrained individuals; although, this does not appear to be empirically important. In this case, borrowing constraints lead to even stronger negative effects of ability on attendance. Lochner and Monge (2007) argue that endogenous borrowing limits that depend on educational investment levels (e.g. as embodied in government student loan programs) are likely to generate a more positive ability - attendance relationship.

${ }^{45}$ Prior to 1986 , dependent students were able to borrow up to $\$ 2,500$ per year in Stafford loans. Beginning in the 1986-87 year, Stafford loan limits for first- and second-year dependent students were raised to $\$ 2,625$ while limits for third- to fifth-year students were raised to $\$ 3,500$. In 1992 , the loan limit for second-year dependent students rose further to $\$ 3,500$, while loan limits for third- to fifth-year students rose to $\$ 5,500$.
} 
near doubling in tuition, fees, room, and board charges (in real terms) at four-year public institutions between 1980 and 2000 (College Board 2005) is further cause for concern that the real value of borrowing opportunities has shrunk considerably.

Consider the effects of reducing borrowing opportunities by lowering $\bar{d}$. Stricter borrowing limits will cause some college attendees to become constrained when they previously were not. This of course, lowers the value of college for them. Furthermore, lower borrowing limits will reduce the value of college among those who are already constrained. Both of these forces serve to lower overall college attendance rates. The effects will, not surprisingly, be greater on those youth of high ability or from families with low resources, since they are more likely to be constrained already or to become constrained in response to the tighter limits. As discussed earlier, family resources have a stronger positive effect on college attendance rates among youth who are constrained than among those who are unconstrained. To the extent that lowering borrowing limits causes more youth to become constrained, it should strengthen the relationship between family resources and attendance. In particular, it should extend the range of ability types that face constraints (to cover less and less able individuals), thereby generating a more positive resource - attendance relationship for lower ability types than previously existed.

Comparing the NLSY79 and NLSY97 cohorts, attendance rates increase rather than decrease, in contrast to the predicted response to reduced borrowing opportunities. However, empirical changes in the role of ability and family income are more consistent with the model's predictions. For example, attendance rates appear to increase less at the high end of the ability distribution (the model predicts the strongest negative effects for these youth who are most likely to be constrained). More interestingly, the substantial increase in the effects of family income on college attendance rates is consistent with the possibility that borrowing constraints have become substantially more severe, to the point where they may even constrain low ability youth in the later cohort (see Table 4). However, it is more difficult to explain why the effects of income appear to have decreased for the most able, since they are predicted to be most affected by restricted borrowing opportunities. As we show below, the most able poor appear to have responded by working more while enrolled in college rather than foregoing college altogether.

All three economic changes are predicted to increase the fraction of the population that is borrowing constrained, consistent with the large rise in the fraction of students borrowing the maximum allowable amount from federal student loan programs (Berkner 2000 and Titus 2002). Table 7 summarizes the 
predicted theoretical responses to increases in the skill premium, rising tuition, and lower borrowing limits for constrained and unconstrained individuals. Estimated changes between the NLSY79 and NLSY97 are also shown in the final column. None of these factors, by itself, can explain the changing patterns in attendance by ability and family income/wealth (with or without borrowing constraints). Clearly, it is important to consider the effects of all these changes simultaneously to have any hope of matching the data.

\section{Additional Evidence on College Quality, Delay, and Work}

Although the model developed in the previous section does not incorporate choices about college quality, the decision to delay college, or to work while enrolled, these are additional margins that individuals may adjust in response to borrowing constraints. We, therefore, examine how these decisions are affected by family income, controlling for AFQT and family background as above.

We estimate the effects of income and ability on college quality, as measured by enrollment in a four-year institution. In the NLSY97, we also study enrollment in four-year private institutions. Approximately $33 \%$ of NLSY79 youth were enrolled in any type of college at age 20, and $23 \%$ were enrolled in a four-year institution. Among NLSY97 youth, 44\% were enrolled in any type of college; $33 \%$ in four-year colleges; and 10\% in four-year private colleges. Our analysis of college quality is reported in Table 8. We first show the estimated effects of income and ability on current enrollment in any college at age 20. This offers an alternative measure of college-going to that discussed earlier and serves as a benchmark for our analysis of four-year and private four-year enrollment. The estimated effects of both ability and family income, controlling for family background, on current enrollment in any college at age 20 are similar to the estimated effects on college attendance by age 21 reported in Table 3. Table 8 also reports the estimated effects of family income and AFQT on current enrollment in four-year and private four-year institutions at age 20. Consistent with the presumption that these institutions are of better quality (than two-year institutions), we see that AFQT positively effects enrollment in four-year and private four-year schools conditional on enrollment in any college. Estimated effects of income on enrollment in a four-year college are slightly smaller than for enrollment in any college for the NLSY79 and slightly larger for the NLSY97. Across the two cohorts, the highest - lowest income differential grew by about 7.5 percentage points for enrollment in a four-year college and by about 4.5 percentage points for enrollment in any college. In the NLSY97, students enrolled in any college are significantly more likely to be enrolled in a four-year college if they come from higher 
income families. This is not true for the NLSY79. The effects of income on enrollment in four-year private colleges appears to be small but statistically significant in the NLSY97. However, considering that only $10 \%$ of all youth in our sample are enrolled in such institutions, the estimated difference between the highest and lowest income quartiles (0.035) is sizeable. Among those enrolled in any college, there is little difference in enrollment rates at private four-year schools by family income.

Approximately $10 \%$ of all youth who attended college by age 22 had not attended as of age 20 in both NLSY cohorts. As discussed earlier, Table A2 suggests that family income is negatively correlated with college delay beyond age 20 in the NLSY79, while Table A3 implies little relationship between family income and delay in the NLSY97. Table 9 provides a different look at the effects of ability and family income on college delay at the transition period between secondary and post-secondary schooling (i.e. ages 18 and 19). Here, someone is considered to have delayed college if they were enrolled in college at some point from ages 18-21 but were not enrolled in any school at age 18 or were enrolled in high school at age 18 but not college at age 19. Using this measure of delay as our dependent variable and the sample of individuals ever enrolled in college over ages 18-21, we explore the effects of family income and AFQT on college delay, controlling for family background. The NLSY79 estimates suggest that college delay is strongly decreasing in ability but weakly (and insignificantly) increasing in family income. The NLSY97 reveals similar, though slightly weaker, effects of ability and weak (and insignificant) negative effects of family income. Altogether, there is little evidence that family income plays an important role in college delay decisions.

Since those who delay college are more likely to be borrowing constrained than those who enroll immediately after finishing high school, it is natural to ask whether they make different choices about college quality. The model of Section 5 predicts that those who are borrowing constrained will be less likely to attend college and that their attendance decisions will be more responsive to changes in family income. In Table 10, we explore whether this prediction carries over to college quality decisions. Among those who were enrolled in college at any age from 18-21, we examine whether college delay (a rough proxy for being constrained) affects the type of first college attended and whether the effects of income on the type of college differ by delay status. In both NLSY cohorts, those who delay are significantly less likely to initially enroll in a four-year college (by 16-18 percentage points). In the NLSY97, delay also reduces the likelihood that someone enrolls in a private four-year institution. Unfortunately, sample sizes make it difficult to determine whether the effects of income on college type differ between those who delay and those who do not. While the estimated effects of income on 
enrollment in a four-year college are roughly twice as large for those who delayed relative to those who did not in the NLSY97, the estimates are also very noisy.

Finally, we examine the effects of income and ability on work during the academic year among college enrollees. Figures 4 and 5 show the average fraction of weeks worked and the average hours worked per week (including zero hours for weeks without work) during the academic year by AFQT and family income quartiles for youth age 20 who are enrolled in college. The academic year is defined here to be the last sixteen weeks of the calendar year and the first sixteen weeks of the following calendar year when the youth is enrolled in college. ${ }^{46}$ Figure 4 reveals that students, on average, work about half of all weeks during the academic year (a sizeable majority work at least five weeks). There appears to be a slight increase in weeks worked from the NLSY79 to NLSY97 cohort, but the differences are small for most ability - family income types. There is little variation in weeks worked by family income or ability; however, among the more able students in the NLSY97, family income is negatively related to weeks worked. These conclusions are confirmed in the first two columns of Tables 11 and 12, which control for family background. As Table 12 shows, the effect of income (entered linearly here) on weeks worked is only significant for the highest ability quartile in the NLSY97, and the magnitudes of all estimated income effects are relatively small.

Figure 5 shows that, on average, students from most ability and family income backgrounds worked between 10 and 15 hours per week in the NLSY79. Among the NLSY97 cohort, hours worked are slightly higher for most income groups in the lower half of the ability distribution. Changes over time were more dramatic among the upper ability quartiles. Average hours of work increased by about 5 hours per week, roughly one-third their initial level, for those in AFQT quartile three. Within AFQT quartile 4, average hours worked per week nearly doubled from the NLSY79 to NLSY97 for the lowest income quartiles while it changed very little for the highest income quartile. Thus, among the most able in the NLSY97, average hours worked per week were roughly twice as high for the lowest income as the highest income quartile. Again, these patterns are largely confirmed using regressions as reported in Tables 11 and 12. Focusing on Table 12, we see that hours worked per week are unaffected by income in the NLSY79. In the NLSY97, the estimated effects are significantly negative for the highest ability quartile (estimated effects are of similar magnitude for ability quartile two, though much less precise) and suggest that the $\$ 85,000$ average income difference between the highest and lowest income quartiles is associated with a five hour difference in weekly work hours during the academic year.

\footnotetext{
${ }^{46}$ Students missing more than four weeks of relevant work data are dropped from the analysis.
} 
These results suggest that family income reduces work (both weeks worked and hours worked per week) for the most able college students in the NLSY97, but it has little affect on work among college students in the NLSY79. This is consistent with (though not necessarily evidence of) an increasing financial burden and binding borrowing constraints among more able college students in the NLSY97 - precisely the group of students that showed little change in family income - attendance patterns over time. It is possible that rising tuition levels, coupled with shrinking real borrowing opportunities, have made college a less attractive choice among youth from low-income families, despite the rising college premium. More able financially disadvantaged youth in the recent NLSY cohort may find the financial rewards of college so great that they are still willing to attend despite limited borrowing options. For them, work while in college may be a second-best option worth taking. In contrast, many lower ability youth from poor families may find it too difficult to work while attending classes, instead opting to forego college altogether.

Given the evidence on the increasing effects of family income on college attendance and quality, it is perhaps surprising that there is little correlation between family income and delay in both NLSY samples. Given the amount of work taking place while students are enrolled in college, it is possible that delaying college is rarely a better alternative than part-time work and attendance. Indeed, based on their findings in the NLSY79, Keane and Wolpin (2001) argue that borrowing constraints largely lead to increased work while in college rather than decreased attendance.

\section{Conclusions}

Based on recent evidence arguing that short-term borrowing constraints at college-going ages are unimportant, many economists have begun to argue that government policy should shift toward improving the college-preparedness of children from lower income families. ${ }^{47}$ It is argued that an expansion of student loan programs or additional tuition subsidies would do little to improve the outlook for economically disadvantaged youth or eliminate enrollment gaps by family income. While this may be true, most of the evidence that these arguments are based on comes from the NLSY79, a sample of youth making their college attendance decisions over twenty-five years ago. A lot has changed since then. If recent rises in tuition and reductions in Pell Grant disbursements have forced youth to borrow more for college, mandated limits on federal student loans may have begun to take their toll on those

\footnotetext{
${ }^{47}$ See, e.g., Cunha et al. (2007).
} 
from low income families. ${ }^{48}$ Borrowing constraints may bind for many more youth today than in the early 1980s. Consistent with this hypothesis, our findings suggest that family income has become a substantially more important determinant of college attendance in recent years.

This result is difficult to reconcile with a 'consumption' value of schooling. When the financial returns to college are positive for most youth, the marginal student dislikes school and is willing to 'pay' to avoid it. In this case, we show that income and college attendance should be negatively related if youth are not borrowing constrained. More importantly, the well-documented increase in the net financial returns to college should have weakened any positive income - attendance relationship in the absence of binding constraints.

While broadly consistent with the increased role of family income over time, borrowing constraints are difficult to reconcile with two features of the NLSY97 data. First, we document sizeable effects of family income on youth from the top half of the family income distribution. It seems unlikely that these youth are constrained by limits on borrowing; although, we cannot rule this out. Among these youth, a positive consumption value of college (at the margin) may play an important role, since they are more likely to attend private universities whose prices have skyrocketed over the past few decades. Second, borrowing constraints are most likely to bind for the most able poor; yet, our estimated effects of income on college attendance in the NLSY97 are largest for the least able (interestingly, they are strongest for the most able in the NLSY79). Among the most able NLSY97 youth, family income appears to significantly reduce work hours during the academic year. It is possible that the financial rewards are currently so great for the most able that college attendance is worthwhile even in the face of severe constraints on borrowing. For these youth, part-time work while enrolled in college may be preferable to foregoing college altogether. ${ }^{49}$

Overall, it is likely that borrowing constraints have become more stringent over the past few decades and that this is at least partially responsible for the increase in college attendance gaps by family income. It is also possible that other factors (e.g. social networks, imperfect information, college admissions policies) have contributed to these gaps. Given the policy importance of distinguishing between borrowing constraints and these other factors, additional evidence on this issue is certainly warranted.

\footnotetext{
${ }^{48}$ In 1999-2000, more than half of all undergraduate student borrowers borrowed the maximum allowable amount from the Stafford Loan program (Berkner 2000 and Titus 2002).

${ }^{49}$ Of course, this does not imply that borrowing constraints are harmless in this case - any distortion in behavior is inefficient.
} 
Perhaps surprisingly, the documented rise in the return to ability in the labor market has had relatively little impact on the role played by ability in determining educational outcomes. Cognitive ability appears to be extremely important for both high school completion and college-going decisions, past and present.

\section{References}

Barrow, L., and C. Rouse (2005), "Do Returns to Schooling Differ by Race and Ethnicity?" Federal Reserve Bank of Chicago Working Paper No. 2005-02.

Becker, G. (1975), Human Capital, 2nd Ed., New York, NY: Columbia University Press.

Belley, P., and L. Lochner (2007), "The Changing Role of Family Income and Ability in Determining Educational Achievement", Working Paper.

Berkner, L. (2000), Trends in Undergraduate Borrowing: Federal Student Loans in 1989-90, 1992-93, and 1995-96, Washington DC: National Center for Education Statistics Report 2000-151.

Blackburn, M., and D. Neumark (1993), "Omitted-Ability Bias and the Increase in the Return to Schooling", Journal of Labor Economics, 11, p.521-544.

Brown, M., M. Mazzocco, J.K. Scholz, and A. Seshadri (2006), "Tied Transfers", University of Wisconsin-Madison Working Paper.

Cameron, S., and C. Taber (2004), "Estimation of Educational Borrowing Constraints Using Returns to Schooling", The Journal of Political Economy, 112, 132-182.

Cameron, S., and J.J. Heckman (1998), "Life Cycle Schooling and Dynamic Selection Bias: Models and Evidence for Five Cohorts of American Males ", The Journal of Political Economy, 106, 262-333.

Cameron, S., and J.J. Heckman (2001), "The dynamics of educational attainment for black, hispanic and white males", The Journal of Political Economy, 109, 455-499.

Card, D., and T. Lemieux (2001), "Can Falling Supply Explain the Rising Return to College for Younger Men? A Cohort-Based Analysis", Quarterly Journal of Economics, 116, p.705-746.

Carneiro, P., and J.J. Heckman (2002), "The Evidence on Credit Constraints in Post-Secondary Schooling", Economic Journal, 112, 989-1018. 
Cawley, J., J.J. Heckman, L. Lochner and E. Vytlacil (2000), "Understanding the Role of Cognitive Ability in Accounting for the Recent Rise in the Economic Return to Education", in K.J. Arrow, S. Bowles and S. Durlauf (eds.), Meritocracy and Economic Inequality, Princeton University Press.

College Board (2005), Trends in College Pricing 2005.

Cunha, F., and J.J. Heckman (2006), "A New Framework for the Analysis of Inequality," NBER Working Paper No. 12505.

Cunha, F., J.J. Heckman, L. Lochner, and D. Masterov (2007), "Interpreting the Evidence on Life Cycle Skill Formation", in E. Hanushek and F. Welch (eds.), Handbook of the Economics of Education, Amsterdam: Elsevier Science.

Cunha, F., J.J. Heckman, and S. Navarro (2005), "Separating Uncertainty from Heterogeneity in Life Cycle Earnings," NBER Working Paper No. 11024.

Dick, A., A. Edlin, and E. Emch (2003), "The Savings Impact of College Financial Aid", Contributions to Economic Analysis and Policy, 2(1).

Dynarski, S., and J. Scott-Clayton (2006), "The Cost of Complexity in Federal Student Aid: Lessons from Optimal Tax Theory and Behavioral Economics," NBER Working Paper No. 12227.

Ellwood, D., and T. Kane (2000), "Who Is Getting a College Education? Family Background and the Growing Gaps in Enrollment", in S. Danziger and J. Waldfogel (eds.), Securing the Future: Investing in Children from Birth to College, Russell Sage Foundation.

Heckman, J.J., L. Lochner and C. Taber (1998), "Explaining Rising Wage Inequality: Explorations with a Dynamic General Equilibrium Model of Labor Earnings with Heterogeneous Agents", Review of Economic Dynamics, 1, 1-58.

Heckman, J.J., L. Lochner, and P. Todd (2007), "Earnings Functions, Rates of Return and Treatment Effects: The Mincer Equation and Beyond", in E. Hanushek and F. Welch (eds.), Handbook of the Economics of Education, Amsterdam: Elsevier Science.

Juhn, C. (2003), "Labor Market Dropouts and Trends in the Wages of Black and White Men", Industrial and Labor Relations Review, 56(4), 643-62.

Kane, T. (2007), "Public Intervention in Postsecondary Education", in E. Hanushek and F. Welch (eds.), Handbook of the Economics of Education, Amsterdam: Elsevier Science. 
Kane, T., and C. Rouse (1999), "The Community College: Educating Students at the Margin Between College and Work", Journal of Economic Perspectives, 13(1), 63-84.

Katz, L., and K.M. Murphy (1992), "Changes in Relative Wages, 1963-1987: Supply and Demand Factors", Quarterly Journal of Economics, 107, 35-78.

Keane, M. (2002), "Financial Aid, Borrowing Constraints, and College Attendance: Evidence from Structural Estimates", American Economic Review, 92, 293-297.

Keane, M., and K. Wolpin (2001), "The Effect of Parental Transfers and Borrowing Constraints on Educational Attainment", International Economic Review, 42, 1051-1103.

Lochner, L., and A. Monge (2007), "Human Capital Formation with Endogenous Constraints", Working Paper.

McPherson, M., and M. Schapiro (1998), The Student Aid Game: Meeting Need and Rewarding Talent in American Higher Education, Princeton, NJ: Princeton University Press.

MaCurdy, T., and E. Vytlacil (2003), "Establishing New Norms for the AFQT Using Data from Pay97", Working Paper.

Manski, C., and D. Wise (1983), College Choice in America, Cambridge, MA: Harvard University Press.

Murnane, R., J. Willett, and F. Levy (1995), "The Growing Importance of Cognitive Skills in Wage Determination", Review of Economics and Statistics, 77, 251-266.

Rivkin, S. (1995), "Black/White Differences in Schooling and Employment", Journal of Human Resources, 30(4), 826-52.

Stinebrickner, T., and R. Stinebrickner (2007), "The Effect of Credit Constraints on the College Drop-Out Decision: A Direct Approach Using a New Panel Study", Working Paper.

Titus, M. (2002), Supplemental Table Update for Trends in Undergraduate Borrowing: Federal Student Loans in 1989-90, 1992-93, and 1995-96, http://nces.ed.gov/pubs2000/2000151update.pdf. 
Figure 1a: High School Completion by AFQT and Family Income Quartiles (NLSY79)

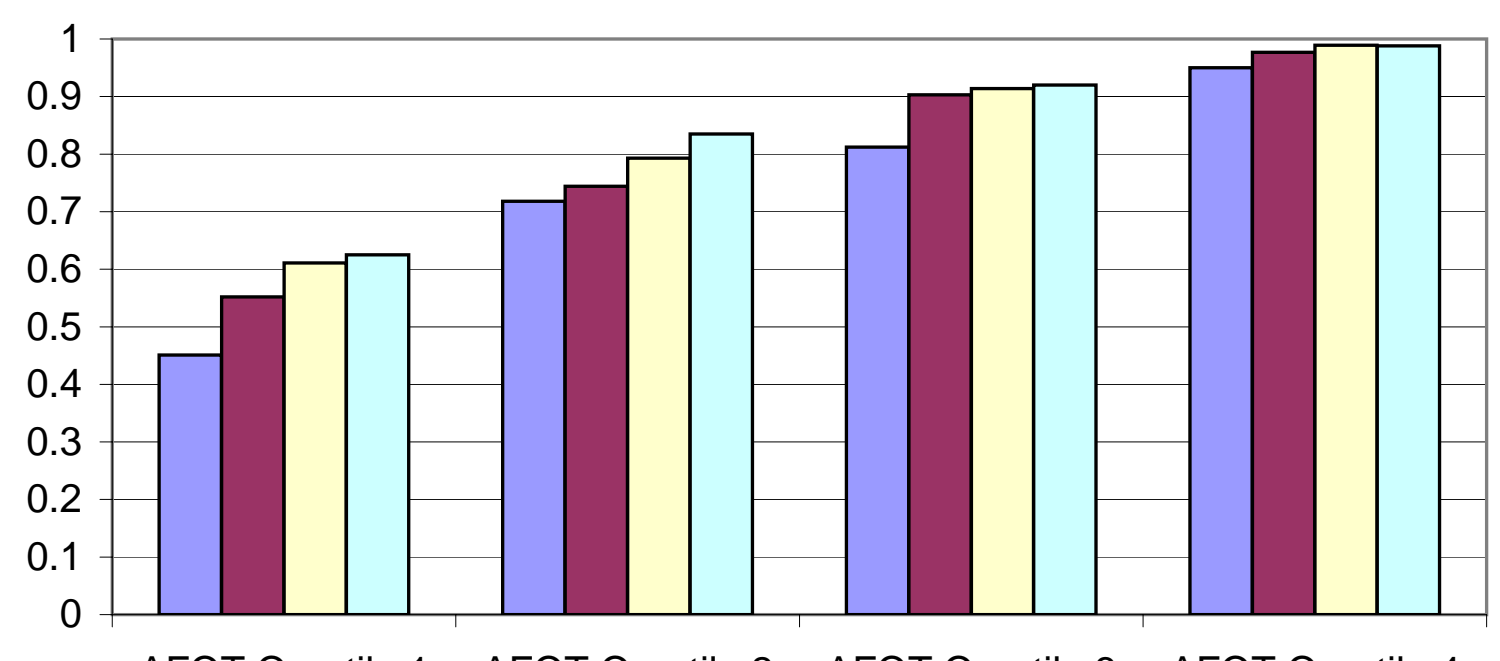

AFQT Quartile $1 \quad$ AFQT Quartile $2 \quad$ AFQT Quartile $3 \quad$ AFQT Quartile 4

$\square$ Family Income Quartile $1 \square$ Family Income Quartile 2

$\square$ Family Income Quartile 3 Family Income Quartile 4

Figure 1b: High School Completion by AFQT and Family Income Quartiles (NLSY97)

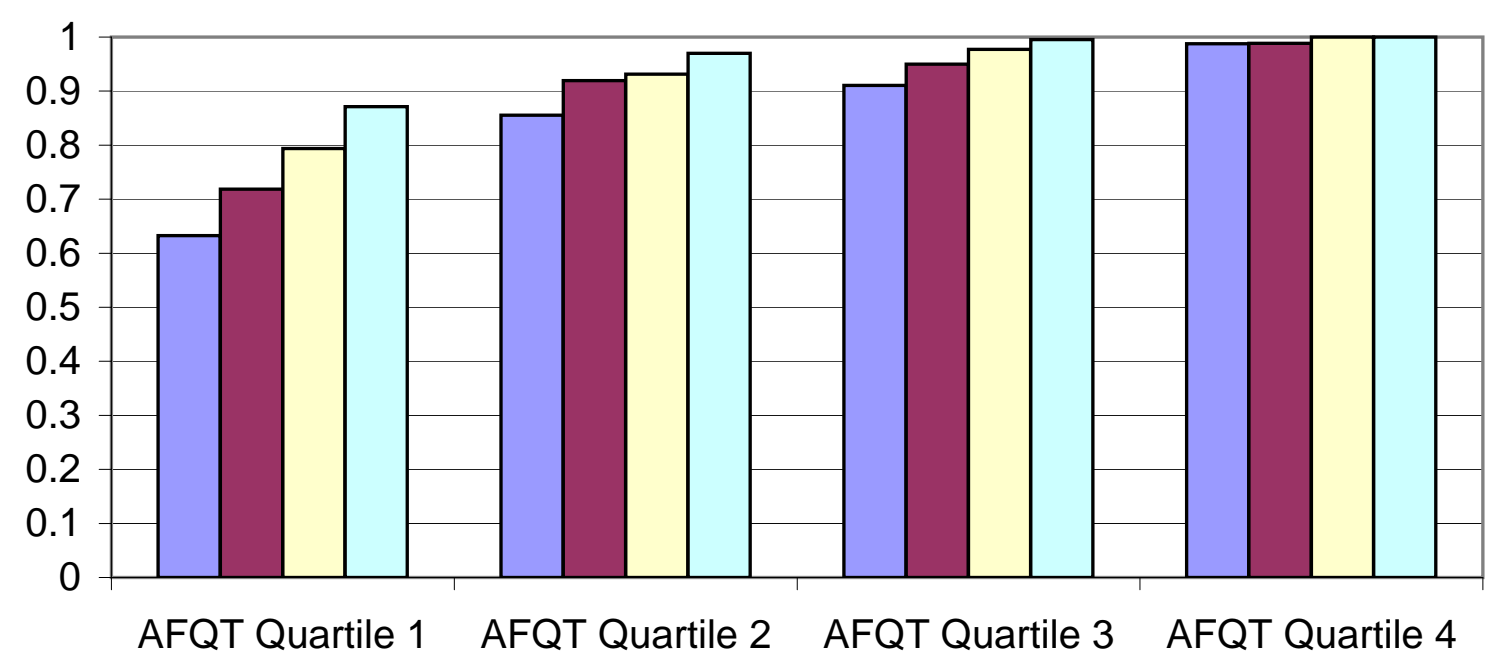

$\square$ Family Income Quartile $1 \square$ Family Income Quartile 2

$\square$ Family Income Quartile 3 GFamily Income Quartile 4 
Figure 2a: College Attendance by AFQT and Family Income Quartiles (NLSY79)

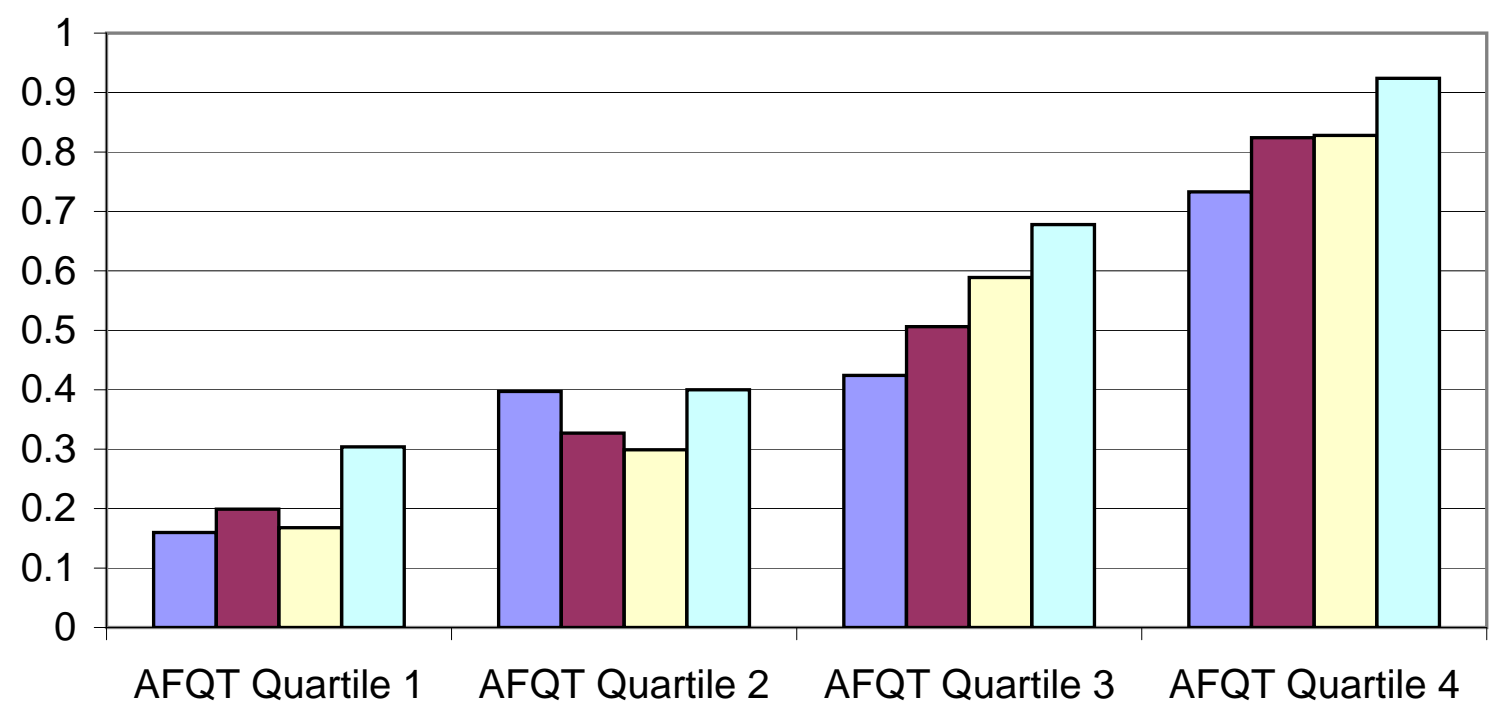

$\square$ Family Income Quartile 1 Family Income Quartile 2

$\square$ Family Income Quartile 3 Family Income Quartile 4

Figure 2b: College Attendance by AFQT and Family Income Quartiles (NLSY97)

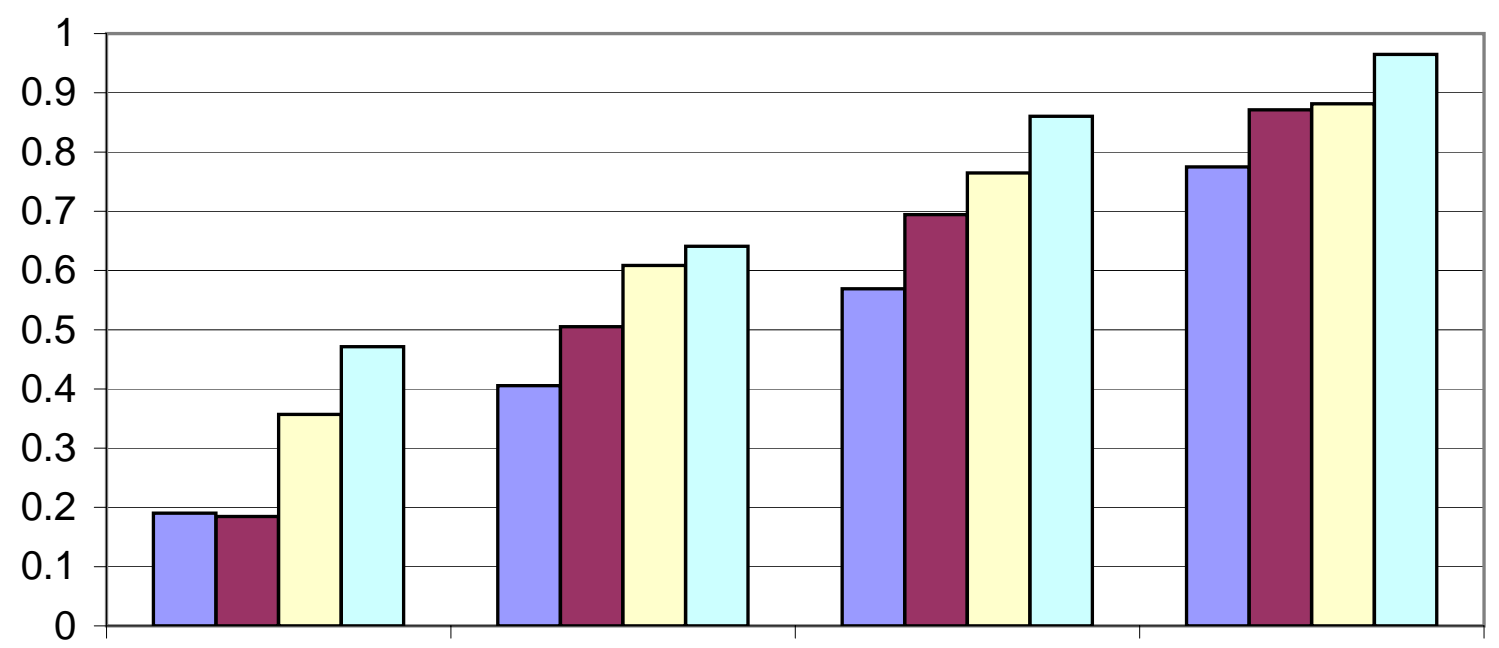

AFQT Quartile $1 \quad$ AFQT Quartile 2 AFQT Quartile $3 \quad$ AFQT Quartile 4

$\square$ Family Income Quartile $1 \square$ Family Income Quartile 2 $\square$ Family Income Quartile 3 aFamily Income Quartile 4 
Figure 3: Estimated Effects (with 95\% Confidence Intervals) of Income on Educational Attainment (NLSY79 and NLSY97, Polynomial Estimates)

(a) High School Completion

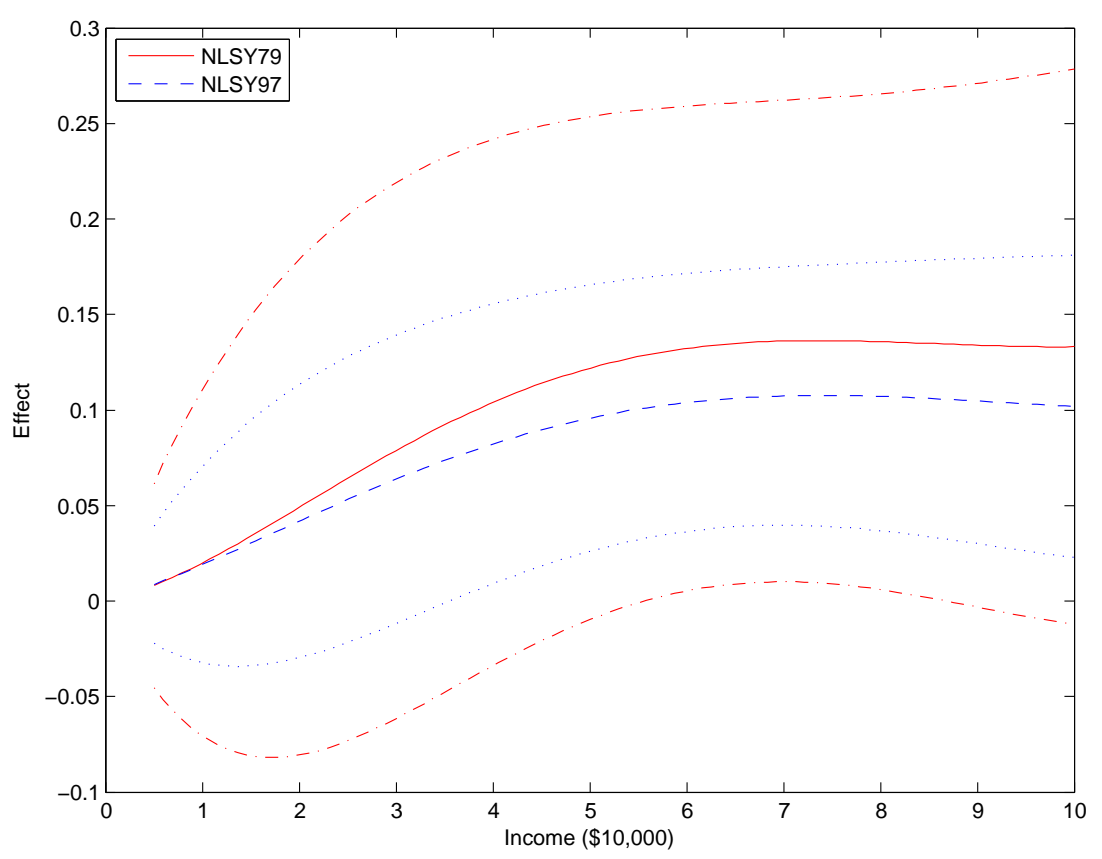

(b) College Attendance

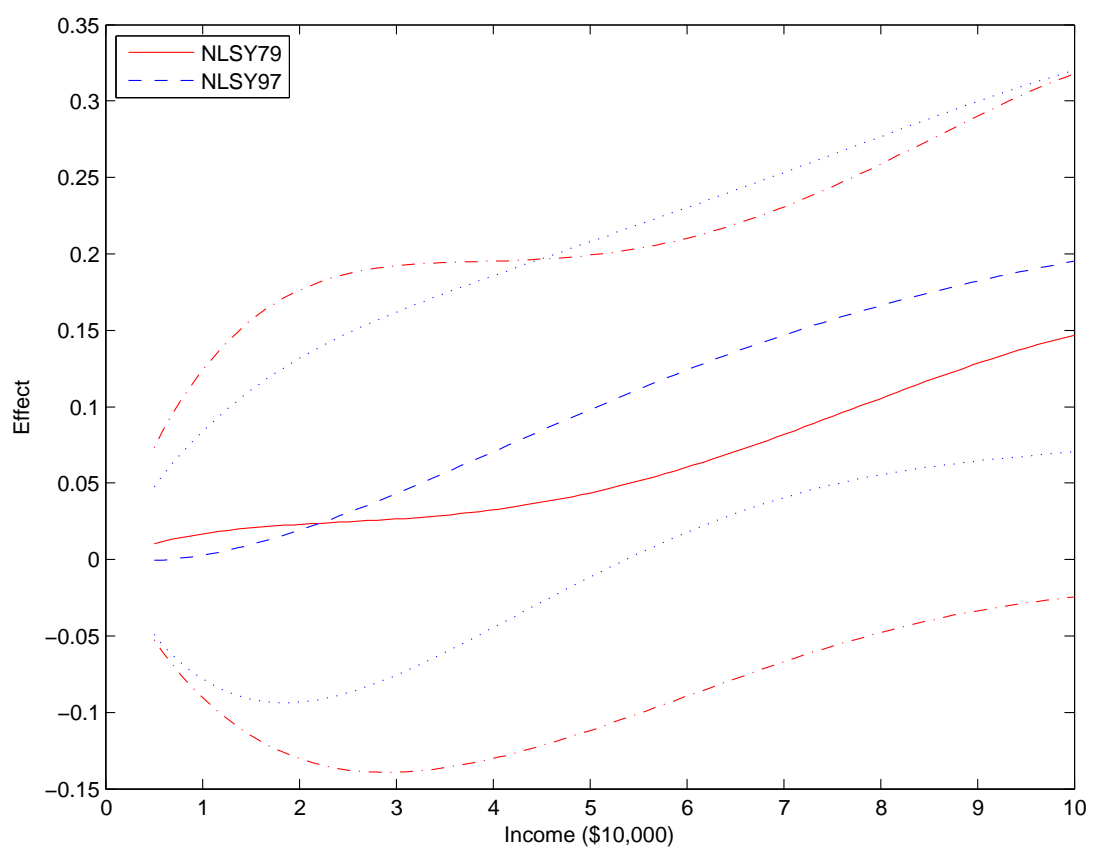


Figure 4a: Share of Weeks Worked during School Year by AFQT and Family Income Quartiles (NLSY79)

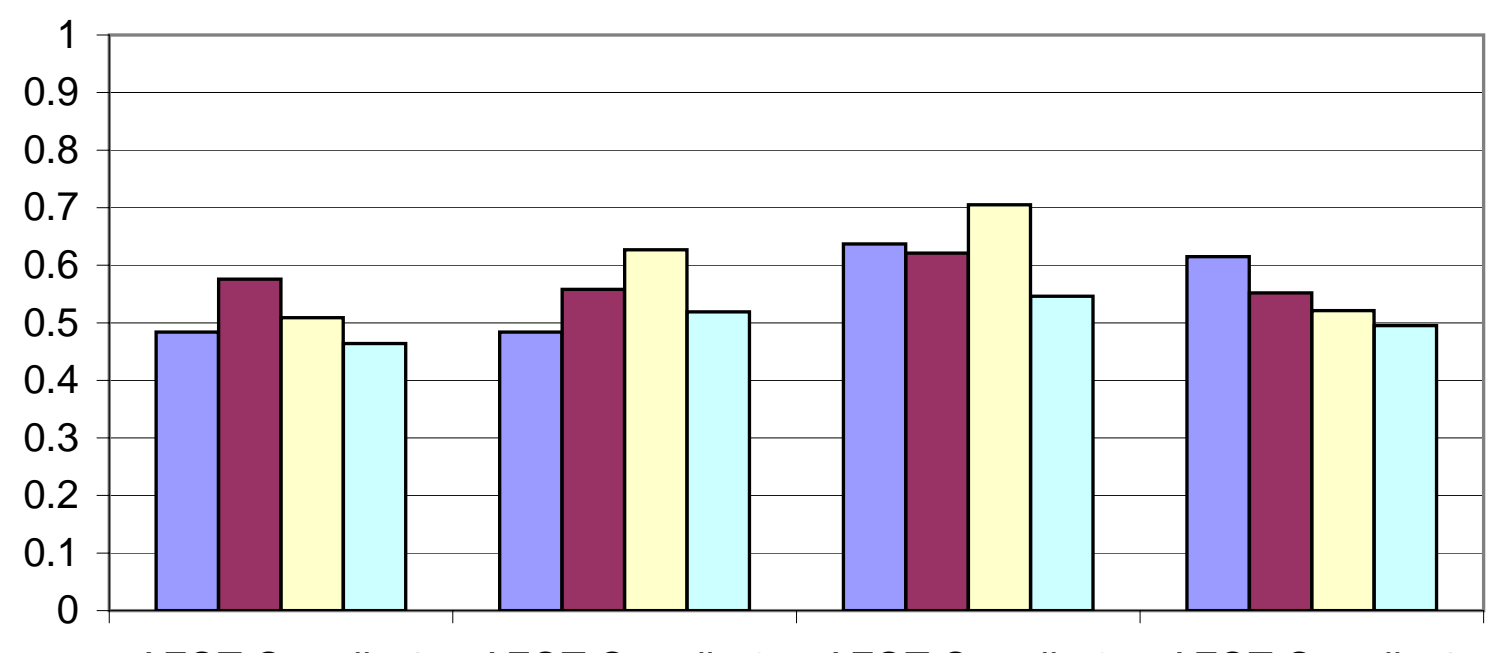

AFQT Quartile $1 \quad$ AFQT Quartile $2 \quad$ AFQT Quartile $3 \quad$ AFQT Quartile 4

$\square$ Family Income Quartile 1 Family Income Quartile 2

$\square$ Family Income Quartile 3 FFamily Income Quartile 4

Figure 4b: Share of Weeks Worked during School Year by AFQT and Family Income Quartiles (NLSY97)

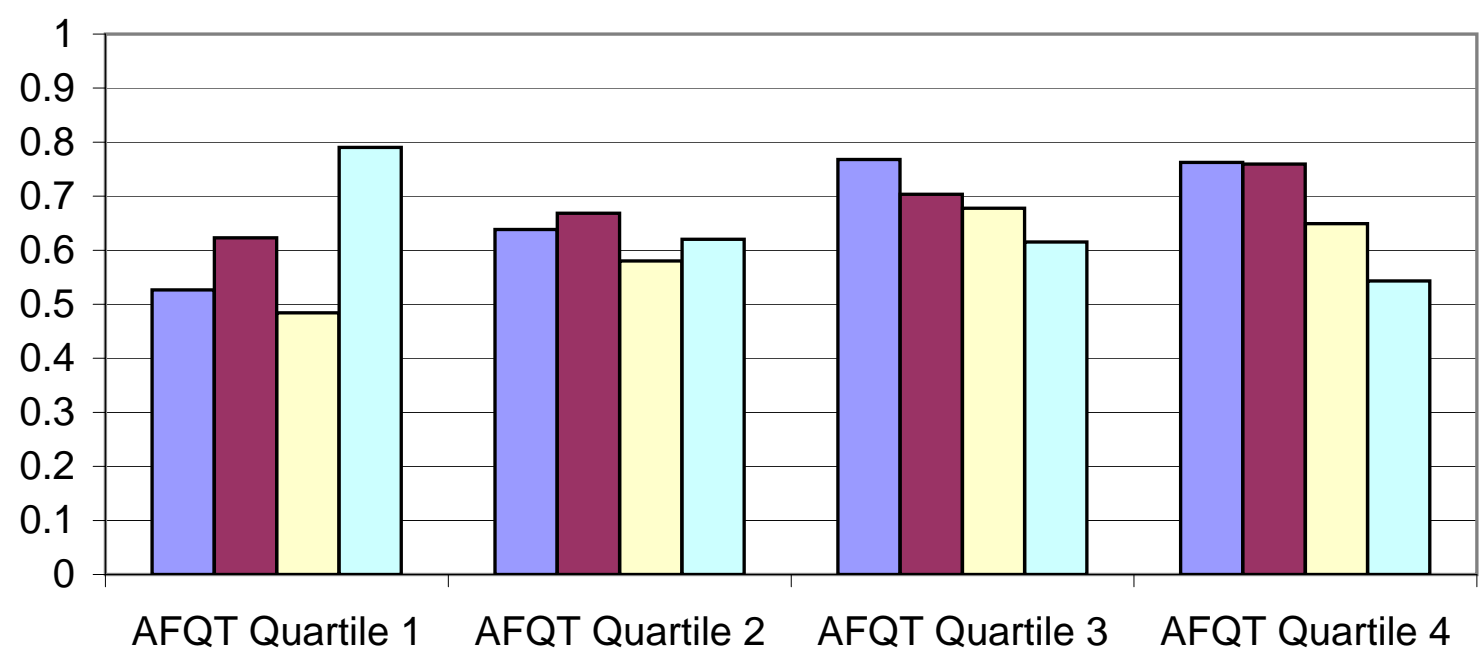

$\square$ Family Income Quartile $1 \square$ Family Income Quartile 2

$\square$ Family Income Quartile $3 \square$ Family Income Quartile 4 
Figure 5a: Average Hours Worked per Week during School Year by AFQT and Family Income Quartiles (NLSY79)

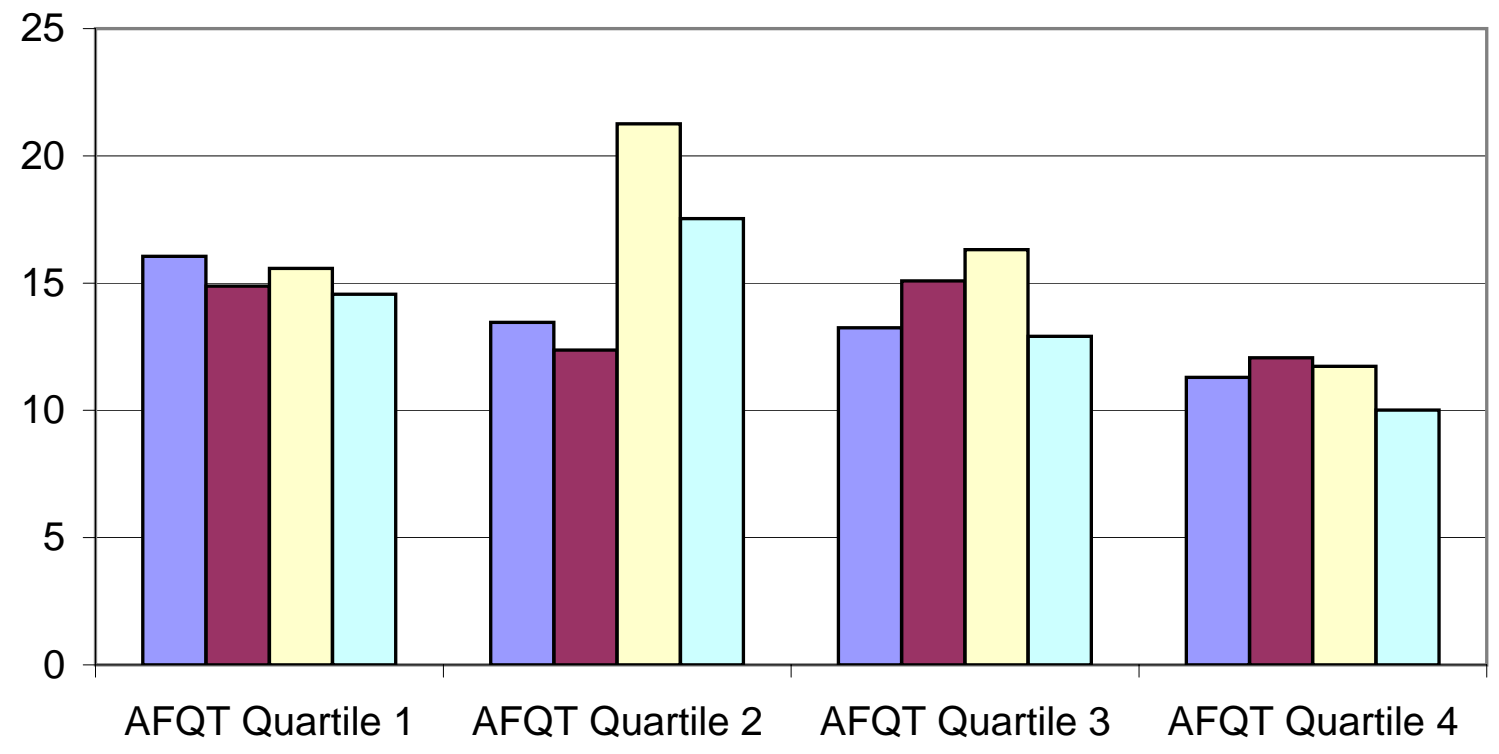

$\square$ Family Income Quartile $1 \square$ Family Income Quartile 2 $\square$ Family Income Quartile 3 GFamily Income Quartile 4

Figure 5b: Average Hours Worked per Week during School Year by AFQT and Family Income Quartiles (NLSY97)

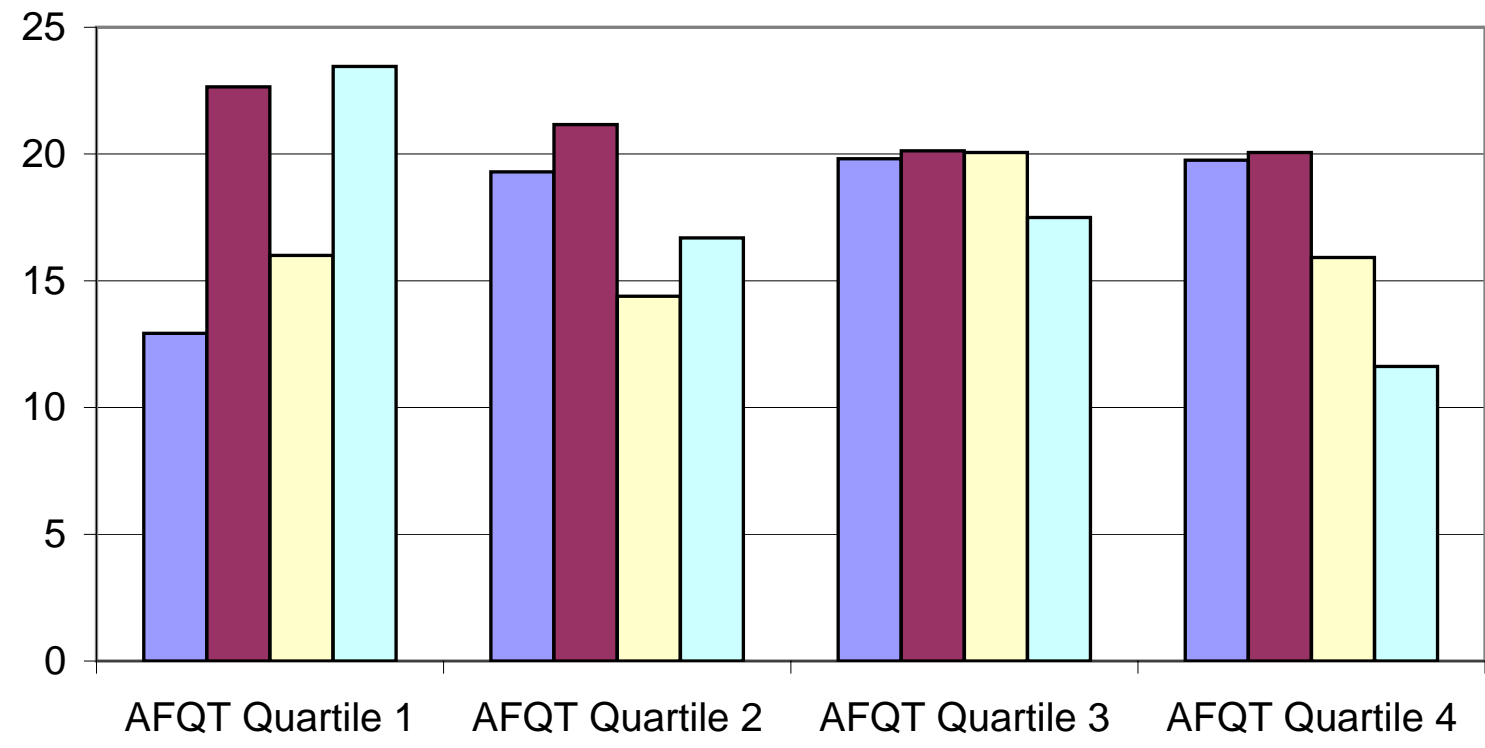

$\square$ Family Income Quartile $1 \square$ Family Income Quartile 2 $\square$ Family Income Quartile 3 FFamily Income Quartile 4 
Table 1: Sample Descriptive Statistics

\begin{tabular}{|c|c|c|}
\hline & NLSY79 & NLSY97 \\
\hline \multirow[t]{2}{*}{ Completed High School (age 21) } & 0.792 & 0.905 \\
\hline & $(0.406)$ & $(0.294)$ \\
\hline \multirow[t]{2}{*}{ Attended College (age 21) } & 0.493 & 0.622 \\
\hline & $(0.500)$ & $(0.485)$ \\
\hline \multirow[t]{2}{*}{ Completed at Least One Year of College (age 21) } & 0.381 & 0.529 \\
\hline & $(0.486)$ & $(0.499)$ \\
\hline \multirow[t]{2}{*}{ Male } & 0.514 & 0.501 \\
\hline & $(0.500)$ & $(0.500)$ \\
\hline \multirow[t]{2}{*}{ Black } & 0.123 & 0.147 \\
\hline & $(0.329)$ & $(0.354)$ \\
\hline \multirow[t]{2}{*}{ Hispanic } & 0.076 & 0.113 \\
\hline & $(0.264)$ & $(0.317)$ \\
\hline \multirow[t]{2}{*}{ Mother's Age at Birth } & 26.647 & 25.512 \\
\hline & $(6.218)$ & $(5.076)$ \\
\hline \multirow[t]{2}{*}{ Intact Family during Adolescence } & 0.728 & 0.552 \\
\hline & $(0.445)$ & $(0.497)$ \\
\hline \multirow[t]{2}{*}{ Urban/Metropolitan Area during Adolescence } & 0.763 & 0.785 \\
\hline & $(0.425)$ & $(0.411)$ \\
\hline \multirow[t]{2}{*}{ Number of Siblings/Children under 18} & 3.200 & 2.277 \\
\hline & $(2.178)$ & $(1.133)$ \\
\hline \multirow[t]{2}{*}{ Mother HS Graduate } & 0.674 & 0.849 \\
\hline & $(0.469)$ & $(0.358)$ \\
\hline \multirow[t]{2}{*}{ Mother at Least Some College } & 0.197 & 0.476 \\
\hline & $(0.398)$ & $(0.499)$ \\
\hline \multirow[t]{2}{*}{ Family Income (in \$10,000) during Late Adolescence } & 5.227 & 5.462 \\
\hline & $(2.952)$ & $(3.435)$ \\
\hline \multirow[t]{2}{*}{ Average Family Income (in $\mathbf{\$ 1 0 , 0 0 0 )}$ ) in Quartile 1} & 1.864 & 1.538 \\
\hline & $(0.709)$ & $(0.734)$ \\
\hline \multirow[t]{2}{*}{ Average Family Income (in \$10,000) in Quartile 2} & 4.040 & 3.829 \\
\hline & $(0.548)$ & $(0.621)$ \\
\hline \multirow[t]{2}{*}{ Average Family Income (in \$10,000) in Quartile 3} & 5.905 & 6.064 \\
\hline & $(0.586)$ & (0.769) \\
\hline \multirow[t]{2}{*}{ Average Family Income (in \$10,000) in Quartile 4} & 9.383 & 10.252 \\
\hline & $(2.030)$ & $(2.471)$ \\
\hline \multirow{2}{*}{\multicolumn{2}{|c|}{ Avg. Net Family Wealth (in $\$ \mathbf{1 0 , 0 0 0}$ ) during Late Adolescence }} & 11.635 \\
\hline & & (14.415) \\
\hline \multirow[t]{2}{*}{ Avg. Net Family Wealth (in \$10,000) in Quartile 1} & & 0.108 \\
\hline & & $(0.770)$ \\
\hline \multirow[t]{2}{*}{ Avg. Net Family Wealth (in \$10,000) in Quartile 2} & & 3.141 \\
\hline & & (1.338) \\
\hline \multirow[t]{2}{*}{ Avg. Net Family Wealth (in $\$ 10,000$ ) in Quartile 3} & & 10.267 \\
\hline & & (2.968) \\
\hline \multirow[t]{2}{*}{ Avg. Net Family Wealth (in \$10,000) in Quartile 4} & & 31.677 \\
\hline & & $(14.801)$ \\
\hline Sample Size & 2,528 & 3,182 \\
\hline
\end{tabular}

Note: Table reports means with standard deviations in parentheses. NLSY79 sample includes individuals with non-missing AFQT and family income measured at ages 16 or 17 (i.e. cohorts born in 1961-64). NLSY97 sample includes individuals with non-missing AFQT and family income measured in 1997 if they had reached age 21 by 2004. 
Table 2: Distribution over Family Income and AFQT Quartiles (NLSY79 and NLSY97)

AFQT Quartile:

1

$2 \quad 3$

4

\section{a. NLSY79}

Family Income Quartile $1 \quad 12.82 \% \quad 6.25 \% \quad 3.60 \% \quad 2.37 \%$

$\begin{array}{lllll}\text { Family Income Quartile } 2 & 6.37 \% & 6.88 \% & 6.29 \% & 5.38 \%\end{array}$

$\begin{array}{lllll}\text { Family Income Quartile } 3 & 3.96 \% & 6.57 \% & 7.36 \% & 7.20 \%\end{array}$

$\begin{array}{lllll}\text { Family Income Quartile } 4 & 2.22 \% & 4.63 \% & 8.03 \% & 10.09 \%\end{array}$

b. NLSY97

$\begin{array}{lllll}\text { Family Income Quartile } 1 & 9.68 \% & 6.00 \% & 4.09 \% & 2.64 \%\end{array}$

Family Income Quartile $2 \quad 6.63 \% \quad 6.79 \% \quad 6.22 \% \quad 5.81 \%$

$\begin{array}{lllll}\text { Family Income Quartile } 3 & 4.12 \% & 6.32 \% & 7.45 \% & 8.01 \%\end{array}$

$\begin{array}{lllll}\text { Family Income Quartile } 4 & 2.42 \% & 5.91 \% & 7.48 \% & 10.43 \%\end{array}$

Notes: NLSY79 sample contains 2,528 individuals. NLSY97 sample contains 3,182 individuals (at least 21 years old in 2004). See Table 1 for data sample description. 
Table 3: Estimated Effects of Family Income, AFQT, and Family Background on Educational Attainment at Age 21

\begin{tabular}{|c|c|c|c|c|}
\hline & \multicolumn{2}{|c|}{ High School Completion } & \multicolumn{2}{|c|}{ College Attendance } \\
\hline & NLSY79 & NLSY97 & NLSY79 & NLSY97 \\
\hline Male & $\begin{array}{l}-0.0794 \\
(0.0145)\end{array}$ & $\begin{array}{c}-0.0046 \\
(0.0101)\end{array}$ & $\begin{array}{c}-0.0658 \\
(0.0172)\end{array}$ & $\begin{array}{c}-0.0854 \\
(0.0160)\end{array}$ \\
\hline Black & $\begin{array}{c}0.1632 \\
(0.0256)\end{array}$ & $\begin{array}{c}0.0483 \\
(0.0157)\end{array}$ & $\begin{array}{c}0.2236 \\
(0.0302)\end{array}$ & $\begin{array}{c}0.1445 \\
(0.0249)\end{array}$ \\
\hline Hispanic & $\begin{array}{c}0.0558 \\
(0.0295)\end{array}$ & $\begin{array}{c}0.0487 \\
(0.0169)\end{array}$ & $\begin{array}{c}0.1712 \\
(0.0349)\end{array}$ & $\begin{array}{c}0.0272 \\
(0.0266)\end{array}$ \\
\hline Other Non-White & & $\begin{array}{c}0.0181 \\
(0.0259)\end{array}$ & & $\begin{array}{c}0.1467 \\
(0.0412)\end{array}$ \\
\hline Mother's Age at Birth & $\begin{array}{c}0.0045 \\
(0.0012)\end{array}$ & $\begin{array}{c}0.0001 \\
(0.0011)\end{array}$ & $\begin{array}{c}0.0058 \\
(0.0015)\end{array}$ & $\begin{array}{c}0.0024 \\
(0.0018)\end{array}$ \\
\hline Intact Family during Adolescence & $\begin{array}{c}0.0807 \\
(0.0185)\end{array}$ & $\begin{array}{c}0.0535 \\
(0.0117)\end{array}$ & $\begin{array}{c}0.0080 \\
(0.0218)\end{array}$ & $\begin{array}{c}0.1106 \\
(0.0185)\end{array}$ \\
\hline Urban/Metropolitan Area during Adolescence & $\begin{array}{l}-0.0506 \\
(0.0175)\end{array}$ & $\begin{array}{c}-0.0237 \\
(0.0126)\end{array}$ & $\begin{array}{c}0.0330 \\
(0.0207)\end{array}$ & $\begin{array}{c}0.0210 \\
(0.0200)\end{array}$ \\
\hline Number of Siblings/Children under 18 & $\begin{array}{l}-0.0208 \\
(0.0038)\end{array}$ & $\begin{array}{c}-0.0012 \\
(0.0048)\end{array}$ & $\begin{array}{c}-0.0211 \\
(0.0045)\end{array}$ & $\begin{array}{l}-0.0061 \\
(0.0077)\end{array}$ \\
\hline Mother HS Graduate & $\begin{array}{c}0.0885 \\
(0.0182)\end{array}$ & $\begin{array}{c}0.1183 \\
(0.0165)\end{array}$ & $\begin{array}{c}0.1483 \\
(0.0216)\end{array}$ & $\begin{array}{c}0.1049 \\
(0.0261)\end{array}$ \\
\hline Mother at Least Some College & $\begin{array}{c}0.0127 \\
(0.0199)\end{array}$ & $\begin{array}{c}0.0023 \\
(0.0115)\end{array}$ & $\begin{array}{c}0.1789 \\
(0.0235)\end{array}$ & $\begin{array}{c}0.0658 \\
(0.0182)\end{array}$ \\
\hline AFQT quartile 2 & $\begin{array}{c}0.1983 \\
(0.0219)\end{array}$ & $\begin{array}{c}0.1570 \\
(0.0155)\end{array}$ & $\begin{array}{c}0.1315 \\
(0.0259)\end{array}$ & $\begin{array}{c}0.2413 \\
(0.0245)\end{array}$ \\
\hline AFQT quartile 3 & $\begin{array}{c}0.3095 \\
(0.0232)\end{array}$ & $\begin{array}{c}0.1889 \\
(0.0158)\end{array}$ & $\begin{array}{c}0.3243 \\
(0.0275)\end{array}$ & $\begin{array}{c}0.4003 \\
(0.0250)\end{array}$ \\
\hline AFQT quartile 4 & $\begin{array}{c}0.3701 \\
(0.0245)\end{array}$ & $\begin{array}{c}0.2073 \\
(0.0163)\end{array}$ & $\begin{array}{c}0.5489 \\
(0.0290)\end{array}$ & $\begin{array}{c}0.5210 \\
(0.0258)\end{array}$ \\
\hline Family Income Quartile 2 & $\begin{array}{c}0.0674 \\
(0.0222)\end{array}$ & $\begin{array}{c}0.0421 \\
(0.0156)\end{array}$ & $\begin{array}{c}0.0232 \\
(0.0262)\end{array}$ & $\begin{array}{c}0.0403 \\
(0.0247)\end{array}$ \\
\hline Family Income Quartile 3 & $\begin{array}{c}0.0883 \\
(0.0233)\end{array}$ & $\begin{array}{c}0.0504 \\
(0.0166)\end{array}$ & $\begin{array}{c}0.0292 \\
(0.0275)\end{array}$ & $\begin{array}{c}0.1038 \\
(0.0263)\end{array}$ \\
\hline Family Income Quartile 4 & $\begin{array}{c}0.0848 \\
(0.0247)\end{array}$ & $\begin{array}{c}0.0676 \\
(0.0175)\end{array}$ & $\begin{array}{c}0.0934 \\
(0.0291)\end{array}$ & $\begin{array}{c}0.1606 \\
(0.0276)\end{array}$ \\
\hline Test of no Income Effects (P-value) & 0.0009 & 0.0015 & 0.0058 & $<0.0001$ \\
\hline Test of Equal Income Effects (P-value) & - & 0.5722 & - & 0.1531 \\
\hline Sample Size & 2,292 & 2,518 & 2,288 & 2,529 \\
\hline
\end{tabular}

Notes: All regressions control for year of birth. Education measured as of age 21 (age 22 if missing at age 21). Test of no Income Effects is an F-test (3 d.o.f.) that all three coefficients on family income are zero. Test of Equal Income Effects is a Chi-Square test (3 d.o.f.) that all three income quartile indicators are equal for the NLSY79 and NLSY97. Standard errors are in parentheses. 
Table 4: Estimated Effects of Family Income on Educational Attainment at Age 21 by AFQT Quartile (NLSY79 and NLSY97)

High School Completion:

College Attendance:

$\begin{array}{llllllll}\text { AFQT } & \text { AFQT } & \text { AFQT } & \text { AFQT } & \text { AFQT } & \text { AFQT } & \text { AFQT } & \text { AFQT }\end{array}$

Quartile 1 Quartile 2 Quartile 3 Quartile $4 \quad$ Quartile 1 Quartile 2 Quartile 3 Quartile 4

a. NLSY79

Family Income Quartile 2

$\begin{array}{cccccccc}0.0525 & 0.0201 & 0.0745 & 0.0334 & 0.0273 & -0.0526 & 0.0956 & 0.0862 \\ (0.0516) & (0.0498) & (0.0411) & (0.0210) & (0.0408) & (0.0547) & (0.0668) & (0.0544) \\ 0.1415 & 0.0990 & 0.0364 & 0.0307 & 0.0258 & -0.0730 & 0.1222 & 0.0887 \\ (0.0624) & (0.0521) & (0.0409) & (0.0210) & (0.0490) & (0.0572) & (0.0664) & (0.0544) \\ 0.1338 & 0.1081 & 0.0360 & 0.0250 & 0.1172 & -0.0486 & 0.1818 & 0.1541 \\ (0.0764) & (0.0572) & (0.0425) & (0.0208) & (0.0600) & (0.0627) & (0.0691) & (0.0539) \\ 0.0974 & 0.1123 & 0.2981 & 0.4245 & 0.2810 & 0.6340 & 0.0664 & 0.0232 \\ 540 & 562 & 593 & 597 & 536 & 562 & 593 & 597\end{array}$

Sample Size

\section{b. NLSY97}

Family Income Quartile 2

\begin{tabular}{cccccccc}
0.0248 & 0.0622 & 0.0130 & 0.0081 & -0.0560 & 0.0766 & 0.0518 & 0.0869 \\
$(0.0474)$ & $(0.0302)$ & $(0.0232)$ & $(0.0080)$ & $(0.0460)$ & $(0.0556)$ & $(0.0544)$ & $(0.0431)$ \\
0.0719 & 0.0553 & 0.0222 & 0.0111 & 0.1336 & 0.1545 & 0.0957 & 0.0520 \\
$(0.0574)$ & $(0.0320)$ & $(0.0241)$ & $(0.0079)$ & $(0.0559)$ & $(0.0590)$ & $(0.0564)$ & $(0.0424)$ \\
0.1546 & 0.0908 & 0.0476 & 0.0090 & 0.2793 & 0.1611 & 0.1992 & 0.0905 \\
$(0.0671)$ & $(0.0334)$ & $(0.0248)$ & $(0.0081)$ & $(0.0656)$ & $(0.0616)$ & $(0.0582)$ & $(0.0437)$ \\
0.1295 & 0.0494 & 0.1956 & 0.5805 & $<.0001$ & 0.0310 & 0.0019 & 0.1066 \\
0.8012 & 0.4845 & 0.2504 & 0.7201 & 0.0149 & 0.0342 & 0.8191 & 0.6232 \\
533 & 629 & 653 & 703 & 541 & 630 & 654 & 704 \\
\hline
\end{tabular}

\section{Family Income Quartile 3}

Family Income Quartile 4

Test of no Income Effects (P-value)

Test of Equal Income Effects (P-value)

Sample Size

533

629

653

Notes: All regressions control for gender, race/ethnicity, mother's education (HS graduate, college attendance), intact family during adolescence, number of siblings/children under 18, mother's age at child's birth, urban/metropolitan area during adolescence, and year of birth. Education measured as of age 21 (age 22 if missing at age 21). Test of no Income Effects is an F-test (3 d.o.f.) that all three coefficients on family income are zero. Test of Equal Income Effects is a Chi-Square test (3 d.o.f.) that all three income quartile indicators are equal for the NLSY79 and NLSY97. Standard errors are in parentheses. 
Table 5: Estimated Effects of Family Income and Wealth on Educational Attainment (Age 21, NLSY97)

High School Completion

\begin{tabular}{lcccc}
\hline AFQT Quartile 2 & 0.1579 & 0.1530 & 0.2313 & 0.2237 \\
AFQT Quartile 3 & $(0.0162)$ & $(0.0167)$ & $(0.0242)$ & $(0.0257)$ \\
& 0.1915 & 0.1863 & 0.4039 & 0.3985 \\
AFQT Quartile 4 & $(0.0166)$ & $(0.0172)$ & $(0.0248)$ & $(0.0264)$ \\
& 0.2056 & 0.2058 & 0.5029 & 0.5027 \\
Family Wealth Quartile 2 & $(0.0175)$ & $(0.0179)$ & $(0.0261)$ & $(0.0276)$ \\
& 0.0518 & 0.0292 & 0.0640 & 0.0550 \\
Family Wealth Quartile 3 & $(0.0167)$ & $(0.0181)$ & $(0.0249)$ & $(0.0278)$ \\
& 0.0944 & 0.0685 & 0.1351 & 0.1131 \\
Family Wealth Quartile 4 & $(0.0173)$ & $(0.0194)$ & $(0.0259)$ & $(0.0298)$ \\
& 0.0946 & 0.0723 & 0.2357 & 0.2082 \\
Family Income Quartile 2 & $(0.0187)$ & $(0.0214)$ & $(0.0280)$ & $(0.0329)$ \\
Family Income Quartile 3 & & 0.0270 & & 0.0193 \\
& & $(0.0178)$ & & $(0.0273)$ \\
Family Income Quartile 4 & & 0.0278 & & 0.0622 \\
& & $(0.0197)$ & & $(0.0302)$ \\
Test of no Wealth Effects (P-value) & $<.0001$ & 0.0378 & & 0.0822 \\
Test of no Income Effects (P-value) & & $(0.0214)$ & & $(0.0329)$ \\
Test of no Income and no Wealth & & 0.0015 & & $<.0001$ \\
Effects (P-value) & & & & 0.0474 \\
Sample Size & & $<.0001$ & & $<.0001$ \\
\hline
\end{tabular}

Notes: All regressions control for gender, race (black, hispanic, white), mother's education (HS graduate, college attendance), intact family during adolescence, number of children under 18, mother's age at child's birth, metropolitan area during adolescence, and year of birth. Education measured as of age 21 (age 22 if missing at age 21). Family income and wealth are measured in 1997. Test of no Income Effects is an F-test (3 d.o.f.) that all three coefficients on family income are zero. Test of no Wealth Effects is an F-test (3 d.o.f.) that all three coefficients on family wealth are zero. Test of no Income and no Wealth Effects is an F-test (6 d.o.f.) that all three coefficients on family income and all three coefficients on wealth are zero. Standard errors are in parentheses. 
Table 6: Estimated Effects of Family Income and AFQT on Completion of 2+ or 4+ Years of College

\begin{tabular}{|c|c|c|c|c|c|c|}
\hline & \multicolumn{3}{|c|}{ NLSY79 } & \multicolumn{3}{|c|}{ NLSY97 } \\
\hline & \multicolumn{2}{|c|}{$\begin{array}{c}\text { Completed 2+ Years } \\
\text { of College }\end{array}$} & \multirow{2}{*}{$\begin{array}{c}\text { Completed 4+ } \\
\text { Years of College } \\
\text { Age } 23 \\
\end{array}$} & \multicolumn{2}{|c|}{$\begin{array}{c}\text { Completed 2+ Years } \\
\text { of College }\end{array}$} & \multirow{2}{*}{$\begin{array}{c}\text { Completed 4+ } \\
\text { Years of College } \\
\text { Age } 23\end{array}$} \\
\hline & Age 21 & Age 23 & & Age 21 & Age 23 & \\
\hline AFQT Quartile 2 & $\begin{array}{c}0.0510 \\
(0.0235)\end{array}$ & $\begin{array}{c}0.0712 \\
(0.0243)\end{array}$ & $\begin{array}{c}0.0077 \\
(0.0212)\end{array}$ & $\begin{array}{c}0.1086 \\
(0.0251)\end{array}$ & $\begin{array}{c}0.1361 \\
(0.0379)\end{array}$ & $\begin{array}{c}0.0808 \\
(0.0357)\end{array}$ \\
\hline AFQT Quartile 3 & $\begin{array}{c}0.2291 \\
(0.0249)\end{array}$ & $\begin{array}{c}0.2597 \\
(0.0257)\end{array}$ & $\begin{array}{c}0.1094 \\
(0.0224)\end{array}$ & $\begin{array}{c}0.3065 \\
(0.0256)\end{array}$ & $\begin{array}{c}0.3566 \\
(0.0390)\end{array}$ & $\begin{array}{c}0.2335 \\
(0.0367)\end{array}$ \\
\hline AFQT Quartile 4 & $\begin{array}{c}0.5170 \\
(0.0262)\end{array}$ & $\begin{array}{c}0.5528 \\
(0.0272)\end{array}$ & $\begin{array}{c}0.4000 \\
(0.0237)\end{array}$ & $\begin{array}{c}0.5128 \\
(0.0265)\end{array}$ & $\begin{array}{c}0.5646 \\
(0.0402)\end{array}$ & $\begin{array}{c}0.4492 \\
(0.0379)\end{array}$ \\
\hline Family Income Quartile 2 & $\begin{array}{l}-0.0341 \\
(0.0237)\end{array}$ & $\begin{array}{l}-0.0207 \\
(0.0244)\end{array}$ & $\begin{array}{l}-0.0263 \\
(0.0213)\end{array}$ & $\begin{array}{c}0.0263 \\
(0.0254)\end{array}$ & $\begin{array}{c}0.0445 \\
(0.0382)\end{array}$ & $\begin{array}{l}-0.0126 \\
(0.0360)\end{array}$ \\
\hline Family Income Quartile 3 & $\begin{array}{l}-0.0325 \\
(0.0249)\end{array}$ & $\begin{array}{l}-0.0165 \\
(0.0258)\end{array}$ & $\begin{array}{l}-0.0567 \\
(0.0225)\end{array}$ & $\begin{array}{c}0.0593 \\
(0.0270)\end{array}$ & $\begin{array}{c}0.1159 \\
(0.0403)\end{array}$ & $\begin{array}{c}0.0286 \\
(0.0379)\end{array}$ \\
\hline Family Income Quartile 4 & $\begin{array}{c}0.0346 \\
(0.0264)\end{array}$ & $\begin{array}{c}0.0614 \\
(0.0272)\end{array}$ & $\begin{array}{c}0.0537 \\
(0.0238)\end{array}$ & $\begin{array}{c}0.1539 \\
(0.0283)\end{array}$ & $\begin{array}{c}0.1450 \\
(0.0431)\end{array}$ & $\begin{array}{c}0.0982 \\
(0.0406)\end{array}$ \\
\hline Test of no Income Effects (P-value) & 0.0050 & 0.0014 & $<.0001$ & $<.0001$ & 0.0032 & 0.0139 \\
\hline Sample Size & 2,292 & 2,225 & 2,225 & 2,518 & 1,140 & 1,140 \\
\hline
\end{tabular}

Notes: All regressions control for gender, race/ethnicity, mother's education (HS graduate, college attendance), intact family during adolescence, number of siblings/children under 18, mother's age at child's birth, urban/metropolitan area during adolescence, and year of birth. Standard errors are in parentheses. Test of no Income Effects is an F-test (3 d.o.f.) that all three coefficients on family income are zero. 


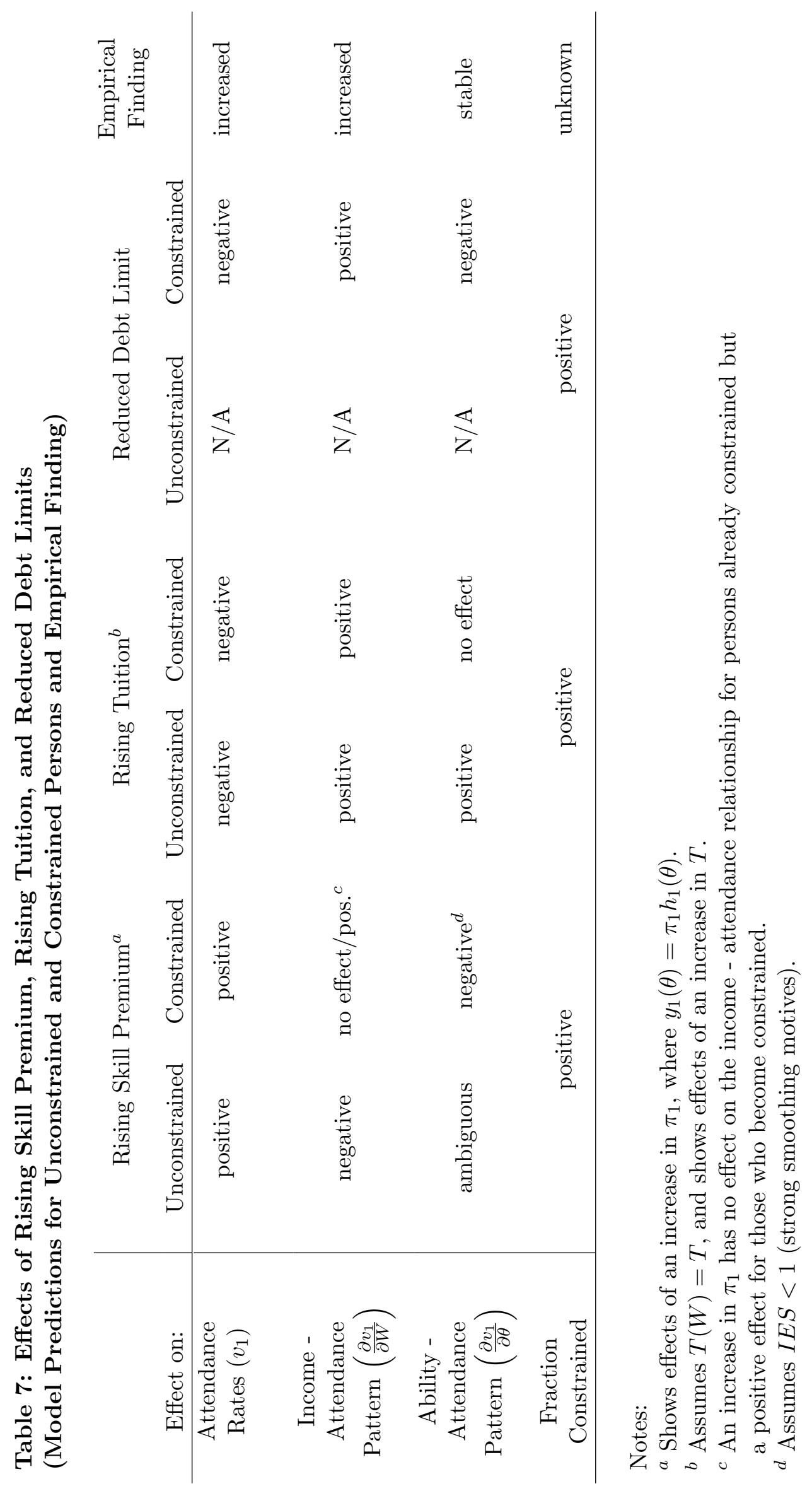


Table 8: Estimated Effects of Family Income and AFQT on College Enrollment at Age 20

\begin{tabular}{|c|c|c|c|c|c|c|c|c|}
\hline & \multicolumn{3}{|c|}{ NLSY79 } & \multicolumn{5}{|c|}{ NLSY97 } \\
\hline & $\begin{array}{c}\text { Enrolled in } \\
\text { Any College }\end{array}$ & $\begin{array}{c}\text { Enrolled in 4- } \\
\text { Year College }\end{array}$ & $\begin{array}{l}\text { Enrolled in 4- } \\
\text { Year College } \\
\text { Conditional on } \\
\text { Enrollment in } \\
\text { Any College }\end{array}$ & $\begin{array}{c}\text { Enrolled } \\
\text { in Any } \\
\text { College }\end{array}$ & $\begin{array}{c}\text { Enrolled } \\
\text { in 4-Yr } \\
\text { College }\end{array}$ & $\begin{array}{l}\text { Enrolled in 4- } \\
\text { Yr College } \\
\text { Cond. on } \\
\text { Enroll. in Any } \\
\text { College } \\
\end{array}$ & $\begin{array}{c}\text { Enrolled in 4- } \\
\text { Yr Private } \\
\text { College }\end{array}$ & $\begin{array}{l}\text { Enrolled in 4-Yr } \\
\text { Private College } \\
\text { Cond. on } \\
\text { Enroll. in Any } \\
\text { College } \\
\end{array}$ \\
\hline AFQT Quartile 2 & $\begin{array}{c}0.0701 \\
(0.0252)\end{array}$ & $\begin{array}{c}0.0387 \\
(0.0227)\end{array}$ & $\begin{array}{c}0.2045 \\
(0.0782)\end{array}$ & $\begin{array}{c}0.1242 \\
(0.0235)\end{array}$ & $\begin{array}{c}0.0868 \\
(0.0220)\end{array}$ & $\begin{array}{c}0.1888 \\
(0.0498)\end{array}$ & $\begin{array}{c}0.0150 \\
(0.0161)\end{array}$ & $\begin{array}{l}-0.0001 \\
(0.0510)\end{array}$ \\
\hline AFQT Quartile 3 & $\begin{array}{c}0.1916 \\
(0.0267)\end{array}$ & $\begin{array}{c}0.1445 \\
(0.0240)\end{array}$ & $\begin{array}{c}0.3490 \\
(0.0765)\end{array}$ & $\begin{array}{c}0.2780 \\
(0.0238)\end{array}$ & $\begin{array}{c}0.2368 \\
(0.0223)\end{array}$ & $\begin{array}{c}0.3213 \\
(0.0478)\end{array}$ & $\begin{array}{c}0.0398 \\
(0.0163)\end{array}$ & $\begin{array}{c}0.0097 \\
(0.0491)\end{array}$ \\
\hline AFQT Quartile 4 & $\begin{array}{c}0.4788 \\
(0.0281)\end{array}$ & $\begin{array}{c}0.4348 \\
(0.0253)\end{array}$ & $\begin{array}{c}0.5018 \\
(0.0761)\end{array}$ & $\begin{array}{c}0.4609 \\
(0.0247)\end{array}$ & $\begin{array}{c}0.4651 \\
(0.0231)\end{array}$ & $\begin{array}{c}0.4549 \\
(0.0476)\end{array}$ & $\begin{array}{c}0.1611 \\
(0.0169)\end{array}$ & $\begin{array}{c}0.1334 \\
(0.0489)\end{array}$ \\
\hline Family Income Quartile 2 & $\begin{array}{l}-0.0085 \\
(0.0254)\end{array}$ & $\begin{array}{l}-0.0376 \\
(0.0229)\end{array}$ & $\begin{array}{l}-0.1086 \\
(0.0566)\end{array}$ & $\begin{array}{c}0.0034 \\
(0.0233)\end{array}$ & $\begin{array}{c}0.0025 \\
(0.0218)\end{array}$ & $\begin{array}{c}0.0131 \\
(0.0402)\end{array}$ & $\begin{array}{l}-0.0066 \\
(0.0159)\end{array}$ & $\begin{array}{l}-0.0161 \\
(0.0412)\end{array}$ \\
\hline Family Income Quartile 3 & $\begin{array}{l}-0.0172 \\
(0.0267)\end{array}$ & $\begin{array}{l}-0.0318 \\
(0.0241)\end{array}$ & $\begin{array}{l}-0.0830 \\
(0.0589)\end{array}$ & $\begin{array}{c}0.0539 \\
(0.0247)\end{array}$ & $\begin{array}{c}0.0482 \\
(0.0231)\end{array}$ & $\begin{array}{c}0.0509 \\
(0.0395)\end{array}$ & $\begin{array}{c}0.0068 \\
(0.0169)\end{array}$ & $\begin{array}{l}-0.0016 \\
(0.0405)\end{array}$ \\
\hline Family Income Quartile 4 & $\begin{array}{c}0.0840 \\
(0.0283)\end{array}$ & $\begin{array}{c}0.0683 \\
(0.0255)\end{array}$ & $\begin{array}{l}-0.0428 \\
(0.0580)\end{array}$ & $\begin{array}{c}0.1307 \\
(0.0263)\end{array}$ & $\begin{array}{c}0.1430 \\
(0.0246)\end{array}$ & $\begin{array}{c}0.1094 \\
(0.0401)\end{array}$ & $\begin{array}{c}0.0354 \\
(0.0180)\end{array}$ & $\begin{array}{c}0.0168 \\
(0.0410)\end{array}$ \\
\hline $\begin{array}{l}\text { Test of no Income Effects (P-value) } \\
\text { Sample Size }\end{array}$ & $\begin{array}{c}<.0001 \\
2,304 \\
\end{array}$ & $\begin{array}{c}<.0001 \\
2,293 \\
\end{array}$ & $\begin{array}{c}0.1754 \\
753 \\
\end{array}$ & $\begin{array}{c}<.0001 \\
3,194 \\
\end{array}$ & $\begin{array}{l}<.0001 \\
3,194\end{array}$ & $\begin{array}{c}0.0061 \\
1,453 \\
\end{array}$ & $\begin{array}{c}0.0504 \\
3,184 \\
\end{array}$ & $\begin{array}{c}0.7749 \\
1,445 \\
\end{array}$ \\
\hline
\end{tabular}

Notes: All regressions control for gender, race/ethnicity, mother's education (HS graduate, college attendance), intact family during adolescence, number of siblings/children under 18, mother's age at child's birth, urban/metropolitan area during adolescence, and year of birth. Standard errors are in parentheses. Test of no Income Effects is an F-test (3 d.o.f.) that all three coefficients on family income are zero. 
Table 9: Estimated Effects of Family Income and AFQT on College Delay

\begin{tabular}{lcc} 
& NLSY79 & NLSY97 \\
\hline AFQT Quartile 2 & -0.0472 & -0.0543 \\
AFQT Quartile 3 & $(0.0503)$ & $(0.0384)$ \\
AFQT Quartile 4 & -0.1896 & -0.1465 \\
& $(0.0497)$ & $(0.0373)$ \\
Family Income Quartile 2 & -0.2680 & -0.1745 \\
& $(0.0498)$ & $(0.0375)$ \\
Family Income Quartile 3 & 0.0420 & -0.0129 \\
Family Income Quartile 4 & $(0.0401)$ & $(0.0315)$ \\
& 0.0820 & -0.0343 \\
& $(0.0413)$ & $(0.0317)$ \\
Test of no Income Effects (P-value) & 0.0446 & -0.0338 \\
Sample Size & $(0.0414)$ & $(0.0322)$ \\
\hline
\end{tabular}

Notes: Samples includes anyone enrolled at age 18, 19, 20, or 21. Dependent variable, college delay equals one if not enrolled in school at age 18 or if not enrolled in college at age 19 (if enrolled in high school at age 18). All regressions control for gender, race/ethnicity, mother's education (HS graduate, college attendance), intact family during adolescence, number of siblings/children under 18, mother's age at child's birth, urban/metropolitan area during adolescence, and year of birth. Standard errors are in parentheses. Test of no Income Effects is an F-test (3 d.o.f.) that all three coefficients on family income are zero. 
Table 10: Type of First College Attended and the Effects of College Delay (NLSY79 and NLSY97)

\section{NLSY79}

4-Yr College:

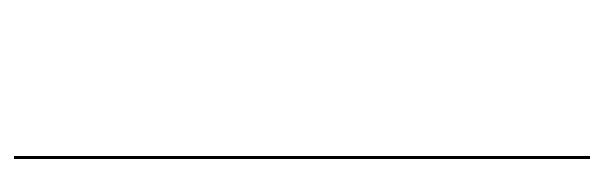

Delayed College

AFQT Quartile 2

AFQT Quartile 3

\section{AFQT Quartile 4}

Family Income Quartile 2

Family Income Quartile 3

Family Income Quartile 4

Test of no Income Effects (P-value)

Sample Size

\section{Did Not}

Delay

All College

-

$-0.1598$

$(0.0392)$

0.2226

(0.0637)

0.2533

(0.0633)

0.4685

(0.0638)

$\begin{array}{lll}-0.0189 & 0.0142 & -0.0507\end{array}$

(0.0506)

$-0.0054$

(0.0520)

0.0515

(0.0519)

(0.0562)

(0.1218)

$-0.0211 \quad 0.1589$

(0.0572)

0.0631

(0.1301)

(0.0566)

0.0748

$\begin{array}{lll}0.2776 & 0.1932 & 0.2570\end{array}$

$\begin{array}{lll}1,034 & 845 & 189\end{array}$
4-Yr College:

\section{NLSY97}

\section{Delayed}

4-Yr Private College:

All College College

\begin{tabular}{ccc} 
& Did Not & \\
Delay & Delayed \\
All & College & College \\
\hline
\end{tabular}

-0.1819
$(0.0252)$
0.1403

$\begin{array}{ccc}0.1403 & 0.1611 & 0.0970 \\ (0.0426) & (0.0511) & (0.0821) \\ 0.2704 & 0.2939 & 0.2178 \\ (0.0415) & (0.0491) & (0.0840) \\ 0.4536 & 0.4898 & 0.3460 \\ (0.0417) & (0.0491) & (0.0863)\end{array}$

$-0.0595$

(0.0230)

$\begin{array}{lll}0.0220 & 0.0089 & 0.0719\end{array}$

$\begin{array}{lll}(0.0388) & (0.0486) \quad(0.0596)\end{array}$

$\begin{array}{lll}0.0401 & 0.0392 & 0.0672\end{array}$

$\begin{array}{lll}(0.0378) & (0.0467) & (0.0612)\end{array}$

$\begin{array}{lll}0.1699 & 0.1808 & 0.1056\end{array}$

$\begin{array}{lll}(0.0380) & (0.0467) & (0.0628)\end{array}$

$\begin{array}{cccccc}-0.0154 & -0.0010 & -0.0629 & -0.0344 & -0.0228 & -0.0307 \\ (0.0348) & (0.0394) & (0.0781) & (0.0317) & (0.0376) & (0.0568)\end{array}$

$\begin{array}{llllll}0.0649 & 0.0591 & 0.1093 & -0.0118 & -0.0102 & 0.0472\end{array}$

$\begin{array}{llllll}(0.0351) & (0.0394) & (0.0824) & (0.0319) & (0.0375) & (0.0599)\end{array}$

$\begin{array}{llllll}0.0834 & 0.0734 & 0.1382 & -0.0270 & -0.0151 & -0.0315\end{array}$

$\begin{array}{llllll}(0.0357) & (0.0401) & (0.0827) & (0.0324) & (0.0382) & (0.0597)\end{array}$

Notes: College delay samples include those enrolled at age 18, 19, 20, or 21 but not enrolled in school at age 18, or in college at age 19 (if enrolled in high school at age 18). Non-delay college samples includes all others who were enrolled at age 18, 19, 20, or 21 . Type of college enrollment measured at age 18 or 19 (if not enrolled in college at age 18) or 20 (if not enrolled in college at age 18 and 19, or if not enrolled in college at age 18 and missing at age 19). All regressions control for gender, race/ethnicity, mother's education (HS graduate, college attendance), intact family during adolescence, number of siblings/children under 18, mother's age at child's birth, urban/metropolitan area during adolescence, and year of birth. Standard errors are in parentheses.

Test of no Income Effects is an F-test (3 d.o.f.) that all three coefficients on family income are zero. 
Table 11: Estimated Effects of Family Income and AFQT on Work During School Year at Age 20

\begin{tabular}{lcccc} 
& \multicolumn{2}{c}{ Share of Weeks Worked } & \multicolumn{2}{c}{ Wverage Hours Worked per } \\
& NLSY79 & NLSY97 & NLSY79 & NLSY97 \\
\hline & & & & \\
AFQT Quartile 2 & 0.0110 & 0.0136 & -0.4330 & -0.7334 \\
& $(0.0763)$ & $(0.0573)$ & $(2.3394)$ & $(2.0279)$ \\
AFQT Quartile 3 & 0.1139 & 0.0597 & -1.3293 & 1.0625 \\
& $(0.0733)$ & $(0.0552)$ & $(2.2478)$ & $(1.9517)$ \\
AFQT Quartile 4 & 0.0329 & 0.0261 & -4.2684 & -2.5995 \\
& $(0.0713)$ & $(0.0548)$ & $(2.1856)$ & $(1.9379)$ \\
Family Income Quartile 2 & -0.0074 & -0.0188 & 0.7292 & 1.7159 \\
Family Income Quartile 3 & $(0.0559)$ & $(0.0488)$ & $(1.7141)$ & $(1.7244)$ \\
Family Income Quartile 4 & 0.0091 & -0.0349 & 2.4292 & 0.3482 \\
& $(0.0577)$ & $(0.0475)$ & $(1.7693)$ & $(1.6818)$ \\
Test of no Income Effects (P-value) & -0.0639 & -0.0907 & 0.2649 & -1.5831 \\
Sample Size & $(0.0566)$ & $(0.0482)$ & $(1.7357)$ & $(1.7038)$ \\
\hline
\end{tabular}

Notes: All regressions control for gender, race/ethnicity, mother's education (HS graduate, college attendance), intact family during adolescence, number of siblings/children under 18, mother's age at child's birth, urban/metropolitan area during adolescence, and year of birth. Standard errors are in parentheses. Test of no Income Effects is an F-test (3 d.o.f.) that all three coefficients on family income are zero. Sample includes those enrolled in college at age 20. 
Table 12: Estimated Effects of Family Income on Work during School Year at Age 20 by AFQT Quartile (NLSY79 and NLSY97) Linear-in-Income Specifications

\section{Share of Weeks Worked \\ Average Hours Worked per}

Effect of Family Income (in $\$ 10,000)$ for:

NLSY79 NLSY97

Full Sample

AFQT Quartile 1

AFQT Quartile 2

AFQT Quartile 3

AFQT Quartile 4

Week

\begin{tabular}{llll} 
NLSY79 & NLSY97 & NLSY79 & NLSY97 \\
\hline-0.0112 & -0.0100 & -0.0858 & -0.3734 \\
$(0.0058)$ & $(0.0040)$ & $(0.1787)$ & $(0.1410)$
\end{tabular}

\begin{tabular}{cccc}
-0.0230 & 0.0145 & -0.2380 & 0.7041 \\
$(0.0311)$ & $(0.0173)$ & $(1.1120)$ & $(0.6545)$ \\
0.0095 & -0.0155 & 0.5011 & -0.6522 \\
$(0.0171)$ & $(0.0095)$ & $(0.6253)$ & $(0.3495)$ \\
-0.0191 & -0.0113 & -0.1568 & -0.1899 \\
$(0.0120)$ & $(0.0072)$ & $(0.3707)$ & $(0.2784)$ \\
-0.0114 & -0.0133 & -0.1462 & -0.5953 \\
$(0.0076)$ & $(0.0061)$ & $(0.2122)$ & $(0.2025)$ \\
\hline
\end{tabular}

Notes: Each cell of the table reflects the effect of family income on the education measure at the top within the sample of individuals denoted at the left--each cell is from a separate regression. All regressions control for gender, race/ethnicity, mother's education (HS graduate, college attendance), intact family during adolescence, number of siblings/children under 18, mother's age at child's birth, urban/metropolitan area during adolescence, and year of birth. Regressions for full sample also control for AFQT quartiles. Sample includes those enrolled in school at age 20. Standard errors are in parentheses. 
Table A1: Log Family Income Regressions for 1979 and 1997 NLSY Cohorts and 1980 and 2000 Censuses

\section{NLSY79 1980 Census}

NLSY97 2000 Census

\begin{tabular}{lcccc} 
Intercept & 1.2400 & 1.1981 & 0.4972 & 0.5530 \\
Black & $(0.0604)$ & $(0.0149)$ & $(0.0823)$ & $(0.0169)$ \\
& -0.6104 & -0.5402 & -0.5227 & -0.6096 \\
Hispanic & $(0.0388)$ & $(0.0109)$ & $(0.0413)$ & $(0.0092)$ \\
& -0.3370 & -0.3118 & -0.3487 & -0.2979 \\
Other Non-White & $(0.0484)$ & $(0.0135)$ & $(0.0465)$ & $(0.0091)$ \\
& & & 0.0008 & -0.2030 \\
Mother's Age at Respondent's Birth & & & $(0.0723)$ & $(0.0110)$ \\
& 0.0007 & 0.0044 & 0.0200 & 0.0190 \\
Urban/Metropolitan Area during Child's Adolescence & $(0.0020)$ & $(0.0005)$ & $(0.0029)$ & $(0.0005)$ \\
& 0.0773 & 0.1339 & 0.1686 & 0.2755 \\
Mother HS Graduate & $(0.0291)$ & $(0.0065)$ & $(0.0345)$ & $(0.0067)$ \\
& 0.3384 & 0.3339 & 0.4295 & 0.3711 \\
Mother at Least Some College & $(0.0287)$ & $(0.0075)$ & $(0.0440)$ & $(0.0107)$ \\
& 0.1910 & 0.1754 & 0.1909 & 0.3479 \\
& $(0.0331)$ & $(0.0067)$ & $(0.0312)$ & $(0.0059)$ \\
R-squared & & & & \\
Sample Size & 0.2299 & 0.1598 & 0.2029 & 0.2070 \\
\hline
\end{tabular}

Notes: 1980 Census is the $1 \%$ urban/rural sample restricted to youths aged 16 or 17 , and 2000 Census is the $1 \%$ unweighted sample restricted to youths aged 14 to 17 . Dependent variable is log average family income measured at ages 16-17 for the NLSY79, log family income in 1996 for the NLSY97, log of total family income in 1979 for the 1980 Census, and log of total household income in 1999 for the 2000 Census. All incomes are in \$10,000 year 2000 dollars. High income values in the Censuses are coded to be consistent with their respective NLSY counterparts. Urban status is measured when the child is age 14 in NLSY79; metropolitan area of residence is measured when the child is age 12 in NLSY97. Census race and ethnicity are coded to be consistent with the NLSY samples. See text for details. Standard errors are in parentheses. 
Table A2: Robustness Checks for College Attendence Regressions at Different Ages (NLSY79)

(i) (ii) (iii) (iv)

\begin{tabular}{lccccc} 
& $\begin{array}{c}\text { Attendance } \\
\text { Measured at } \\
\text { Age 20 }\end{array}$ & $\begin{array}{c}\text { Attendance } \\
\text { Measured at } \\
\text { Age 21 }\end{array}$ & $\begin{array}{c}\text { Attendance } \\
\text { Measured at } \\
\text { Age 22 }\end{array}$ & $\begin{array}{c}\text { Attendance } \\
\text { Measured at } \\
\text { Age 23 }\end{array}$ & $\begin{array}{c}\text { Attendance } \\
\text { Measured at } \\
\text { Age 24 }\end{array}$ \\
\hline AFQT Quartile 2 & 0.1156 & 0.1315 & 0.1333 & 0.1292 & 0.1410 \\
& $(0.0256)$ & $(0.0259)$ & $(0.0262)$ & $(0.0265)$ & $(0.0267)$ \\
AFQT Quartile 3 & 0.3093 & 0.3243 & 0.3286 & 0.3338 & 0.3406 \\
& $(0.0272)$ & $(0.0275)$ & $(0.0278)$ & $(0.0281)$ & $(0.0282)$ \\
AFQT Quartile 4 & 0.5477 & 0.5489 & 0.5464 & 0.5356 & 0.5431 \\
Family Income Quartile 2 & $(0.0286)$ & $(0.0290)$ & $(0.0294)$ & $(0.0297)$ & $(0.0299)$ \\
Family Income Quartile 3 & 0.0150 & 0.0232 & 0.0215 & 0.0090 & 0.0007 \\
Family Income Quartile 4 & $(0.0259)$ & $(0.0262)$ & $(0.0265)$ & $(0.0267)$ & $(0.0269)$ \\
& 0.0224 & 0.0292 & 0.0368 & 0.0316 & 0.0323 \\
& $(0.0272)$ & $(0.0275)$ & $(0.0277)$ & $(0.0282)$ & $(0.0282)$ \\
Test of no Income Effects (P-value) & 0.0966 & 0.0934 & 0.0845 & 0.0738 & 0.0666 \\
Sample Size & $(0.0288)$ & $(0.0291)$ & $(0.0294)$ & $(0.0297)$ & $(0.0299)$ \\
\hline
\end{tabular}

Notes: All regressions control for gender, race/ethnicity, mother's education (HS graduate, college attendance), intact family during adolescence, number of siblings, mother's age at child's birth, urban area residence during adolescence, and year of birth. Education measured as of age in column heading (measured in following year if missing for that age). Test of no Income Effects is an F-test (3 d.o.f.) that all three coefficients on family income are zero. Standard errors are in parentheses. 
Table A3: Robustness Checks for College Attendence Regressions at Different Ages (NLSY97)

Attendance

Measured at

AFQT Quartile 2

AFQT Quartile 3

AFQT Quartile 4

Family Income Quartile 2

Family Income Quartile 3

Family Income Quartile 4 (i)

Age 20

(ii)

Attendance

Measured at

Age 21

0.2013

$(0.0221)$

0.3683

$(0.0224)$

0.4791

(0.0233)

0.0258

$(0.0219)$

0.0733

$(0.0234)$

0.1522

(0.0248)

(0.0258)

0.0403

$(0.0247)$

0.1038

$(0.0263)$

0.1606

(0.0276) (iii)

Attendance Attendance

Measured at Measured at

Age 22

0.2654

$(0.0291)$

0.4016

(0.0295)

0.5438

(0.0307)

0.0045

(0.0291)

0.0737

(0.0312)

0.1163

(0.0329)

$<0.0001$

0.0004

0.0004

Test of no Inco
Sample Size

$<.0001$

2,529

1,809

Age 23

0.2539

$(0.0366)$

0.4125

$(0.0377)$

0.5434

$(0.0389)$

Notes: All regressions control for gender, race/ethnicity, mother's education (HS graduate, college attendance), intact family during adolescence, number of children under 18, mother's age at child's birth, metropolitan area residence during adolescence, and year of birth. Education measured as of age in column heading (measured in following year if missing for that age). Test of no Income Effects is an F-test (3 d.o.f.) that all three coefficients on family income are zero. Standard errors are in parentheses. 
Table A4: Robustness Checks for College Attendence at Age 21 Regressions (NLSY79)

\begin{tabular}{lccccc} 
& (i) & (ii) & (iii) & (iv) & (v) \\
& $\begin{array}{c}\text { Finer Mother's } \\
\text { \& Father's } \\
\text { Education } \\
\text { Controls }\end{array}$ & $\begin{array}{c}\text { High School } \\
\text { Graduate } \\
\text { Sample }\end{array}$ & $\begin{array}{c}\text { Controls for } \\
\text { All ASVAB } \\
\text { scores }\end{array}$ & $\begin{array}{c}\text { Controls for } \\
\text { Measures of } \\
\text { Criminal } \\
\text { Activity }\end{array}$ & $\begin{array}{c}\text { Per Capita } \\
\text { Family Income } \\
\text { Quartiles }\end{array}$ \\
\hline AFQT Quartile 2 & 0.1221 & 0.1195 & -0.0251 & 0.1359 & 0.1293 \\
& $(0.0259)$ & $(0.0333)$ & $(0.0359)$ & $(0.0265)$ & $(0.0260)$ \\
AFQT Quartile 3 & 0.2979 & 0.2767 & 0.0434 & 0.3215 & 0.3243 \\
& $(0.0277)$ & $(0.0339)$ & $(0.0517)$ & $(0.0281)$ & $(0.0276)$ \\
AFQT Quartile 4 & 0.5109 & 0.4649 & 0.1080 & 0.5252 & 0.5521 \\
& $(0.0294)$ & $(0.0350)$ & $(0.0740)$ & $(0.0296)$ & $(0.0290)$ \\
Family Income Quartile 2 & 0.0224 & -0.0050 & 0.0138 & 0.0122 & 0.0524 \\
Family Income Quartile 3 & $(0.0260)$ & $(0.0318)$ & $(0.0262)$ & $(0.0266)$ & $(0.0268)$ \\
& 0.0199 & 0.0043 & 0.0145 & 0.0314 & 0.0584 \\
Family Income Quartile 4 & $(0.0273)$ & $(0.0328)$ & $(0.0274)$ & $(0.0279)$ & $(0.0282)$ \\
& 0.0605 & 0.0744 & 0.0747 & 0.0949 & 0.0703 \\
Test of no Income Effects (P-value) & $(0.0294)$ & $(0.0343)$ & $(0.0291)$ & $(0.0294)$ & $(0.0303)$ \\
Sample Size & 0.1852 & 0.0173 & 0.0267 & 0.0031 & 0.1049 \\
\hline
\end{tabular}

Notes: All regressions control for gender, race/ethnicity, intact family during adolescence, number of siblings, mother's age at child's birth, urban area residence during adolescence, and year of birth. Respondent's education measured as of age 21 (age 22 if missing at age 21). Column (i) controls for the following mother's and father's education indicators: HS graduate, college attendance, college graduate (plus an indicator for missing father's education). All other specifications control for mother's baseline education categories: HS graduate and college attendance. ASVAB test scores in column (iii) are normalized by year of birth to have mean zero and standard deviation one. Crime measures in column (iv) are indicators for crime committed in the year prior to the 1980 survey (measured at ages 15-18). See text for details on ASVAB tests and types of crime included. Column (v) controls for per capita (rather than total) family income quartiles. Test of no Income Effects is an F-test (3 d.o.f.) that all three coefficients on family income are zero. Standard errors are in parentheses. 
Table A5: Robustness Checks for College Attendence at Age 21 Regressions (NLSY97)

(i)

(ii)

(iii)

(iv)

(v)

\begin{tabular}{lccccc} 
& $\begin{array}{c}\text { Finer Mother's } \\
\text { \& Father's } \\
\text { Education } \\
\text { Controls }\end{array}$ & $\begin{array}{c}\text { High School } \\
\text { Graduate } \\
\text { Sample }\end{array}$ & $\begin{array}{c}\text { Controls for } \\
\text { All ASVAB } \\
\text { scores }\end{array}$ & $\begin{array}{c}\text { Controls for } \\
\text { Measures of } \\
\text { Criminal } \\
\text { Activity }\end{array}$ & $\begin{array}{c}\text { Per Capita } \\
\text { Family Income } \\
\text { Quartiles }\end{array}$ \\
\hline AFQT Quartile 2 & 0.2358 & 0.2086 & 0.0774 & 0.2399 & 0.2365 \\
& $(0.0244)$ & $(0.0270)$ & $(0.0340)$ & $(0.0248)$ & $(0.0244)$ \\
AFQT Quartile 3 & 0.3881 & 0.3528 & 0.1244 & 0.4022 & 0.3906 \\
& $(0.0250)$ & $(0.0272)$ & $(0.0454)$ & $(0.0252)$ & $(0.0250)$ \\
AFQT Quartile 4 & 0.4988 & 0.4573 & 0.1183 & 0.5070 & 0.5113 \\
& $(0.0262)$ & $(0.0279)$ & $(0.0608)$ & $(0.0263)$ & $(0.0259)$ \\
Family Income Quartile 2 & 0.0379 & 0.0322 & 0.0340 & 0.0420 & 0.0525 \\
Family Income Quartile 3 & $(0.0247)$ & $(0.0270)$ & $(0.0248)$ & $(0.0249)$ & $(0.0246)$ \\
Family Income Quartile 4 & 0.0903 & 0.0919 & 0.0910 & 0.1012 & 0.1400 \\
& $(0.0266)$ & $(0.0282)$ & $(0.0264)$ & $(0.0265)$ & $(0.0267)$ \\
Test of no Income Effects (P-value) & 0.1345 & 0.1356 & 0.1368 & 0.1608 & 0.1975 \\
Sample Size & $(0.0281)$ & $(0.0293)$ & $(0.0280)$ & $(0.0279)$ & $(0.0287)$ \\
\hline
\end{tabular}

Notes: All regressions control for gender, race/ethnicity, intact family during adolescence, number of children under 18, mother's age at child's birth, metropolitan area residence during adolescence, and year of birth. Respondent's education measured as of age 21 (age 22 if missing at age 21).Column (i) controls for the following mother's and father's education indicators: HS graduate, college attendance, college graduate (plus an indicator for missing father's education). All other specifications control for mother's baseline education categories: HS graduate and college attendance. ASVAB test scores in column (iii) are normalized by age at test date to have mean zero and standard deviation one. Crime measures in column (iv) are indicators for crime committed since the date of last interview as surveyed in 1998 (measured at ages 14-18). See text for details on ASVAB tests and types of crime included. Column (v) controls for per capita (rather than total) family income quartiles. Test of no Income Effects is an F-test (3 d.o.f.) that all three coefficients on family income are zero. Standard errors are in parentheses. 
Table A6: Effects of Family Income and AFQT on College Attendance by Age 21 by Race and Gender (NLSY79)

\begin{tabular}{lccccc} 
& Males & Females & Whites & Blacks & Hispanics \\
\hline AFQT Quartile 2 & 0.1196 & 0.0795 & 0.1010 & 0.2554 & 0.2536 \\
& $(0.0367)$ & $(0.0369)$ & $(0.0312)$ & $(0.0312)$ & $(0.0390)$ \\
AFQT Quartile 3 & 0.2824 & 0.2661 & 0.3001 & 0.4048 & 0.3957 \\
& $(0.0372)$ & $(0.0399)$ & $(0.0310)$ & $(0.0488)$ & $(0.0498)$ \\
AFQT Quartile 4 & 0.5657 & 0.4200 & 0.5341 & 0.4770 & 0.5629 \\
& $(0.0387)$ & $(0.0425)$ & $(0.0321)$ & $(0.0684)$ & $(0.0646)$ \\
Family Income Quartile 2 & -0.0051 & -0.0187 & 0.0354 & 0.0071 & 0.1220 \\
& $(0.0360)$ & $(0.0383)$ & $(0.0308)$ & $(0.0343)$ & $(0.0432)$ \\
Family Income Quartile 3 & 0.0121 & -0.0361 & 0.0398 & 0.0542 & 0.0737 \\
& $(0.0377)$ & $(0.0398)$ & $(0.0312)$ & $(0.0475)$ & $(0.0498)$ \\
Family Income Quartile 4 & 0.0883 & 0.0039 & 0.1001 & 0.1215 & 0.0927 \\
& $(0.0393)$ & $(0.0428)$ & $(0.0323)$ & $(0.0605)$ & $(0.0617)$ \\
Test of no Income Effects (P-value) & 0.0372 & 0.6562 & 0.0096 & 0.1855 & 0.0374 \\
Sample Size & 1,158 & 1,130 & 1,852 & 1,090 & 721 \\
\hline
\end{tabular}

Notes: All regressions control for mother's education (HS graduate, college attendance), intact family during adolescence, number of siblings, mother's age at child's birth, urban residence during adolescence, and year of birth. Specifications by gender control for race/ethnicity and specifications by race/ethnicity control for gender. Education measured as of age 21 (age 22 if missing at age 21). Test of no Income Effects is an F-test (3 d.o.f.) that all three coefficients on family income are zero. Standard errors are in parentheses. 
Table A7: Effects of Family Income and AFQT on College Attendance by Age 21 by Race and Gender (NLSY97)

\begin{tabular}{lccccc} 
& Males & Females & Whites & Blacks & Hispanics \\
\hline AFQT Quartile 2 & 0.2380 & 0.2430 & 0.2294 & 0.3293 & 0.1503 \\
& $(0.0347)$ & $(0.0346)$ & $(0.0309)$ & $(0.0381)$ & $(0.0474)$ \\
AFQT Quartile 3 & 0.3569 & 0.4438 & 0.3955 & 0.4514 & 0.3762 \\
& $(0.0356)$ & $(0.0353)$ & $(0.0305)$ & $(0.0488)$ & $(0.0541)$ \\
AFQT Quartile 4 & 0.5184 & 0.5310 & 0.5321 & 0.4351 & 0.4806 \\
& $(0.0364)$ & $(0.0368)$ & $(0.0303)$ & $(0.0708)$ & $(0.0683)$ \\
Family Income Quartile 2 & 0.0445 & 0.0336 & 0.1096 & 0.0210 & 0.0897 \\
& $(0.0361)$ & $(0.0338)$ & $(0.0311)$ & $(0.0390)$ & $(0.0500)$ \\
Family Income Quartile 3 & 0.0780 & 0.1235 & 0.1528 & 0.1494 & 0.0062 \\
& $(0.0380)$ & $(0.0364)$ & $(0.0317)$ & $(0.0523)$ & $(0.0598)$ \\
Family Income Quartile 4 & 0.1777 & 0.1394 & 0.2113 & 0.1304 & 0.1878 \\
& $(0.0396)$ & $(0.0385)$ & $(0.0328)$ & $(0.0637)$ & $(0.0735)$ \\
Test of no Income Effects (P-value) & $<.0001$ & 0.0003 & $<.0001$ & 0.0182 & 0.0224 \\
Sample Size & 1,271 & 1,258 & 1,794 & 750 & 562 \\
\hline
\end{tabular}

Notes: All regressions control for mother's education (HS graduate, college attendance), intact family during adolescence, number of children under 18, mother's age at child's birth, metropolitan area during adolescence, and year of birth. Specifications by gender control for race/ethnicity and specifications by race/ethnicity control for gender. Education measured as of age 21 (age 22 if missing at age 21). Test of no Income Effects is an F-test (3 d.o.f.) that all three coefficients on family income are zero. Standard errors are in parentheses. 


\section{Appendix B: Intergenerational Model (no Borrowing Constraints)}

This appendix extends the theoretical model to an intergenerational setting and analyzes the impacts of changes in parental wealth on schooling decisions in the absence of borrowing constraints. As in the single-generation model of Section 5, this intergenerational model predicts a negative relationship between family resources and college attendance when the financial returns to college are positive, generalizing a key theoretical result of the paper. To focus on this result, we maintain the assumption of positive financial gains from college (i.e. $G(\theta)>0$ ) throughout this appendix. ${ }^{50}$

The model assumes parents value their own consumption as well as their child's utility from consumption. Furthermore, parents receive a direct 'psychic' benefit/cost from their child's college attendance and they also place some (perhaps discounted) value on their child's 'psychic' benefit/cost. Parents are assumed to live for only one period, overlapping with their child's schooling period, and their utility is given by:

$$
U^{p}=u\left(c^{p}\right)+\left[u\left(c_{1}\right)+\beta u\left(c_{2}\right)\right]+s\left[\delta \xi+\xi^{p}\right],
$$

where $c^{p}$ reflects parental consumption, $\xi^{p}$ reflects the parental 'psychic' benefit/cost of their child attending college, $\delta \in[0,1]$ reflects the rate at which parents discount their child's 'psychic' taste for college, and all other variables are the same as in Section 5. For simplicity, we assume that parents do not discount their child's utility from goods consumption. We consider two special cases: (1) parents make non-contingent financial transfers to their children during the first period but the child determines his own schooling level and (2) parents dictate the child's schooling decision and consumption behavior.

\section{Non-Contingent Parental Transfers}

First, we consider the case where parents have a level of wealth, $W^{p}>0$, and make non-contingent financial transfers to their children, $W \geq 0$. Children decide whether or not to attend college based on the level of transfer. Conditional on the parental transfer, children make their schooling decisions as described in Section 5. While parents cannot condition transfers on the child's schooling, they will take their children's preferences and decision rule into account.

For simplicity, we assume tuition is constant for everyone, T. Parent's variables are superscripted with $p$. Parental consumption is given by $c^{p}=W^{p}-W$, and parents solve

$$
V^{p}\left(W^{p}, \xi^{p}, \theta, \xi\right)=\max _{\{W: W \geq 0\}}\left\{u\left(W^{p}-W\right)+s(W, \theta, \xi)\left[v_{1}(W, \theta)+\delta \xi+\xi^{p}\right]+[1-s(W, \theta, \xi)] v_{0}(W, \theta)\right\}
$$

subject to

$$
s(W, \theta, \xi)= \begin{cases}1 & \text { if } \xi \geq v_{0}(W, \theta)-v_{1}(W, \theta) \equiv \bar{\xi}(W, \theta) \\ 0 & \text { otherwise }\end{cases}
$$

\footnotetext{
${ }^{50}$ We also maintain all other assumptions of Section 5.
} 
This incorporates the child's optimal response to transfer $W$ and the child's value functions $v_{0}(W, \theta)$ and $v_{1}(\theta)$ as described in Section 5 .

Positive financial gains from college (i.e. $G(\theta)>0$ ) imply that $c_{0}(W, \theta) \equiv \frac{R W+(1+R) y_{0}(\theta)}{1+R}<$ $\frac{R(W-T)+y_{1}(\theta)}{1+R} \equiv c_{1}(W, \theta)$ for any $W$. Thus, for all $W$, we have $\bar{\xi}(W, \theta)<0$, which implies that $s(W, \theta, \xi)=1$ for all individuals with positive tastes for college $(\xi \geq 0)$ regardless of parental transfers, tastes, or wealth. Since utility functions are concave and $c_{1}(W, \theta)>c_{0}(W, \theta)$, it is clear that $\frac{\partial \bar{\xi}(W, \theta)}{\partial W}>0$. This implies that an increase in parental transfers makes it less likely that a child attends college (holding $\theta$ constant). Therefore, $s(W, \theta, \xi)=0$ for all $\xi<\bar{\xi}(0, \theta)$, regardless of parental transfers, $W \geq 0$, tastes, or family wealth. ${ }^{51}$ In short, parental wealth does not affect the college-going decisions of youth with positive tastes for college or sufficiently negative tastes.

To determine how parental wealth affects attendance rates, we must consider those youth who have modestly negative tastes for college, or $\xi \in[\bar{\xi}(0, \theta), 0)$. For these individuals, there exists some transfer level, $\bar{W}(\theta, \xi) \geq 0$, satisfying $\xi=\bar{\xi}(\bar{W}, \theta)$. Those receiving transfers $W<\bar{W}(\theta, \xi)$ will attend while those with $W>\bar{W}(\theta, \xi)$ will not. So, parents of these youth can, in principle, influence their children's educational choices through their choice of transfers.

We now solve for schooling-contingent optimal transfers by parents and their own resulting utility: $W_{s}^{*}$ and $V_{s}\left(W^{p}, \xi^{p}, \theta, \xi\right)$, respectively, for both $s \in\{0,1\}$. Then, we determine whether these transfers are consistent with the youth's decision rule (i.e. $\left.s\left(W_{s^{\prime}}^{*}, \theta, \xi\right)=s^{\prime}\right)$. If both are consistent with behavior, parents will choose the transfer (either $W_{0}^{*}$ or $W_{1}^{*}$ ) that offers the highest utility. When one of the two schooling-contingent transfers is not consistent with the youth's behavior (at least one will always be consistent), parents will compare the utility obtained from the consistent choice with the utility obtained by the corner solution that sets the transfer equal to $\bar{W}(\theta, \xi)$, the level which makes the youth indifferent between attending and not attending college.

Consider, first, the preferred transfer to a youth who will attend college. In this case, parents would choose $W_{1}^{*}$ to maximize

$$
u\left(W^{p}-W\right)+(1+\beta) u\left(\frac{R(W-T)+y_{1}(\theta)}{1+R}\right) .
$$

$W_{1}^{*}$ equates parental consumption with the child's consumption if he goes to college, $c_{1}\left(W_{1}^{*}, \theta\right)$, and is given by

$$
W_{1}^{*}\left(W^{p}, \theta\right)=\frac{(1+R) W^{p}+R T-y_{1}(\theta)}{1+2 R} .
$$

We can similarly solve for $W_{0}^{*}$, the preferred transfer to a child who will not attend college. This equates parental consumption with child non-college consumption, $c_{0}\left(W_{0}^{*}, \theta\right)$, yielding

$$
W_{0}^{*}\left(W^{p}, \theta\right)=\left[\frac{1+R}{1+2 R}\right]\left(W^{p}-y_{0}(\theta)\right) .
$$

\footnotetext{
${ }^{51}$ Allowing for negative parental transfers would clearly shrink this region.
} 
Positive financial gains from college imply that $W_{0}^{*}>W_{1}^{*}$, so parents prefer to transfer more to their children when they do not attend college. This is because youth who attend college will earn more on their own over their lifetimes. In both cases, schooling-contingent optimal transfers are increasing in parental wealth and decreasing in youth ability. Parental utility associated with each child's schooling choice is given by:

$$
\begin{aligned}
V_{1}^{p}\left(W^{p}, \xi^{p}, \theta, \xi\right) & =(2+\beta) u\left(\frac{R\left(W^{p}-T\right)+y_{1}(\theta)}{1+2 R}\right)+\left(\delta \xi+\xi^{p}\right) \\
V_{0}^{p}\left(W^{p}, \theta\right) & =(2+\beta) u\left(\frac{R W^{p}+(1+R) y_{0}(\theta)}{1+2 R}\right)
\end{aligned}
$$

Letting $\xi_{f}=\delta \xi+\xi^{p}$ reflect total family tastes for college (incorporating any discount parents place on the child's taste), parents would prefer to offer the transfer $W_{1}^{*}$ if such a transfer will induce attendance and if

$$
\xi_{f} \geq(2+\beta)\left[u\left(\frac{R W^{p}+(1+R) y_{0}(\theta)}{1+2 R}\right)-u\left(\frac{R\left(W^{p}-T\right)+y_{1}(\theta)}{1+2 R}\right)\right] \equiv \bar{\xi}_{f}\left(W^{p}, \theta\right) .
$$

Note that $\bar{\xi}_{f}\left(W^{p}, \theta\right)$ is much like $\bar{\xi}(W, \theta)$, replacing $W$ with $W^{p}$. Positive financial gains from college guarantees that $\bar{\xi}_{f}\left(W^{p}, \theta\right)$ is strictly negative and strictly increasing in $W^{p}$. Thus, when transfer $W_{1}^{*}$ will induce college attendance by the youth, the likelihood of the parent choosing that level of transfer is decreasing in parental wealth.

We consider three possible cases when $\xi \in(\bar{\xi}(0, \theta), 0)$ : (i) $W_{1}^{*}<\bar{W}(\theta, \xi)<W_{0}^{*}$, so both schoolingcontingent transfers are consistent with youth behavior; (ii) $\bar{W}(\theta, \xi)<W_{1}^{*}<W_{0}^{*}$, so neither transfer induces college attendance; and (iii) $W_{1}^{*}<W_{0}^{*}<\bar{W}(\theta, \xi)$, so both transfers induce attendance. ${ }^{52}$

In case (i), parent's choose between $W_{0}^{*}$ and $W_{1}^{*}$. The fact that optimal schooling-contingent transfers elicit the assumed behavior by youth implies that youth tastes satisfy $\bar{\xi}\left(W_{1}^{*}, \theta\right)<\xi<$ $\bar{\xi}\left(W_{0}^{*}, \theta\right)<0$. Families of these youth with $\xi_{f}=\bar{\xi}_{f}\left(W^{p}, \theta\right)<0$ are on the margin. Because $\frac{\partial \bar{\xi}_{f}}{\partial W^{p}}>0$, a decrease in parental wealth causes these marginal families to reduce their transfers from $W_{0}^{*}$ to $W_{1}^{*}$ so that the youth attends college. Thus, a negative wealth - attendance relationship exists for youth with $\xi \in\left(\bar{\xi}\left(W_{1}^{*}, \theta\right), \bar{\xi}\left(W_{0}^{*}, \theta\right)\right)$.

Cases (ii) and (iii) require that parents consider the corner solution transfer that makes a youth indifferent between attending and not attending, $\bar{W}(\theta, \xi)$. This option offers the values

$$
\begin{aligned}
\tilde{V}_{0}\left(W^{p}, \theta, \xi\right) & =u\left(W^{p}-\bar{W}(\theta, \xi)\right)+(1+\beta) u\left(\frac{R \bar{W}(\theta, \xi)+(1+R) y_{0}(\theta)}{1+R}\right) \\
\tilde{V}_{1}\left(W^{p}, \xi^{p}, \theta, \xi\right) & =u\left(W^{p}-\bar{W}(\theta, \xi)\right)+(1+\beta) u\left(\frac{R[\bar{W}(\theta, \xi)-T]+y_{1}(\theta)}{1+R}\right)+\left(\delta \xi+\xi^{p}\right),
\end{aligned}
$$

for $s=0$ and $s=1$, respectively. The definition of $\bar{W}(\theta, \xi)$ implies that $\tilde{V}_{1}\left(W^{p}, \xi^{p}, \theta, \xi\right)-\tilde{V}_{0}\left(W^{p}, \theta, \xi\right)=$ $(\delta-1) \xi+\xi^{p}$, since the only gain (or loss) in utility from attending college when the youth is indifferent

\footnotetext{
${ }^{52}$ Corners when $\bar{W}=W_{0}^{*}$ or $\bar{W}=W_{1}^{*}$ are not discussed but yield predictions consistent with those discussed here.
} 
comes from parental tastes (and the fact that parents may not fully internalize their children's taste for school).

Case (ii) arises for youth who dislike school enough that even the lower optimal transfer associated with attendance, $W_{1}^{*}$, does not induce them to attend: $\bar{\xi}(0, \theta)<\xi<\bar{\xi}\left(W_{1}^{*}, \theta\right)$. Here, parents decide between making the transfer $W_{0}^{*}$, providing utility $V_{0}^{p}\left(W^{p}, \theta\right)$ with the child not attending college, and the transfer $\bar{W}(\theta, \xi)$, providing utility $\tilde{V}_{1}\left(W^{p}, \xi^{p}, \theta, \xi\right)$ with the child attending. Notice that $V_{0}^{p}\left(W^{p}, \theta\right)-\tilde{V}_{1}\left(W^{p}, \xi^{p}, \theta, \xi\right)=V_{0}^{p}\left(W^{p}, \theta\right)-\tilde{V}_{0}\left(W^{p}, \theta, \xi\right)-\left[(\delta-1) \xi+\xi^{p}\right]$, so parents are indifferent when $\xi^{p}=V_{0}^{p}\left(W^{p}, \theta\right)-\tilde{V}_{0}\left(W^{p}, \theta, \xi\right)+(1-\delta) \xi \equiv \tilde{\xi}_{0}^{p}\left(W^{p}, \theta, \xi\right)>(1-\delta) \xi$. Notice, when $\delta=1$, the marginal parent must like school. Those with $\xi^{p}>\tilde{\xi}_{0}^{p}\left(W^{p}, \theta, \xi\right)$ will make the lower transfer $\bar{W}(\theta, \xi)$, which is just low enough to cause their children to attend college. Intuitively, parents must receive a large enough direct utility from their child attending college in order to compensate for their child's dislike for school and suboptimal transfer levels that do not smooth consumption across generations. In general, this requires a stronger taste for college than if $W_{1}^{*}$ were low enough to induce attendance. Since $\bar{W}(\theta, \xi)<W_{0}^{*}$ for this case, is is straightforward to show that $\frac{\partial \tilde{\xi}_{0}^{p}}{\partial W^{p}}>0$. Thus, an increase in wealth causes an indifferent parent to offer the higher transfer, $W_{0}^{*}$, and have their child forego college. Overall, we observe a negative wealth - attendance relationship for youth satisfying $\bar{\xi}(0, \theta)<\xi<\bar{\xi}\left(W_{1}^{*}, \theta\right)$.

Finally, case (iii) arises for youth who like school enough that they would attend with either transfer $W_{0}^{*}$ or $W_{1}^{*}$ (i.e. $\bar{\xi}\left(W_{0}^{*}, \theta\right)<\xi<0$ ). Parents decide between making the transfer $W_{1}^{*}$, providing utility $V_{1}^{p}\left(W^{p}, \xi^{p}, \theta\right)$ with the child attending college, and the higher transfer $\bar{W}(\theta, \xi)$, providing utility $\tilde{V}_{0}\left(W^{p}, \theta, \xi\right)$ with the child not attending. Parents are indifferent between these transfers when $\xi^{p}=$ $\tilde{V}_{1}\left(W^{p}, \xi^{p}, \theta, \xi\right)-V_{1}^{p}\left(W^{p}, \xi^{p}, \theta\right)+(1-\delta) \xi \equiv \tilde{\xi}_{1}^{p}\left(W^{p}, \theta, \xi\right)<0$. Those with $\xi^{p}>\tilde{\xi}_{1}^{p}\left(W^{p}, \theta, \xi\right)$ will make the corner solution transfer $\bar{W}(\theta, \xi)$, inducing their child to attend. It is straightforward to show that $\frac{\partial \tilde{\xi}_{1}^{p}}{\partial W^{p}}>0$, so marginal families with $\xi^{p}=\tilde{\xi}_{1}^{p}\left(W^{p}, \theta, \xi\right)$ will opt for the higher transfer, $W_{0}^{*}$, with their child not attending college in response to an increase in parental wealth $W^{p}$. As with the previous cases, an increase in wealth has a negative affect on attendance for marginal families. Note that if all parents have non-negative tastes for school (i.e. $\xi^{p} \geq 0$ ), then all parents of children with $\xi>\bar{\xi}\left(W_{0}^{*}, \theta\right)$ would prefer to transfer $\bar{W}(\theta, \xi)$, such that their child attends school. None of these families would respond to marginal changes in family wealth.

It is useful to summarize all of the results relevant to the wealth - attendance relationship when parental transfers must be non-negative (i.e. $W \geq 0$ ) and the financial gains from college are positive (i.e. $G(\theta)>0$ ). First, all youth with $\xi \geq 0$ attend college regardless of parental wealth. All youth with tastes $\xi<\bar{\xi}(0, \theta)$ do not attend college regardless of parental wealth. The families of these youth are never marginal. Among all youth with $\xi \in(\bar{\xi}(0, \theta), 0)$, attendance rates are decreasing in family wealth (at the margin). These youth can be disaggregated into three categories, with different conditions determining which families are 'marginal'. For youth with $\xi \in\left(\bar{\xi}\left(W_{0}^{*}\left(W^{p}, \theta\right), \theta\right), 0\right)$, parents with 
$\xi^{p}=\tilde{\xi}_{1}^{p}\left(W^{p}, \theta, \xi\right)<0$ are indifferent between offering a transfer that induces attendance and one that does not. For youth with $\xi \in\left(\bar{\xi}\left(W_{1}^{*}\left(W^{p}, \theta\right), \theta\right), \bar{\xi}\left(W_{0}^{*}\left(W^{p}, \theta\right), \theta\right)\right)$, families with $\xi^{f}=\bar{\xi}^{f}\left(W^{p}, \theta\right)<0$ are indifferent between offering a transfer that induces attendance and one that does not. Finally, for youth with $\xi \in\left(\bar{\xi}(0, \theta), \bar{\xi}\left(W_{1}^{*}\left(W^{p}, \theta\right), \theta\right)\right)$, parents with $\xi^{p}=\tilde{\xi}_{0}^{p}\left(W^{p}, \theta, \xi\right)>(1-\delta) \xi$ are indifferent between offering a transfer that induces attendance and one that does not. Among all families at the margin, an increase in wealth discourages the low transfer/college attendance option.

\section{Parents that Dictate Children's Behavior}

When parents can dictate their child's consumption and schooling behavior, perhaps through tied transfers as in Brown, et al. (2006), the problem is nearly identical to the single-generation problem discussed in the text. In this case, parents choose the child's schooling and transfers to maximize:

$$
u\left(W^{p}-W\right)+s\left[v_{1}(W, \theta)+\delta \xi+\xi^{p}\right]+(1-s) v_{0}(W, \theta) .
$$

In this case, parents choose a transfer level to equate their own consumption with their child's consumption each period, where this level of consumption depends on the schooling choice. The level of transfers for each potential schooling choice are $W_{1}^{*}$ (college) and $W_{0}^{*}$ (non-college) as derived in equations (3) and (4), respectively. Parents choose to send their child to college if and only if $V_{1}^{p}\left(W^{p}, \xi^{p}, \theta, \xi\right) \geq V_{0}^{p}\left(W^{p}, \theta\right)$, where $V_{1}^{p}(\cdot)$ and $V_{0}^{p}(\cdot)$ are defined above by equations (5) and (6). That is, the parent will transfer $W_{1}^{*}$ to the child and send the child to college if and only if $\xi_{f} \geq \bar{\xi}_{f}\left(W^{p}, \theta\right)$; otherwise, the parent will transfer $W_{0}^{*}$ and not send the child to college. Notice, this problem is equivalent to case (i) in the non-contingent transfer model, only it holds for all values of child tastes, $\xi$, since parents do not need to worry about whether the transfer level they provide elicits the desired schooling choice. As in that case, increases in family wealth discourage college attendance at the margin. This decision rule is analogous to that of Section 5 where $W$ is replaced with $W^{p}$ and $\xi$ with $\xi_{f}$.

\section{Appendix C: Comparative Statics Results for Section 5}

This appendix shows how changes in college skill prices, tuition levels, and borrowing limits affect the value functions (non-college, unconstrained college, and constrained college) and the marginal value of wealth and ability for the different schooling outcomes.

First, consider changes in $\pi_{1}$, where $y_{1}(\theta)=\pi_{1} h_{1}(\theta)$. This will clearly have no effect on the value of non-college. An increase in $\pi_{1}$ raises the value of college for both constrained and unconstrained youth; although, the effect is smaller on the value of college for constrained youth:

$$
\begin{aligned}
& \frac{\partial v_{1}^{u}}{\partial \pi_{1}}=\beta u^{\prime}\left(\bar{c}^{1}\right) h_{1}(\theta)>0 \\
& \frac{\partial v_{1}^{c}}{\partial \pi_{1}}=\beta u^{\prime}\left(c_{2}^{c}\right) h_{1}(\theta)>0 .
\end{aligned}
$$


Because $c_{2}^{c}>\bar{c}^{1}$ for any $(W, \theta)$ type that is constrained, $\frac{\partial v_{1}^{c}}{\partial \pi_{1}}<\frac{\partial v_{1}^{u}}{\partial \pi_{1}}$. An increase in $\pi_{1}$ has no effect on the marginal value of $W$ for constrained students, but it lowers the marginal value of $W$ for unconstrained college students:

$$
\frac{\partial^{2} v_{1}^{u}}{\partial \pi_{1} \partial W}=\left(1-T^{\prime}(W)\right) u^{\prime \prime}\left(\bar{c}^{1}\right) h_{1}(\theta) /(1+R) \leq 0 .
$$

The effects of $\pi_{1}$ on the marginal value of ability for both constrained and unconstrained college attendees are ambiguous:

$$
\begin{aligned}
\frac{\partial^{2} v_{1}^{u}}{\partial \pi_{1} \partial \theta} & =\beta h_{1}^{\prime}(\theta)\left[u^{\prime \prime}\left(\bar{c}_{1}\right) y_{1}(\theta) /(1+R)+u^{\prime}\left(\bar{c}_{1}\right)\right] \\
\frac{\partial^{2} v_{1}^{c}}{\partial \pi_{1} \partial \theta} & =\beta h_{1}^{\prime}(\theta)\left[u^{\prime \prime}\left(c_{2}^{c}\right) y_{1}(\theta)+u^{\prime}\left(c_{2}^{c}\right)\right]
\end{aligned}
$$

Notice that $\frac{\partial^{2} v_{1}^{u}}{\partial \pi_{1} \partial \theta}>0$ if and only if the intertemporal elasticity of substitution for consumption is greater than the share of total discounted lifetime wealth that comes from post-college earning:

$$
I E S=-\frac{u^{\prime}\left(\bar{c}^{1}\right)}{u^{\prime \prime}\left(\bar{c}^{1}\right) \bar{c}^{1}}>\frac{R^{-1} y_{1}(\theta)}{W-T(W)+R^{-1} y_{1}(\theta)} .
$$

Among constrained borrowers, $\frac{\partial^{2} v_{1}^{c}}{\partial \pi_{1} \partial \theta}>0$ if and only if

$$
I E S=-\frac{u^{\prime}\left(c_{2}^{c}\right)}{u^{\prime \prime}\left(c_{2}^{c}\right) c_{2}^{c}}>\frac{y_{1}(\theta)}{y_{1}(\theta)-R \bar{d}}>1
$$

Since most estimates put the intertemporal elasticity below one (see Browning, Hansen, and Heckman 1999), it is likely that an increase in $\pi_{1}$ will reduce the marginal value of ability for all constrained and many unconstrained college attendees. However, the marginal value of ability is likely to be increasing in $\pi_{1}$ for unconstrained borrowers with relatively high levels of family resources even when the intertemporal elasticity of substitution is less than one.

Now, consider the effect of changes in $T$ when $T(W)=T$ is constant and independent of family resources. This will clearly have no effect on the value of non-college. Not surprisingly, increases in tuition will reduce the value of college with stronger negative effects on those that are constrained:

$$
\begin{aligned}
& \frac{\partial v_{1}^{u}}{\partial T}=-u^{\prime}\left(\bar{c}^{1}\right)<0 \\
& \frac{\partial v_{1}^{c}}{\partial T}=-u^{\prime}\left(c_{1}^{c}\right)<0 .
\end{aligned}
$$

An increase in tuition raises the marginal value of wealth for constrained and unconstrained collegegoers:

$$
\begin{aligned}
\frac{\partial^{2} v_{1}^{u}}{\partial T \partial W} & =-u^{\prime \prime}\left(\bar{c}^{1}\right) R /(1+R)>0 \\
\frac{\partial^{2} v_{1}^{c}}{\partial T \partial W} & =-u^{\prime \prime}\left(c_{1}^{c}\right)>0 .
\end{aligned}
$$


An increase in the level of tuition has no effect on the marginal value of ability for constrained collegegoers, but it raises the marginal value for those that are unconstrained:

$$
\frac{\partial^{2} v_{1}^{u}}{\partial T \partial \theta}=-u^{\prime \prime}\left(\bar{c}^{1}\right) y_{1}^{\prime}(\theta) /(1+R)>0 .
$$

Finally, consider changes in borrowing limits. Changes in $\bar{d}$ do not affect the value of non-college and unconstrained college attendees (unless a reduced limit causes them to become constrained). An increase in borrowing limits raises the value of college attendance, lowers the marginal value of family resources, and raises the marginal value of attendance for constrained youth:

$$
\begin{aligned}
\frac{\partial v_{1}^{c}}{\partial \bar{d}} & =u^{\prime}\left(c_{1}^{c}\right)-u^{\prime}\left(c_{2}^{c}\right)>0 \\
\frac{\partial^{2} v_{1}^{c}}{\partial \bar{d} \partial W} & =\left(1-T^{\prime}(W)\right) u^{\prime \prime}\left(c_{1}^{c}\right) \leq 0 \\
\frac{\partial^{2} v_{1}^{c}}{\partial \bar{d} \partial \theta} & =-u^{\prime \prime}\left(c_{2}^{c}\right) y_{1}^{\prime}(\theta)>0 .
\end{aligned}
$$

